\title{
The Analysis and Specification of Large High-Pressure, High-Temperature Valves for Combustion Turbine Protection in Second-Generation PFB Power Plants
}

\section{Topical Report}

August 1994

Work Performed Under Contract No.: DE-AC21-86MC21023

\author{
For \\ U.S. Department of Energy \\ Office of Fossil Energy \\ Morgantown Energy Technology Center \\ Morgantown, West Virginia \\ By \\ Foster Wheeler Development Corporation \\ Livingston, New Jersey
}




\section{DISCLAIMER}

This report was prepared as an account of work sponsored by an agency of the United States Government. Neither the United States Government nor any agency thereof, nor any of their employees, makes any warranty, express or implied, or assumes any legal liability or responsibility for the accuracy, completeness, or usefulness of any information, apparatus, product, or process disclosed, or represents that its use would not infringe privately owned rights. Reference herein to any specific commercial product, process, or service by trade name, trademark, manufacturer, or otherwise does not necessarily constitute or imply its endorsement, recommendation, or favoring by the United States Government or any agency thereof. The views and opinions of authors expressed herein do not necessarily state or reflect those of the United States Government or any agency thereof.

This report has been reproduced directly from the best available copy.

Available to DOE and DOE contractors from the Office of Scientific and Technical Information, 175 Oak Ridge Turnpike, Oak Ridge, TN 37831; prices available at (615) 576-8401.

Available to the public from the National Technical Information Service, U.S. Department of Commerce, 5285 Port Royal Road, Springfield, VA 22161; phone orders accepted at (703) 487-4650. 


\section{DISCLAIMER}

\section{Portions of this document may be illegible in electronic image products. Images are produced from the best available original document.}




\section{The Analysis and Specification of Large High-Pressure, High-Temperature Valves for Combustion Turbine Protection in Second-Generation PFB Power Plants}

\section{Topical Report}

Work Performed Under Contract No.: DE-AC21-86MC21023

For

U.S. Department of Energy

Office of Fossil Energy

Morgantown Energy Technology Center

P.O. Box 880

Morgantown, West Virginia 26507-0880

By

Foster Wheeler Development Corporation

12 Peach Tree Hill Road

Livingston, New Jersey 07039

August 1994

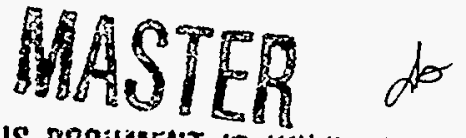

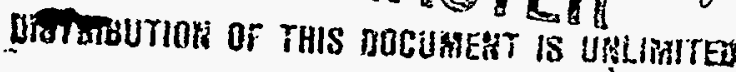


Ref.: DE-AC21-86MC21023

Date: August 1994

\section{ABSTRACT}

The purpose of this study was to provide a specification for the highpressure/high-temperature valves for turbine overspeed protection in a commercial-scale second-generation pressurized fluidized bed combustion (PFBC) power plant. In the event of a loss of external (generator) load, the gas turbine rapidly accelerates from its normal operating speed. Protection from excessive overspeed can be maintained by actuation of fuel isolation and air bypass valves. A design specification for these valves was developed by analyses of the turbine/compressor interaction during a loss of load and analyses of pressure and flow transients during operation of the overspeed protection valves. The basis for these analyses was the Phase 1 plant conceptual design prepared in 1987. 
Ref.: DE-AC21-86MC21023

Date: August 1994

\section{ACKNOWLEDGMENTS}

The authors thank Scott Cloyd of PGTD/CTE for his indispensable guidance in the use of the 501F Performance Code. Run-time improvements to the 501F Code were suggested and implemented by D.K. Whirlow of WSTC. The transient flow model of the CPFBC system is based on work done by B. W. Swanson of WSTC. The topping combustor exit gas equilibrium calculations were performed by D. Bachovchin of WSTC. 
Ref.: DE-AC21-86MC21023

Date: August 1994

\section{CONTENTS}

Section

Page

1. SUMMARY

1.1 Plant Description ................... 3

1.2 Study Objectives .................... 5

1.3 Results........................ 8

1.4 Valve Development and Testing Recommendations . . . . . . . 9

2. FUNCTIONAL SPECIFICATION OF CPFBC VALVE ............. 10

3. OVERSPEED CONTROL SYSTEM RATIONALE

3.1 Introduction ... . . . . . . . . . . . . . . 18

3.2 Alarm and Overspeed Trip Levels . . . . . . . . . . . 18

4. MODELING OF PFBC PIPING AND OVERSPEED CONTROLS . . . . . . . . . 19

4.1 Vitiated Air Supply/Bypass System Simulation . . . . . . . 22

4.2 Fuel Gas Subsystem Simulation .. . . . . . . . . . . 26

4.3 Numerical Methods of Simulations . . . . . . . . . . 30

5. DEVELOPMENT OF MODEL OF

TURBINE/COMPRESSOR PERFORMANCE . . . . . . . . . . . 33

5.1 Plant Operating Conditions at Loss of Load . . . . . . . . 33

5.2 Power Train Rotational Inertia and Acceleration ............... . . 34

5.3 Case Studies of Fuel Gas System . . . . . . . . . . . 35

5.3.1 Reference Case . . . . . . . . . . . 35

5.3.2 100-Percent Vitiated Air/0-Percent Fuel . . . . 36

5.3.3 100-Percent Vitiated Air/

10-Percent Fuel Leakage ........... 36

5.4 PFBC System Valve Actuation to

Decelerate Turbine . . . . . . . . . . . 37

5.5 Coast-Down ................. 44

6. REFERENCES

Appendix A Operating Trend Plots . . . . . . . . . . A-1 
Ref.: DE-AC21-86MC21023

Date:August 1994

\section{TABLES}

\section{Number}

Page

2.1 Process Air Supply Valve Specification (Valve A in Figure 2.1) . . . . . . . . . . . . . . . . . . 11

2.2 Overspeed Air Bypass Valve Specification (Valve B in Figure 2.1) . . . . . . . . . . . . . . . . . . . 12

2.3 Vitiated Air Shutoff Valve Specification (Valve $C$ in Figure 2.1) . . . . . . . . . . . . . . 13

2.4 Primary Flare Vent Valve Specification (Valve 1 in Figure 2.1) . . . . . . . . . . . . . . . 14

2.5 Primary Fuel Trip Valve Specification (Valve 2 in Figure 2.1) ................... 15

2.6 Fuel Piping Valve Specification

(Valve 3 in Figure 2.1) . . . . . . . . . . . . . . 16

2.7 Secondary Fuel Trip/Isolation Valves Specification (Valve $4 a$ and $4 b$ in Figure 2.1) ................ 17

4.1 Summary of Valves . . . . . . . . . . . . . . . . . 20

5.1 Summary of Turbine Inlet Mass Flows and Temperatures During Valve Actuation ................. 39 
Ref.: DE-AC21-86MC21023

Date: August 1994

\section{FIGURES}

Number

Page

1.1 Schematic Representation of the Second-Generation

PFBC Combined Cycle Plant Developed in Phase 1..... 4

1.2 Fuel Gas Schematic ............... 6

1.3 Fuel Gas Manifolding Downstream of Isolation Vaive . . . . 6

1.4 Schematic Arrangement of CPFBC Bypass System ........ 7

2.1 Turbine Overspeed Protection Valve

Identification Diagram . . . . . . . . . . . 10

$4.1 \quad 1600^{\circ} \mathrm{F}$ Carbonizer Plant Heat and Material Balance ......... 21

4.2 CPFBC Bypass-Air Subsystem Simulation ............. 23

4.3 Differential Pressures Across Air-Bypass

Subsystem Valves ................ 25

4.4 Fuel-Gas Subsystem Simulation ................. 27

4.5 Pressures at Valve "1" . . . . . . . . . . . . . 28

4.6 Pressures at Valve "2" 29

4.7 Pipe Section Variables ................... 30

5.1 Turbine Overspeed vs. Time for Fuel Gas System

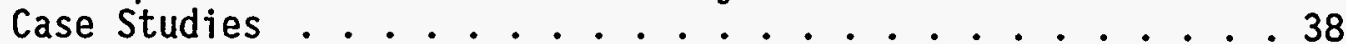

5.2 Turbine Overspeed vs. Time for 30-Percent Bypass Air/

10-Percent Fuel, Illustrating Turnover Point . . . . . 40

5.3 Turbine Overspeed vs. Time for 30-Percent Bypass Air/

10-Percent Fuel, Showing Time to

Decelerate to 3600 RPM .............. . . . 43

5.4 Coastdown Time vs. Speed, from 501F Shop Test Results ..... 45

A.1 Pipeline System Quantization ................. . .

A.2 Energy Nodes and Flow Sections .............. A-2

A.3 Energy Node Schematic . . . . . . . . . . . . A-3

A.4 Flow Section Schematic ..................... A-4

A.5 Junction Schematic .................. A-28

A.6 Sudden Entargement ................. . . . . . . . .

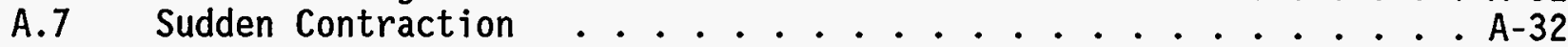

A.8 Resistances of Pipe Entrances ............... A-33 
SECTION 1

SUMMARY 
Ref.: DE-AC21-86MC21023

Date: August 1994

\section{Section 1}

\section{SUMMARY}

\section{$1.1 \quad$ PLANT DESCRIPTION}

The conceptual design of a commercial-scale second-generation pressurized fluidized bed combustion (PFBC) plant was developed in Phase 1 of this contract and is described in the Phase 1 report [1] . The plant is the basis for the system described in this report. A simplified schematic of the plant is shown in Figure 1.1. It operates at a nominal 14-atm compressor pressure ratio and incorporates a $1600^{\circ} \mathrm{F}$ circulating PFB combustor (CPFBC) with a conventional $2400 \mathrm{psig} / 1000^{\circ} \mathrm{F} / 1000^{\circ} \mathrm{F} / 2.5-\mathrm{in}$. Hg steam cycle. Fundamentally, the plant operates as follows: Coal is fed to a pressurized carbonizer that produces a low-Btu fuel gas and char. After the fuel gas is cleaned of particulates by a cyclone and ceramic barrier filter, it is burned in a topping combustor to produce the energy required to drive a gas turbine. The gas turbine drives a generator and a compressor that feeds air to the carbonizer and to the CPFBC. The carbonizer char is burned in the CPFBC with high excess air, and the vitiated air from the CPFBC supports combustion of the fuel gas in the topping combustor. Steam generated in a heat recovery steam generator (HRSG) downstream of the gas turbine and in the fluidized bed heat exchanger (FBHE) associated with the CPFBC drives the steam turbine generator that furnishes the balance of electric power delivered by the plant.

To reach 45-percent efficiency, the second-generation $\mathrm{plant}$ operates with very high excess air (>100 percent rather than 30 percent) and a gas turbine inlet temperature of $2350^{\circ} \mathrm{F}$. Because the gas turbine inlet temperature is much higher than currently operating PFB plants (1500 to $1600^{\circ} \mathrm{F}$ ), the $\mathrm{plant}$ has been called a second-generation PFBC plant.

As indicated in Figure 1.1, the fuel conversion process is carried out in two separate vessels using two different fuels. The carbonizer-produced char-a solid-is consumed in the CPFBC to produce $1600^{\circ} \mathrm{F}$ vitiated air and heat that is transferred to the circulating solids that ultimately provide the means for producing steam. The vitiated air at about $190 \mathrm{psia} / 1600^{\circ} \mathrm{F}$ is filtered and piped to the topping combustion system, where the carbonizerproduced hot fuel gas is consumed to raise the vitiated air temperature to the state-of-the-art turbine inlet temperature.

The carbonizer fuel gas heating value is low-between 5 and 10 percent of the heating value of natural gas. Therefore, its mass flow is much higher under similar operating requirements-between 5 to 10 times more than that required for natural gas. Consequently, the fuel delivery and control system for the second-generation PFBC plant is much larger than a conventional gas turbine fuel system, and the design and operating requirements for it are different. 
Ref.: DE-AC21-86MC21023

Date: August 1994

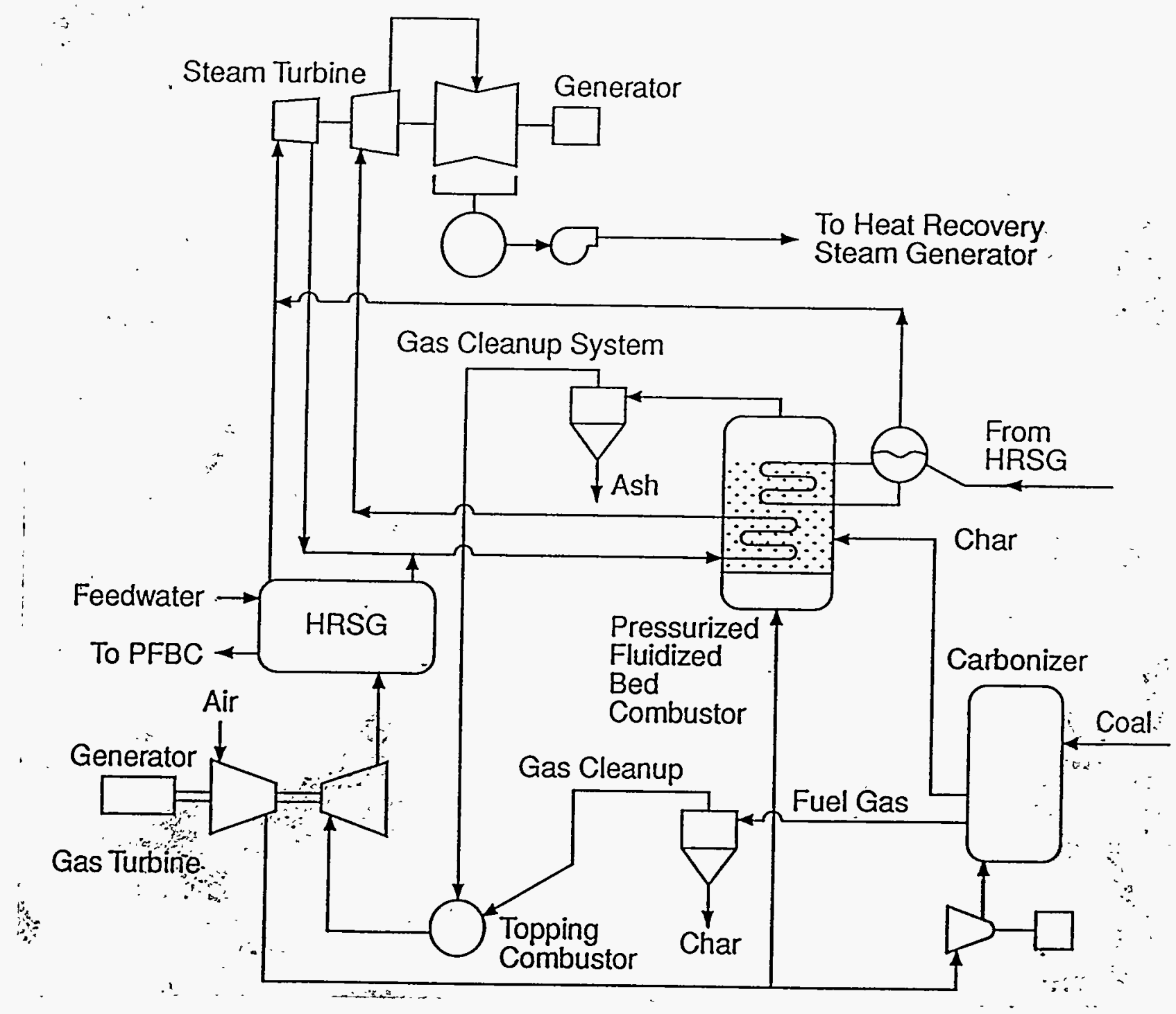

Figure 1.1 Schematic Representation of the Second-Generation PFBC Combined Cycle Plant Developed in Phase 1 
Ref.: DE-AC21-86MC21023

Date: August 1994

Figure 1.2 is a schematic representation of the fuel gas valve system initially proposed. The fuel gas at about $210 \mathrm{psia} / 1600^{\circ} \mathrm{F}$ is filtered and

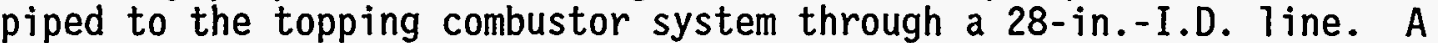
carbonizer vent valve at a tee joint in this pipe allows full-flow venting of the fuel gas to the flare in the event of a system upset. The 28-in. primary fuel trip valve is downstream of the tee. Another vent valve between this trip valve and the fuel throttle valve allows venting of the fuel system at the turbine. Just downstream of the fuel throttle valve, the 28-in. pipe splits into two 22-in. Tines to feed each set of combustors on either side of the turbine casing. Redundant secondary fuel trip valves (22-in. nominal I.D.) in these pipes work in conjunction with the primary fuel trip valve. Figure 1.3 is a conceptual view of how the fuel gas will be manifolded downstream of the secondary fuel trip valve. The fuel gas is delivered in equal quantity to each side of the turbine and is fed to the topping combustors on each side.

The low-Btu fuel gas system contains relatively large valves to regulate or quickly interrupt the fuel flow to the topping combustor and gas flow to the turbine in the event of a plant upset, change of load, or loss of load, and bypass the fuel gas to the flare. Because of the sizes and $1600^{\circ} \mathrm{F}$ temperature involved, these valves are not currently marketed by valve suppliers. An additional system of valves on the vitiated air side, shown schematically in Figure 1.4, have been identified as possibly being needed for overspeed protection for the gas turbine. In addition to the overspeed control valves, there may be a need for a modulating/control valve for normal plant operation. They are shown (but not labeled) in Figure 1.4. They were not considered in this study. The considerable amount of pressurized air and thermal energy that exists in the CPFBC subsystem from the compressor discharge to the topping combustor inlet must be controlled to prevent overspeed of the gas turbine/generator unit and a subsequent possible catastrophic failure.

During normal operation in the assumed scheme, compressed air is extracted and vitiated air is reintroduced to the hot section of the turbine on either side of the unit. Thus two identical sets of valves must work in unison and in conjunction with the primary fuel trip valve. At first indication of a loss of load and the resultant acceleration of the gas turbine unit, Valves $A, B$, and $C$ in Figure 1.4 are actuated.

Valve $A$ (CPFBC inlet valve/26-in. I.D./normally open) closes; Valve $B$ (CPFBC bypass valve/26-in. I.D./normally closed) opens; and Valve C (CPFBC outlet valve/40-in. I.D./normally open) closes. In these new valve positions, the compressor air bypasses the carbonizer and CPFBC systems and is routed directly to the topping combustors.

\subsection{STUDY OBJECTIVES}

The objective of this study was to provide a specification for the highpressure/high-temperature valves required for turbine overspeed protection in a commercial-scale second-generation PFBC power plant. In general, these 
Ref.: DE-AC21-86MC21023

Date: August 1994

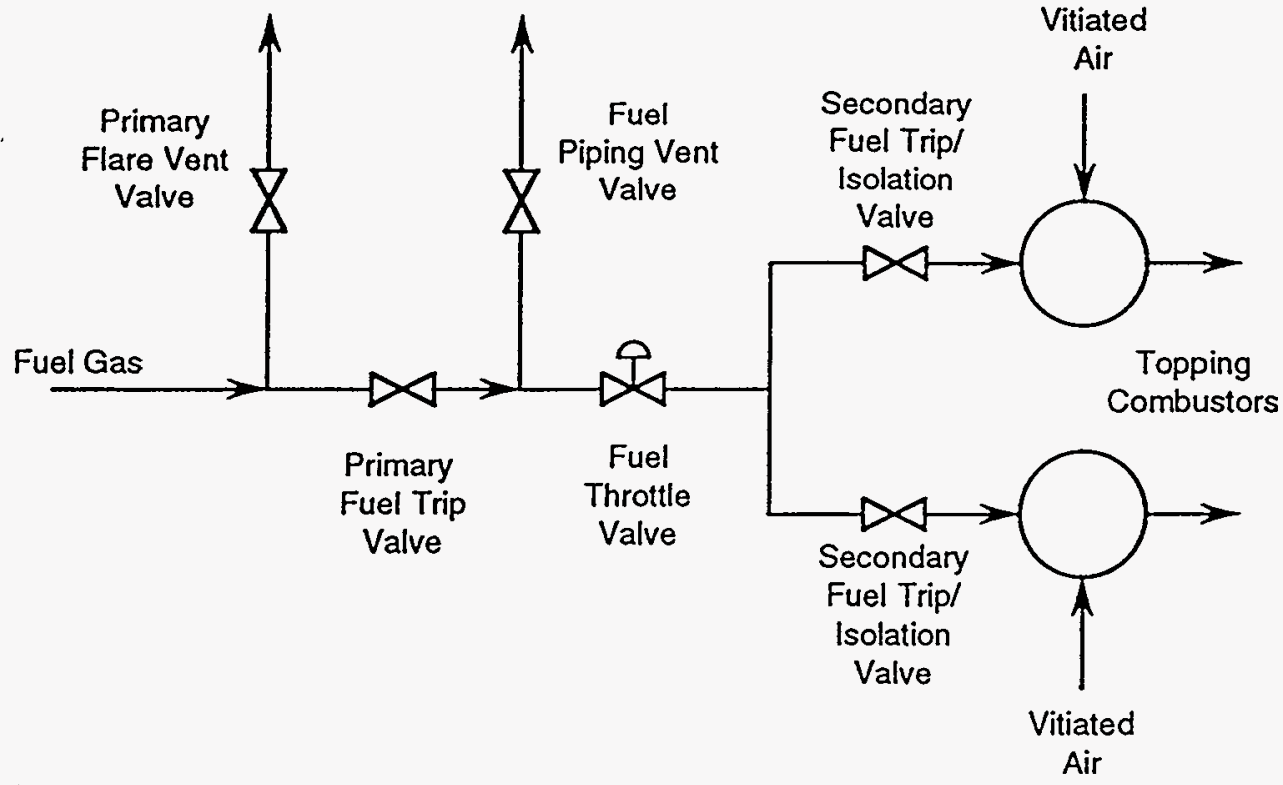

Figure 1.2 Fuel Gas Schematic

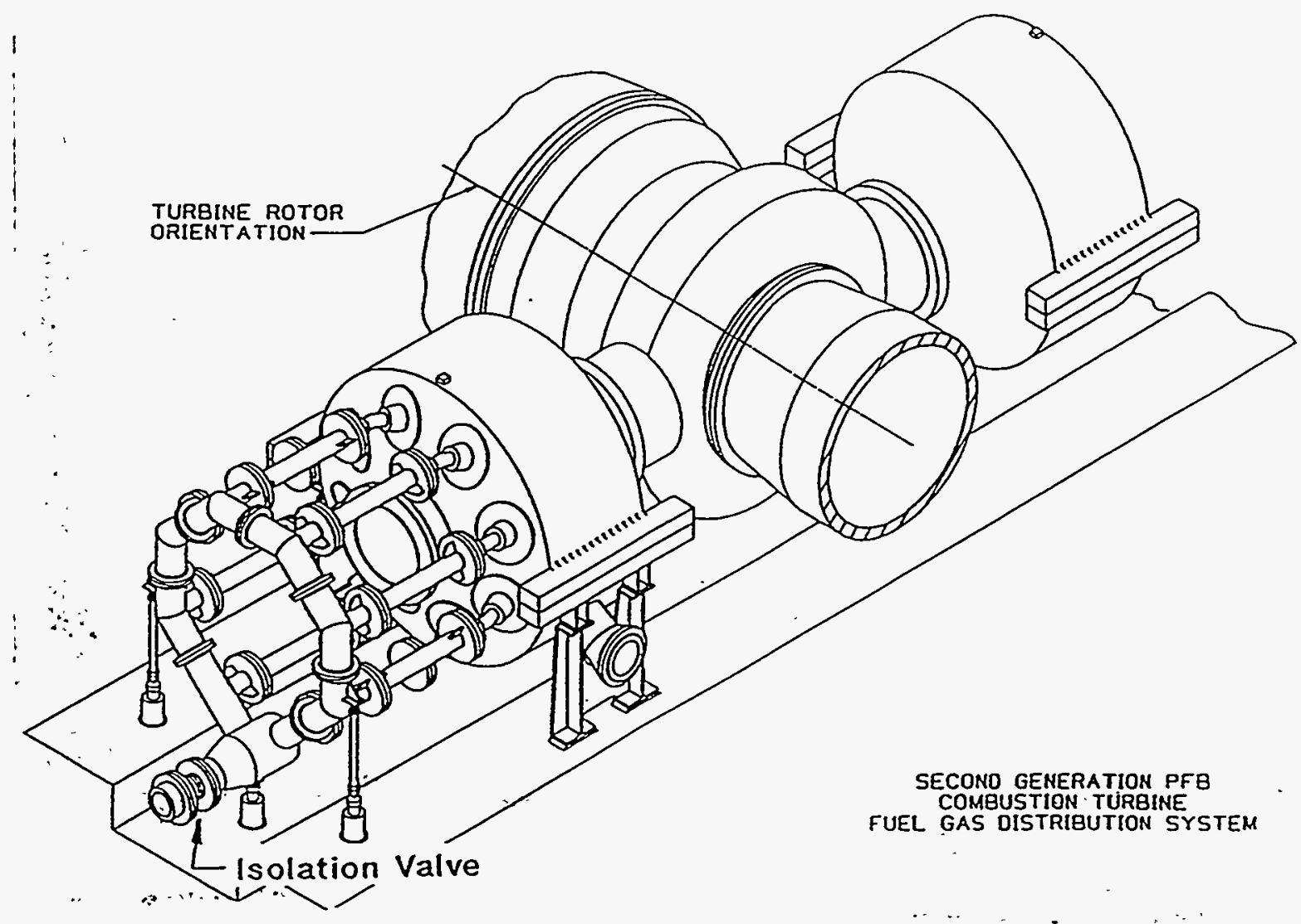

Figure 1.3 Fuel Gas Manifolding Downstream of Isolation Valve 
Ref.: DE-AC21-86MC21023

Date: August 1994

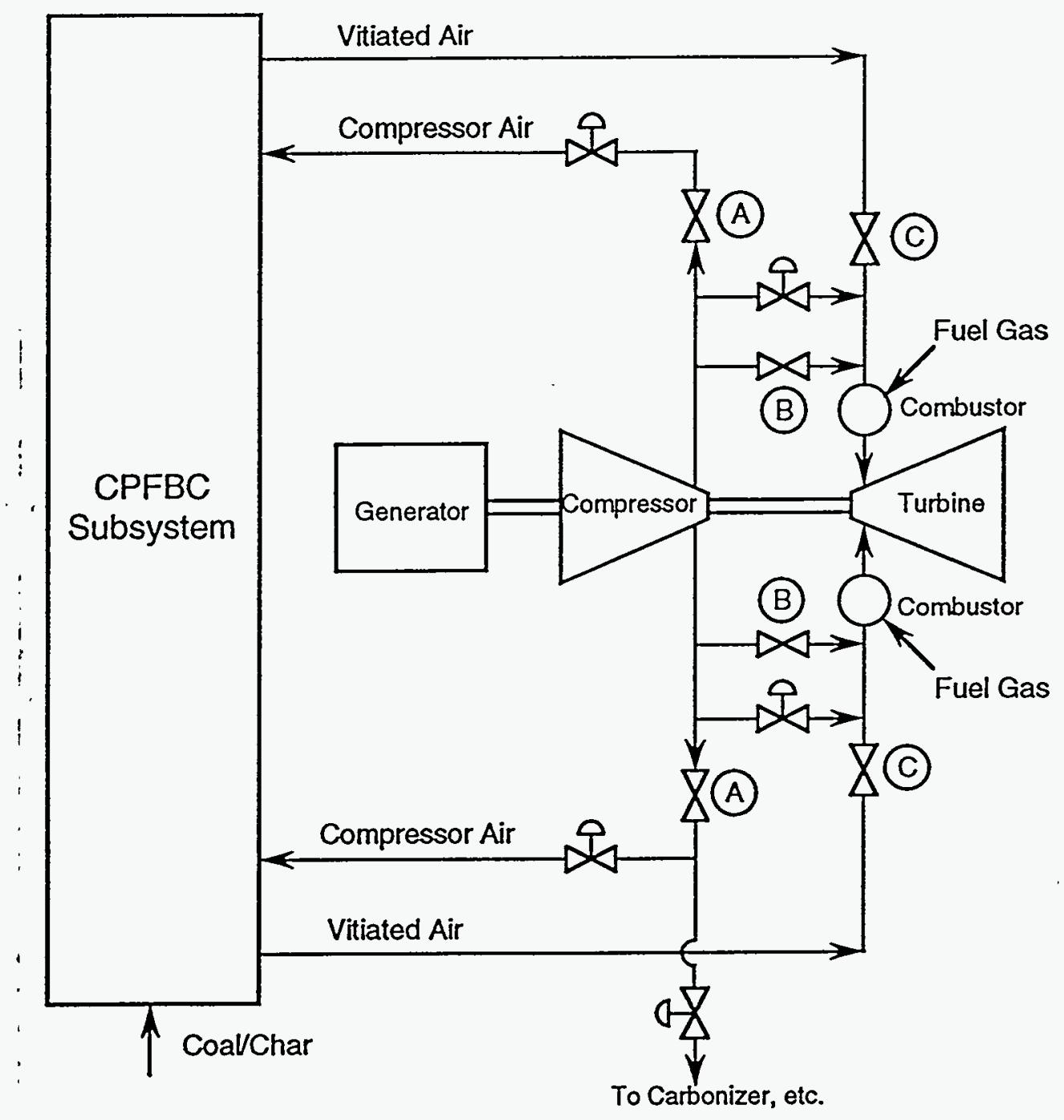
14 Modulating/Control Valve
(A) - Process Air-Supply Valve
$\triangle$ Open/Closed Valve
(B) - Overspeed Air Bypass Valve
(C) - Vitiated Air Shutoff Valve

Figure 1.4 Schematic Arrangement of CPFBC Bypass System 
Ref.: DE-AC21-86MC21023

Date: August 1994

valves are large-diameter (26 to 40 in.) fast-acting, two-position valves (i.e., either open or closed). Plant fuel and air control valves and any other valves not directly associated with turbine overspeed protection were not considered in this study.

To provide the turbine overspeed valve specification, various analyses were required of the plant system response to a loss of external load. These included quantification of the turbine acceleration and the resultant turbine/ compressor work and an analysis of the pressure and flow transients produced during operation of the overspeed valves.

\subsection{RESULTS}

The planned actuation scheme for the turbine overspeed protection valves in the event of a loss of external load is based on the analyses of the plant system response. The results of the analyses are highlighted below:

- Overspeed protection of the gas turbine during a loss of external load event can be achieved by actuating the fuel trip valves to their closed position while opening the fuel vent valves (Figure 1.2) and simultaneously opening the compressor bypass valve (Figure 1.4, Valve B) to allow approximately 30 percent of the compressor discharge air to combine directly with the multiannular swirl burner (MASB) inlet air. These actions will limit the gas turbine rotational speed to about $3600 \mathrm{rpm}$.

- Should the fuel and bypass air valve actuation occur sequentially rather than simultaneously, turbine overspeed protection is maintained if valve actuation times are within 0.6 seconds of each other. This criterion is recommended as the basis for specifying valve requirements, since simultaneous operation of valves cannot be guaranteed.

- Assuming sequential fuel and bypass air valve operation (with 30 -percent bypass air), gas turbine overspeed protection will be maintained even if the fuel gas isolation valve leaks at a rate of 10 percent of its nominal flow rate in its fully closed position. However, a 5-percent or lower leak rate is recommended as a valve specification.

- Stabilization of the gas turbine rotational speed during a loss of external load event can be achieved without actuation of the hot vitiated air valve (Valve C) or the compressor side air valve (Valve A), assuming that the bypass air valve and 1 ine are designed for at least 30-percent flow when fulty opened.

- Maintaining airflow capability through the carbonizer and CPFBC during loss-of-load events may be beneficial to overall process operation.

- Coastdown of the gas turbine following a loss of load can be achieved by decreasing the vitiated airflow. We have assumed that such turndown can be achieved by throttling the CPFBC and carbonizer inlet air from the compressor discharge side. The throttled air is bypassed to the turbine 
Ref.: DE-AC21-86MC21023

Date: August 1994

inlet through either the overspeed protection bypass leg (Valve B) or through the bypass throttle control valve (Figure 1.4), whose normal function is to trim the MASB inlet temperature, vitiated air oxygen level, or both.

- Study results indicate a hot vitiated air valve (Figure 1.4 , Valve C) is not required for turbine overspeed protection. Its presence, al though not considered necessary from the standpoint of turbine overspeed protection, will speed gas turbine coastdown by approximately 5 minutes.

- Pressure and flow transients produced during operation of the overspeed valves have been predicted and factored into the valve specification.

\subsection{VALVE DEVELOPMENT AND TESTING RECOMMENDATIONS}

Review of the functional specifications developed in this study for the turbine overspeed protection valves by selected commercial valve suppliers is recommended to ensure that the scheme is feasible and that such valves can be manufactured.

Testing of the high-pressure/high-temperature valves is recommended to establish the reliability of actuation within the required time intervals and after prolonged periods without operation at normal pressures and temperatures. The 28-in. primary fuel trip valve should be the main focus, since turbine overspeed protection is directly related to the reliable operation of this valve, and it must operate under the most severe conditions. The normally closed vent valves should also be tested with emphasis on system performance considerations such as leakage and tightness after temperature cycling and after reclosure following a plant trip. Ideally, the tests should be performed at prototypical pressures and temperatures and gas flow rates. However, the gas flow rates are very large, and testing at these larger rates may not be practical. A test plan must be formulated to reflect test needs and facility capabilities and to ensure reliable commercial unit operation.

The potential benefits of maintaining partial airflow through the carbonizer and CPFBC during the turbine trip process should be further identified and quantified. Also, the control scheme for supplying the coal and sorbent to these units during a turbine trip needs to be defined and coupled with the turbine coastdown control scheme to avoid damage to the carbonizer and CPFBC as the vitiated air is cut off.

Although the study did not address the modulating control valves in the system, most of the technology associated with the turbine overspeed protection valves naturally applies to them as well. However, we recommend that the overall plant control strategy be refined to clarify the common areas and to identify those areas applying to the control valves alone. 
Ref.: DE-AC21-86MC21023

Date: August 1994

\section{Section 2}

\section{FUNCTIONAL SPECIFICATION OF CPFBC VALVE}

The specification presented in Tables 2.1 through 2.7 identifies the application features, functional requirements, and operating parameters of the large, high-pressure/high-temperature valves for combustion turbine overspeed protection in commercia1-scale second-generation PFBC plants (Figure 2.1). Items for the specification were determined from the analyses described in Sections 4 and 5 of this report. The analyses addressed the system requirements and descriptions summarized in Section 1, and the valve specification reflects the results of these analyses.

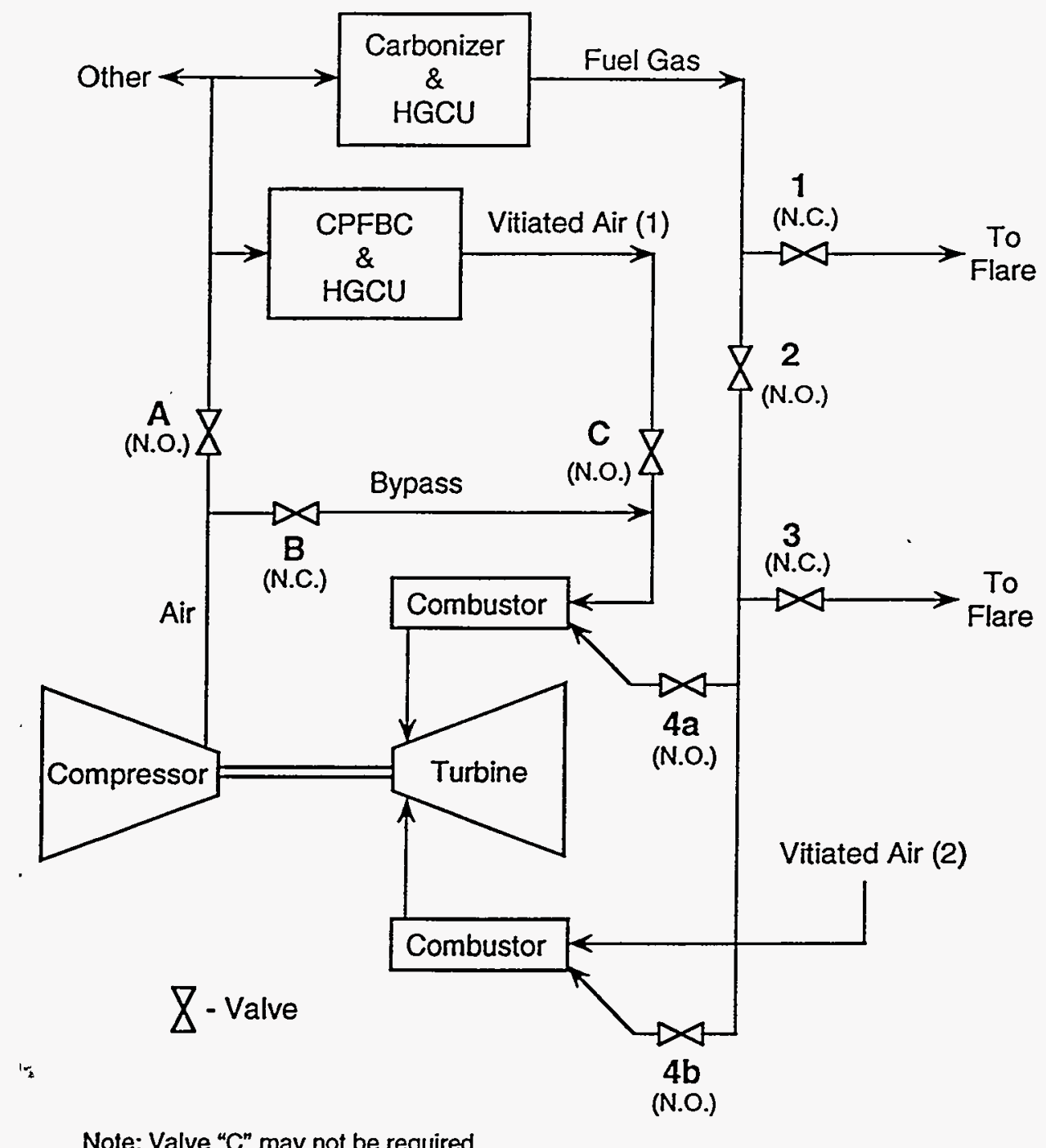

Figure 2.1 Turbine Overspeed Protection Valve Identification Diagram 


\section{SECTION 2}

\section{FUNCTIONAL SPECIFICATION OF CPFBC VALVE}


Table 2.1 Process Air Supply Valve Specification (Valve A in Figure 2.1)

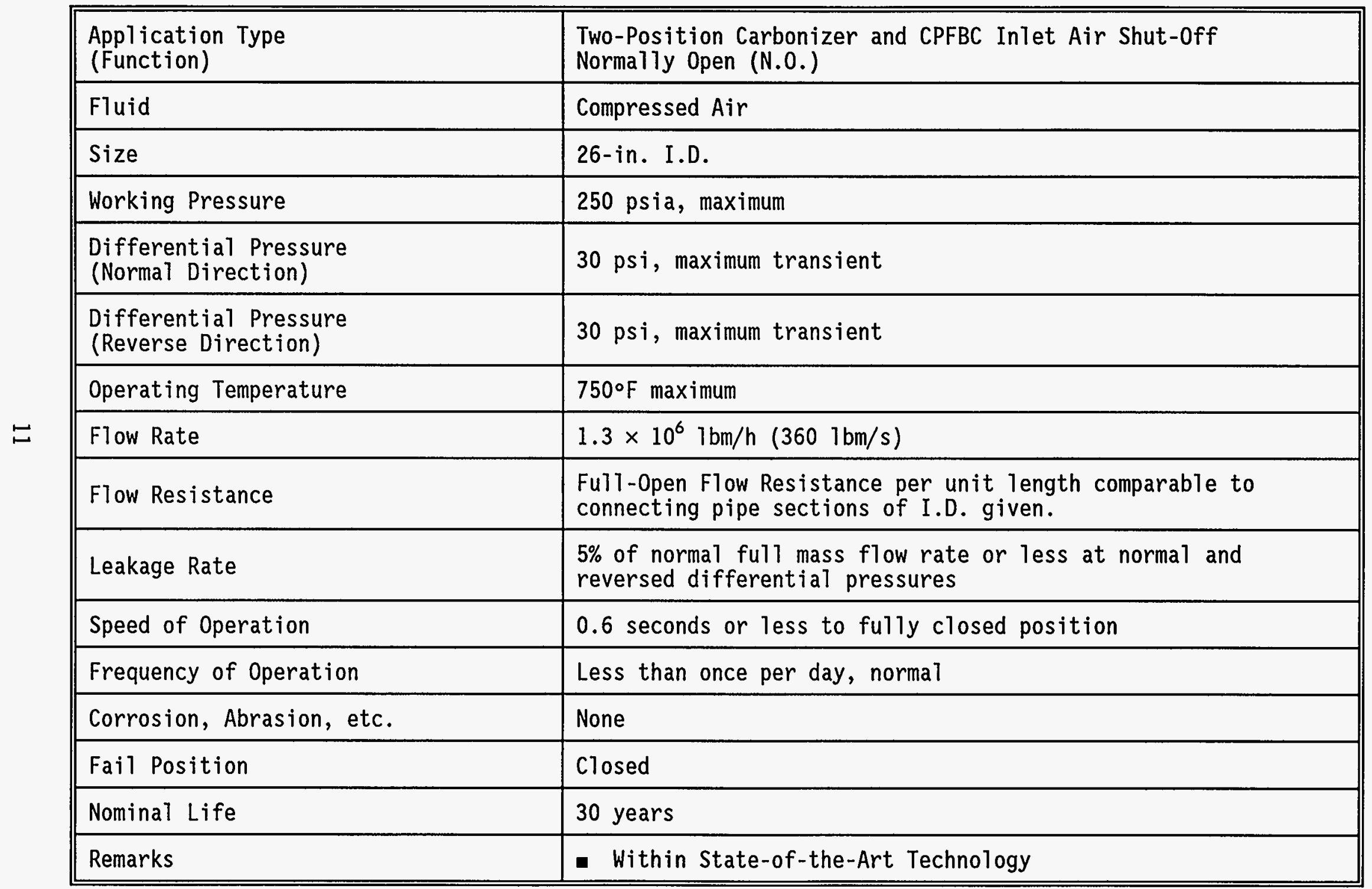


Table 2.2 Overspeed Air Bypass Valve Specification (Valve B in Figure 2.1)

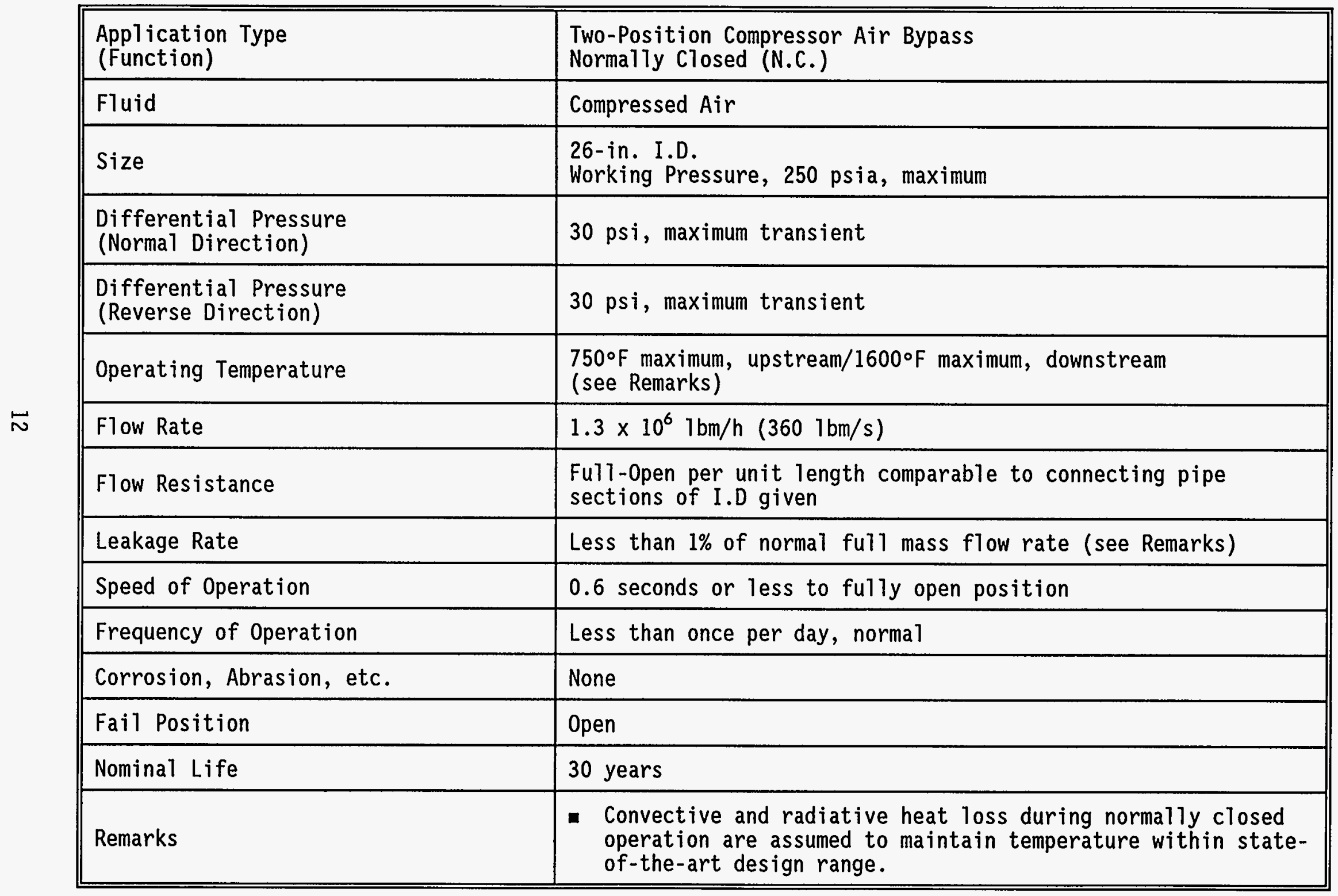


Table 2.3 Vitiated Air Shutoff Valve Specification (Valve $C$ in Figure 2.1)

\begin{tabular}{|c|c|}
\hline $\begin{array}{l}\text { Application Type } \\
\text { (Function) }\end{array}$ & $\begin{array}{l}\text { Two-Position CPFBC Vitiated Shut-0ff } \\
\text { Normally Open (N.O.) }\end{array}$ \\
\hline Fluid & Air (vitiated)-less than 500 ppm(v) sulfur dioxide \\
\hline Working Pressure & 250 psia, maximum \\
\hline $\begin{array}{l}\text { Differential Pressure } \\
\text { (Reverse Direction) }\end{array}$ & 20 psi, maximum transient \\
\hline Operating Temperature & $1600^{\circ} \mathrm{F}$ \\
\hline Flow Rate & $1.3 \times 10^{6} 1 \mathrm{bm} / \mathrm{h}(3601 \mathrm{bm} / \mathrm{s})$ \\
\hline Speed of Operation & 0.6 -seconds or less to fully closed position \\
\hline Frequency of Operation & Less than once per day, normal \\
\hline Corrosion, Abrasion, etc. & Less than $20-\mathrm{ppm}$ particles smaller than 20 microns \\
\hline Fail Position & Closed \\
\hline Nominal Life & 30 years \\
\hline Remarks & $\begin{array}{l}\text { - Anticipated development item if this valve is not } \\
\text { eliminated from design. }\end{array}$ \\
\hline
\end{tabular}


Table 2.4 Primary Flare Vent Valve Specification (Valve 1 in Figure 2.1)

\begin{tabular}{|c|c|}
\hline $\begin{array}{l}\text { Application Type } \\
\text { (Function) }\end{array}$ & $\begin{array}{l}\text { Two-Position Fuel Gas Vent to Flare Stack } \\
\text { Normally Closed (N.C.) }\end{array}$ \\
\hline Fluid & $\begin{array}{llll}\text { Fuel Gas (wt\%) } & & & \\
\mathrm{CO}, 14.54 & \mathrm{CO}_{2}, 17.72 & \mathrm{H}_{2} \mathrm{O}, 4.11 & \mathrm{H}_{2}, 0.51 \\
\mathrm{CH}_{4}, 2.77 ; & \mathrm{C}_{2}{ }^{\prime} \mathrm{s}, 2.10 ; & \mathrm{NH}_{3}, 0.27 ; & \mathrm{H}_{2} \mathrm{~S}, 0.08 ; \\
\mathrm{N}_{2}, 57.90 . & & & \\
\end{array}$ \\
\hline Size & TBD \\
\hline Working Pressure & 250 psia, maximum \\
\hline $\begin{array}{l}\text { Differential Pressure } \\
\text { (Normal Direction) }\end{array}$ & 250 psi, maximum \\
\hline $\begin{array}{l}\text { Differential Pressure } \\
\text { (Reverse Direction) }\end{array}$ & $30 \mathrm{psi}$, maximum transient \\
\hline Operating Temperature & $1600^{\circ} \mathrm{F}$ \\
\hline Flow Rate & $\begin{array}{l}742,000 \mathrm{lbm} / \mathrm{h}(206 \mathrm{lbm} / \mathrm{s}) \text {. Value is for maximum expected } \\
\text { during choked venting flow (see Section } 4.2)\end{array}$ \\
\hline Flow Resistance & $\begin{array}{l}\text { Full-Open flow resistance per unit length comparable to } \\
\text { connecting pipe sections of I.D. given }\end{array}$ \\
\hline Leakage Rate & Zero Teakage (see Remarks) \\
\hline Speed of Operation & 0.6 seconds or less to fully open position \\
\hline Frequency of Operation & Less than once per day, normal \\
\hline Corrosion, Abrasion, etc. & Less than $20 \mathrm{ppm}$ particles smaller than 20 microns \\
\hline Fail Position & Open \\
\hline Nominal Life & 30 years \\
\hline Remarks & $\begin{array}{l}\text { - Leakage through this valve has a major negative impact on } \\
\text { system efficiency. Specify cooling, etc., to maintain } \\
\text { "bubble-tight" closure during normal operation. }\end{array}$ \\
\hline
\end{tabular}


Table 2.5 Primary Fuel Trip Valve Specification (Valve 2 in Figure 2.1)

\begin{tabular}{|c|c|}
\hline $\begin{array}{l}\text { Application Type } \\
\text { (Function) }\end{array}$ & $\begin{array}{l}\text { Two-Position Turbine Overspeed Trip/Fuel Shut-Off Valve } \\
\text { Normally Open (N.O) }\end{array}$ \\
\hline Fluid & Fuel Gas (See Valve 1 in Table 2.4) \\
\hline Size & 28-in. I.D. \\
\hline Working Pressure & 250 psia \\
\hline $\begin{array}{l}\text { Differential Pressure } \\
\text { (Normal Direction) }\end{array}$ & 30 psi, maximum transient \\
\hline $\begin{array}{l}\text { Differential Pressure } \\
\text { (Reverse Direction) }\end{array}$ & 150 psi, maximum transient \\
\hline Operating Temperature & $1600^{\circ} \mathrm{F}$ \\
\hline Flow Rate & $245,000 \mathrm{lbm} / \mathrm{h}(68 \mathrm{lbm} / \mathrm{s})$, normal flow \\
\hline Flow Resistance & $\begin{array}{l}\text { Ful1-Open flow resistance per unit length comparable to } \\
\text { connecting pipe sections of I.D. given }\end{array}$ \\
\hline Leakage Rate & $\begin{array}{l}\text { Less than } 5 \% \text { of ful1 mass flow rate at normal and reversed } \\
\text { differential pressures equal to working pressure }\end{array}$ \\
\hline Speed of Operation & 0.6 seconds or less to fully closed position \\
\hline Frequency of Operation & Less than once per day, normal \\
\hline Corrosion, Abrasion, etc. & See Valve 1 in Table 2.4 \\
\hline Fail Position & Closed \\
\hline Nominat Life & 30 years \\
\hline Remarks & - Valve is anticipated development item. \\
\hline
\end{tabular}


Table 2.6 Fuel Piping Valve Specification (Valve 3 in Figure 2.1)

\begin{tabular}{|c|c|}
\hline $\begin{array}{l}\text { Application Type } \\
\text { (Function) }\end{array}$ & $\begin{array}{l}\text { Two-Position Vent/Purge Valve to Flare Stack } \\
\text { Normally Closed (N.C.) }\end{array}$ \\
\hline Fluid & Fuet Gas-See VaTve 1 in.Table 2.4 \\
\hline Working Pressure & 250 psia \\
\hline $\begin{array}{l}\text { Differential Pressure } \\
\text { (Normal Direction) }\end{array}$ & 250 psi, maximum \\
\hline $\begin{array}{l}\text { Differential Pressure } \\
\text { (Reverse Direction) }\end{array}$ & 30 psi, maximum transient \\
\hline Operating Temperature & $1600^{\circ} \mathrm{F}$ \\
\hline Flow Rate & $\begin{array}{l}742,000 \mathrm{lbm} / \mathrm{h}(206 \mathrm{lbm} / \mathrm{s})-\text { Value is for maximum expected } \\
\text { during choked venting flow (see Section } 4.2 \text { ) }\end{array}$ \\
\hline Speed of Operation & 0.6 seconds or less to fully open position (See Remarks) \\
\hline Frequency of Operation & Less than once per day, normal \\
\hline Corrosion, Abrasion, etc. & See Valve 1 in Table 2.4 \\
\hline Fail Position & Open \\
\hline Nominal Life & 30 years \\
\hline Remarks & $\begin{array}{l}\text { - Leakage through this valve has a major negative impact on } \\
\text { system efficiency. Specify cooling, etc., to maintain } \\
\text { "bubble-tight" closure during normal operation. Valve is } \\
\text { anticipated development item. } \\
\text { - Required if redundant fuel vent-to-flare function is } \\
\text { chosen. }\end{array}$ \\
\hline
\end{tabular}


Table 2.7 Secondary Fuel Trip/Isolation Valves Specification (Valves $4 a$ and $4 b$ in Figure 2.1)

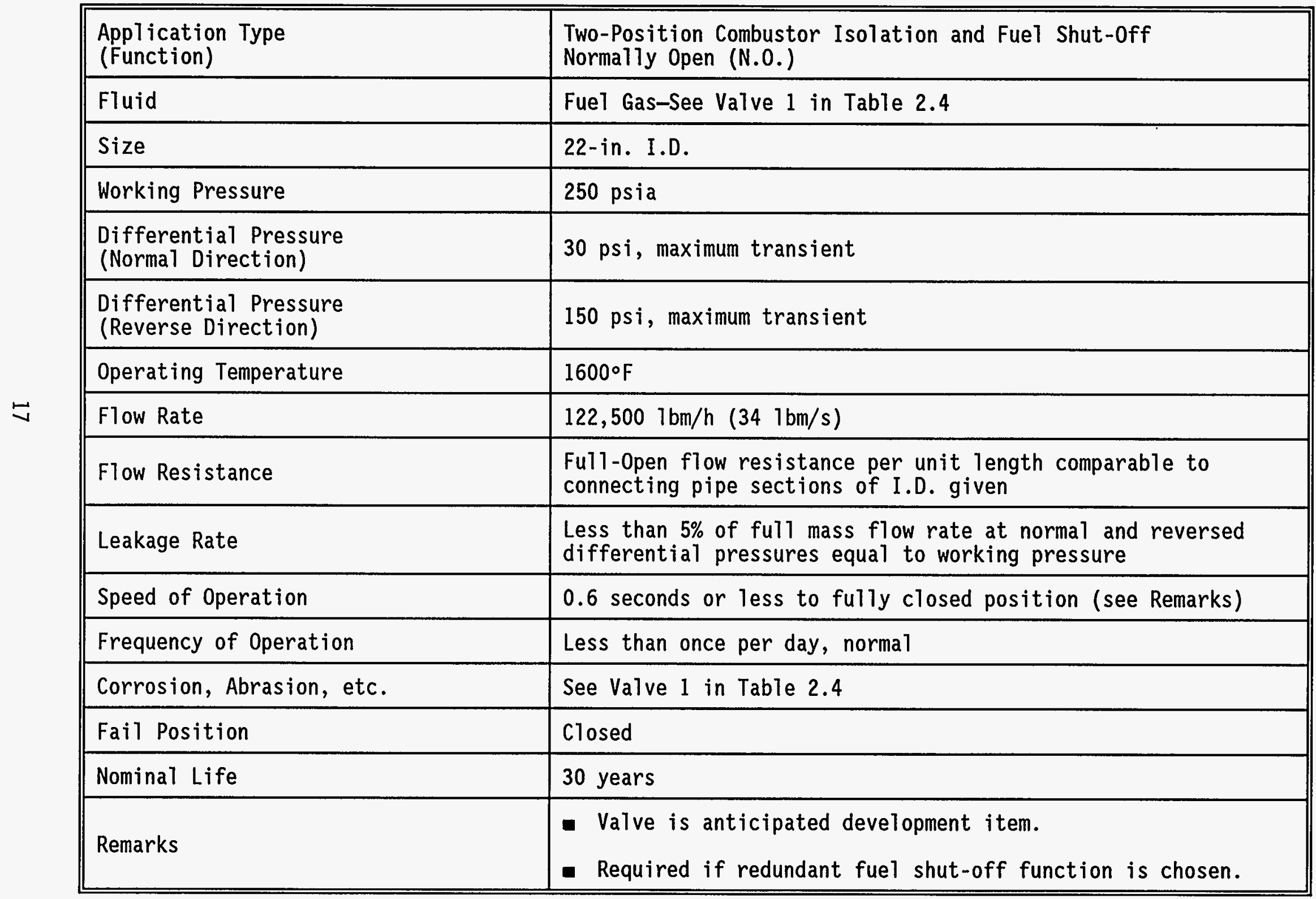


SECTION 3

OVERSPEED CONTROL SYSTEM RATIONALE 
Ref.: DE-AC21-86MC21023

Date: August 1994

\section{Section 3}

\section{OVERSPEED CONTROL SYSTEM RATIONALE}

\section{$3.1 \quad$ INTRODUCTION}

Because the power train will accelerate rapidly after a loss of external load, it is crucial that the turbine speed be monitored at an appropriate sampling rate. The control system signal scanner must read the turbine speed signal frequently enough to guarantee detection of the overspeed within several tenths of a second of its actual occurrence. In addition, there should be no more than a 0.5 -second delay between detection of overspeed and actuation of the fuel isolation valve.

These requirements are within the capabilities of the power plant control system software and hardware presently in use by Westinghouse. The control loops monitoring the fuel trip valves and turbine speed are typically scanned once every 0.1 seconds $(100 \mathrm{~ms})$, which corresponds to a frequency of $10 \mathrm{~Hz}$. However, the controller card can also scan once every $50 \mathrm{~ms}$ if this is desired.

\subsection{ALARM AND OVERSPEED TRIP LEVELS}

For a $60 \mathrm{~Hz}$ generator, the allowable variation from synchronous speed is $1.5 \mathrm{~Hz}$, or $90 \mathrm{rpm}$. Thus for a design rotational speed of $3600 \mathrm{rpm}$, the allowable range of speeds will be from 3510 to $3690 \mathrm{rpm}$. Therefore, any alarm/overspeed trip levels must be at or above $3690 \mathrm{rpm}$. As discussed in Section 5.3, if a loss of external load occurs and al1 overspeed protection valves fail to operate, the turbine will reach its maximum design speed-112 percent of rated speed-in 2.5 seconds.

The recommended overspeed alarm level is 102.5 percent overspeed (3690 rpm), and the recommended overspeed trip level for the CPFBC and fuel gas systems is 104 percent $(3744 \mathrm{rpm})$. To reach the overspeed trip condition starting at $3600 \mathrm{rpm}$ will require $0.8 \mathrm{sec}$. Allowing a 0.5 -second delay for control system response time to actuate the valves and 0.6 seconds travel time for the overspeed protection valves, at least Valve $B$ should complete its travel time no later than 1.9 seconds after a loss of external load. Although seemingly stringent, this low threshold of allowable overspeed is necessary because of the very high mass flow rate of vitiated air in the system.

The choice of trip device (i.e., electrical or mechanical) is considered to be part of the control system specifications for the second-generation PFBC plant and is beyond the scope of this study. 


\section{SECTION 4}

\section{MODELING OF PFBC PIPING AND OVERSPEED CONTROLS}


Ref.: DE-AC21-86MC21023

Date: August 1994

\section{Section 4}

\section{MODELING OF PFBC PIPING AND OVERSPEED CONTROLS}

As discussed in Section 1.2, the objective of this study was to identify the overspeed protection needs of the gas-turbine/generator during a loss of generator electrical load. Steady-state control, load maneuvering, etc., are subjects of a system response study that was not part of this effort. The analysis of the safety system, per se, was also not part of this study; consequently, various concepts relating to this system (for example, redundancy management, fail-safe valve positioning, overall optimal system operation) are not completely developed. However, since this is an emergency system, some issues of redundancy are addressed with respect to seemingly duplicated valve functions in the system. Specifically, the fuel piping vent valve and the secondary fuel trip/isolation valve (Valves 3 and 4 in Figure 2.1) could serve as redundant backup valves to the primary flare vent and primary fuel-trip valves (Valves 1 and 2 ) if the secondary valves were also fast-acting. At the present time, these valves are not $\mathrm{planned}$ for fast action, although this $\mathrm{plan}$ could change if future safety systems studies show redundancy to be necessary. Nevertheless, this study, which simulates the operation of only one pair of valves in the fuel gas system, is applicable. Either there is no redundancy, in which case overspeed protection is provided by the primary pair of valves only, or with two redundant valve pairs, either pair must be capable of functioning as the primary valve pair. Hence modeling of the primary valves and their operation is the main consideration in both cases.

Two subsystems have been identified; they work together to provide turbine emergency overspeed protection. One is the fuel gas valve system comprising the valves and associated piping shown in Figure 1.2. In Figure 2.1 of Section 2, the valves in this system that are not control valves have been numbered for clarity ( 1 through $4 a$ and $4 b$ ). The other subsystem is the vitiated air supply/bypass system, which includes Valves A, B and C in Figure 2.1 with piping connections to the compressor, CPFBC, topping combustors, and gas turbine, as shown in Figure 1.4. The purpose of the fuel gas valve system is to reliably shut off the fuel supply; the air-bypass valve system accomplishes two additional functions in preventing overspeed. The turbine inlet temperature is reduced and the compressor work load is maintained. Both of these effects increase the rotational deceleration of the common-shaft, compressor/turbine/generator unit.

The combined operation of the two subsystems, initiated as discussed in Section 3, is as originally proposed in the Phase 1 study. In the air supply/ bypass subsystem, Valves $A$ and $C$ close while the bypass valve (Valve B) opens. Assuming redundancy in the fuel gas subsystem, there are two sets of simultaneously operating valves-each consisting of shut-off and relief types. In the upstream set, the primary fuel trip valve (Valve 2) closes, blocking the flow of fuel gas to the topping combustors while the primary flare vent valve (Valve 1) opens, diverting the fuel gas flow to the flare stack. The redundant downstream set operates in unison with the upstream set of valves. The secondary fuel trip valves, one for each combustor (Valves $4 a$ and $4 b$ ) 
Ref.: DE-AC21-86MC21023

Date: August 1994

close, while the fuel piping vent valve (Valve 3 ) opens, exhausting the fuel line downstream of Valve 2 to the flare stack. The combined subsystems must achieve the required shut-off, bypass, and relief functions in less then 1.9 seconds, as discussed in Section 3.

Excerpted from the Introduction and the heat and material balance of Figure 4.1 and shown in Table 4.1 is a summary of valves-their sizes and operating conditions-from both subsystems. Success of the emergency overspeed protection system rests with the ability to operate these valves in the sequences described and under the conditions given. However, the combination of high pressures, high temperatures, and relatively large sizes shown in the table has caused concern over whether some of these valves could actually be designed based on current technology and whether such specifications require placing them in the category of "new developments."

Table 4.1 Summary of Valves

\begin{tabular}{|c|c|c|c|c||}
\hline Valve I.D. & Size (in.) & $\begin{array}{c}\text { Temperature } \\
(\text { oF) }\end{array}$ & $\begin{array}{c}\text { Pressure } \\
\text { (psia) }\end{array}$ & Flow (Ibm/s) \\
\hline \hline A & 26 & 750 & 250 & 357 \\
\hline B & 26 & 750 & 250 & 357 \\
\hline C & 40 & 1600 & 250 & 357 \\
\hline 1 & 28 & 1600 & 250 & $206^{*}$ \\
\hline 2 & 28 & 1600 & 250 & 68 \\
\hline 3 & 28 & 1600 & 250 & $206^{*}$ \\
\hline 4a, 4b & 22 & 1600 & 250 & 34 \\
\hline *indicates choked flow, operating singly & & \\
\hline
\end{tabular}

Discussions with valve manufacturers revealed that temperatures in the neighborhood of $1600^{\circ} \mathrm{F}$ are not a problem by themselves. Valves used in refineries operate at these temperatures, but the maximum working and differential pressures are only about 30 psi. Neither is the large size necessarily a problem, since 36 -in.-dia valves are routinely supplied in these applications. However, pressures greater than 40 to 50 psi cause excessive creep at temperatures exceeding about $1300^{\circ} \mathrm{F}$. To counter the resultant loss of structural strength, more material is generally required to construct the valves-possibly as much as three or more times the amount of material. While this simple approach can be satisfactory for small valves (i.e., 2 - to 3 -in. dia), it is not very desirable for valves of the size listed in Table 4.1. Advanced design techniques are required-particularly for those valves which will also be interfaced to the plant refractory-lined piping. Most resultant 
Ref.: DE-AC21-86MC21023

Date: August 1994

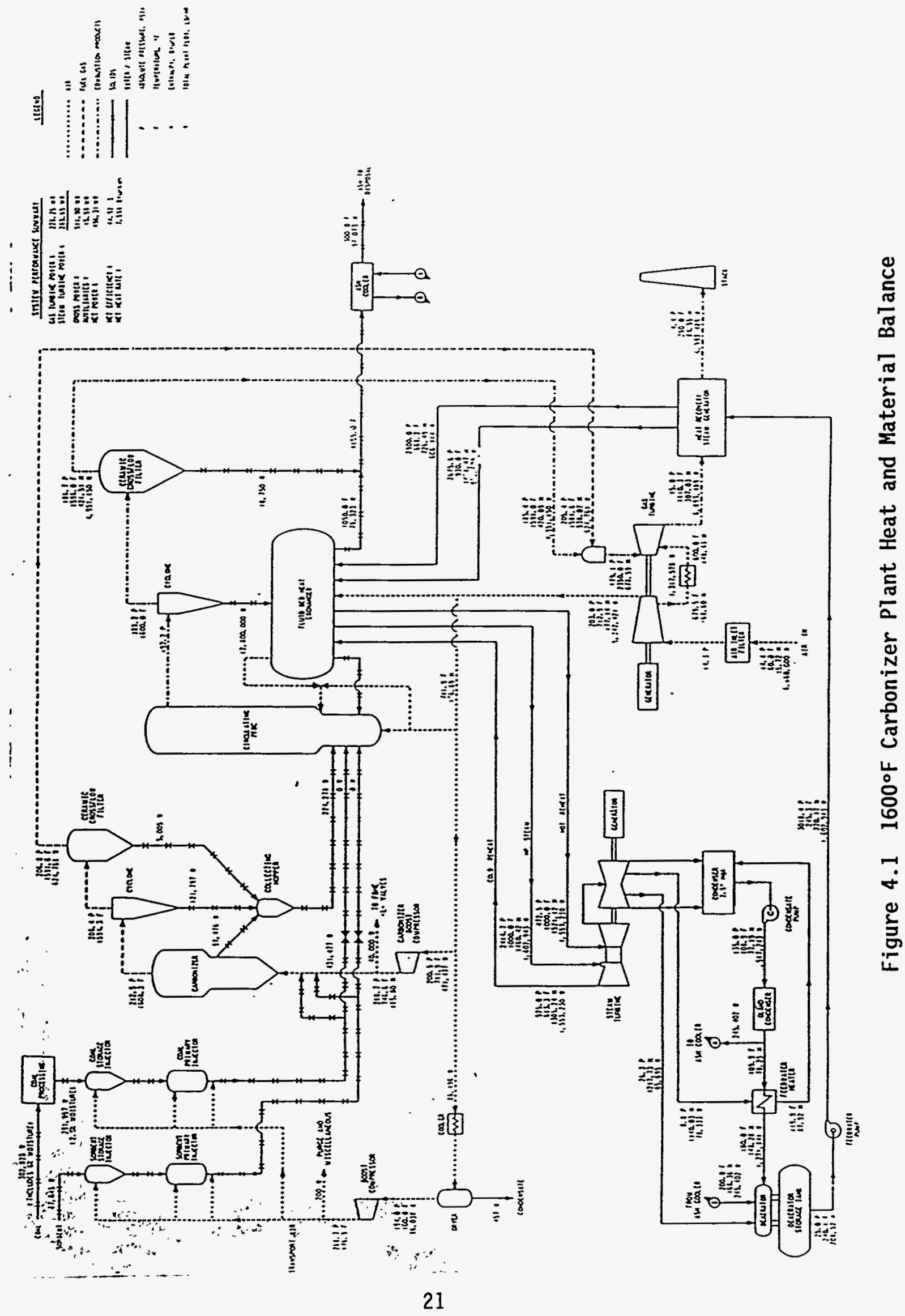


Ref.: DE-AC21-86MC21023

Date: August 1994

valve designs require one or more of the following: special alloys, coatings, or combinations of different materials in different parts of the temperature gradient.

Some basic process information-such as expected differential pressures, reverse flow requirements, and leakage rates-is needed by valve manufacturers to answer these concerns. To this end, we decided to simulate the operation of the system. Since working and differential pressures were of the most concern, the baseline plant configurations were simplified or reworked to concentrate upon and to clearly demonstrate pressure patterns and, in particular, unexpectedly large, short-duration pressure peaks or pulses. Generaliy, the distances between valves and lengths of lines were taken from the Phase I baseline plant layout drawings, and relative locations of valves were replicated to maintain their proper function. Specifically, the simulations are "worst-case" analysis tools. They are described in the following sections, and results are discussed pertaining to formulating the functional specifications given in Section 2.

\subsection{VITIATED AIR SUPPLY/BYPASS SYSTEM SIMULATION}

The arrangement in Figure 4.2 shows how the vitiated air supply/bypass subsystem was simulated. Since pressure differentials at Valves $A, B$, and $C$ were the main concern, we wanted to establish a "worst-case" but simple simulation scenario with respect to operating them. Fixed pressure and temperature boundary conditions were chosen at the inlets to the CPFBC and to the topping combustors and also at the outlets of the CPFBC filters and the compressor. These conditions were chosen for three reasons:

- From a practical standpoint, a model of the remainder of the plant was not available to provide these conditions accurately enough.

- These conditions were not expected to change much during the short operating time of the valves (typically less than 1 second)

- The pressures would be expected to eventually decrease as the system "coasts" down, resulting in lower differential pressures than with constant boundary conditions.

Therefore, the dynamic operation of the subsystem was simulated by changing the flow resistances of the pipe sections in which the three valves were modeled relative to flow resistances of the attached upstream and downstream pipe sections. Simulation of the closing of Valves $A$ and $C$ was accomplished by increasing the flow resistances, and the opening of Valve $B$ was simulated by decreasing its flow resistance from a high value to the lower resistance of the attached piping. The simultaneous operation of the three valves was initiated at time zero and was completed in 0.6 seconds. Although the shortness of the operating time can possibly be relaxed, as discussed in Section 5 , we sought a demonstration of worst-case pressure patterns expected for the shortest anticipated operating time. 
Ref.: DE-AC21-86MC21023

Date: August 1994

To CPFBC, etc. Pres.

\& Temp. Bndry. Conds.

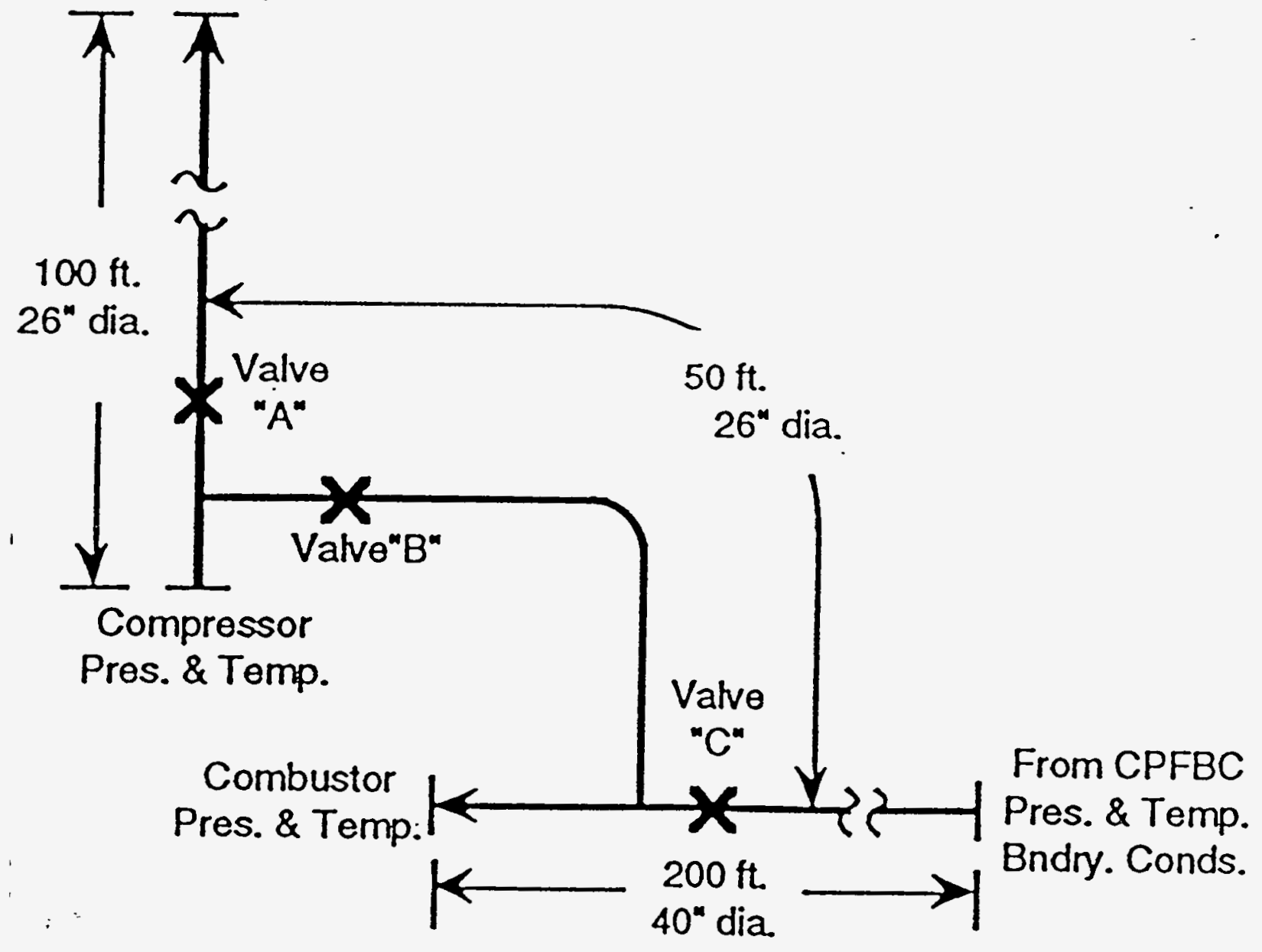

Figure 4.2 CPFBC Bypass-Air Subsystem Simulation 
Ref.: DE-AC21-86MC21023

Date: August 1994

Generally, when the motion of a stream with a high flow rate is abruptly changed, either stopped or started, oscillations in fluid pressure and flow direction similar to "water-hammer" can be expected at all locations in the stream until the new flow patterns have stabilized. The equations and the number of degrees of freedom (pipe sections) for the simulation were chosen to model these effects accurately since, to properly design the valves, the extent of any large anticipated pressure differentials across them is needed.

Clearly, the compressor airflow stream to the CPFBC, etc., is abruptly stopped when Valve A closes in 0.6 seconds. Similarly, the vitiated air stream to the topping combustors from the CPFBC is shut off rapidly when Valve $C$ closes. Substantial oscillations would be expected to occur in the lines containing these flow streams. However, when Valve $B$ opens at the same time, bypassed compressor airflow is essentialiy diverted to the inlet of the topping combustors. Less oscillatory behavior would be expected along this path because the mass flow rate of this stream has, for the most part, been established already by the original compressor airflow to the CPFBC. ATso, since the path length through Valve $B$ is shorter, the volume is smaller, so that final flow patterns can stabilize more quickly.

The plots of pressure differential across each valve vs. time for the simulated operation of the vitiated air supply/bypass subsystem are given in Figure 4.3. As the figure shows, pressure differentials do not exceed 20 psi; with Valves $A$ and $C$, there are also reverse differential pressures of the same order of magnitude. Although not shown, times of reverse flow transients roughly correspond to time segments when the reverse differential pressures occur.

Referring to Figure 4.1 and Table 4.1 , Valve $A$ always operates within conditions that can be met by currently available design techniques. On the other hand, Valve B can have stagnant, hot, vitiated air on its downstream side when it is closed during normal operation. However, we have assumed that convective and radiative heat losses maintain its temperature below values that would require special design considerations.

The only remaining valve in the vitiated air supply/bypass subsystem with high-pressure/high-temperature operating conditions is Valve $C$. However, this valve is a candidate for omission or removal from the system (refer to Section 5). Except for cases requiring a complete emergency coastdown, as opposed to just zeroing rotational acceleration rapidly enough, the normal flow of vitiated air to the combustors can be accommodated; at the same time, turbine overspeed protection can be provided without this valve. The assumption is that any necessary modulation of associated flow streams can be accomplished, on a much expanded time scale, via the normal control valves in the system.

Most of this information is contained in the main items of the specifications given in Tables 2.1 through 2.7 (Section 2). The remarks sections contain information that cannot be translated so directly. 
Ref.: DE-AC21-86MC21023

Date: August 1994

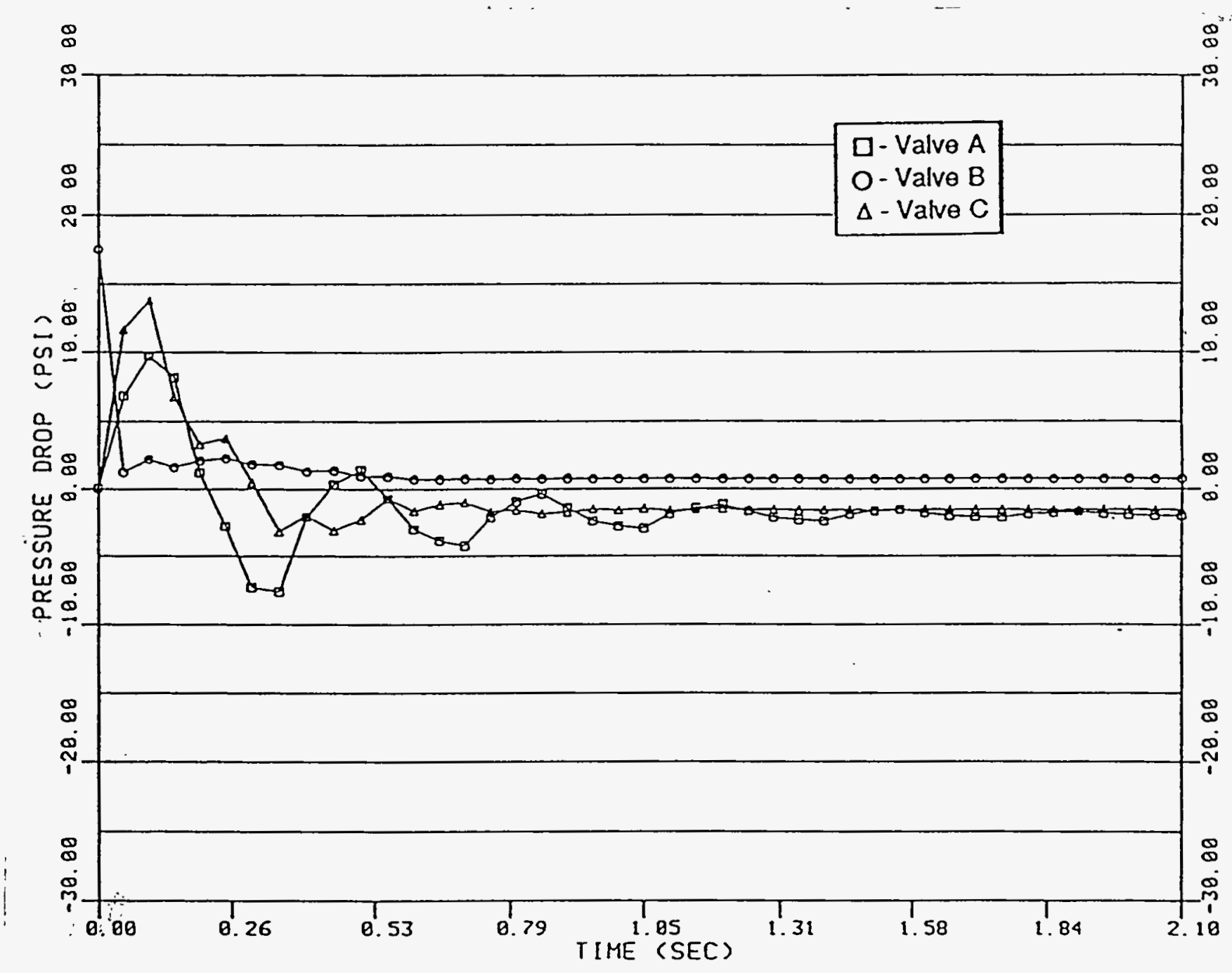

Figure 4.3 Differential Pressures Across Air-Bypass Subsystem Valves 
Ref.: DE-AC21-86MC21023

Date: August 1994

\subsection{FUEL GAS SUBSYSTEM SIMULATION}

Figure 4.4 shows the arrangement used to simulate the operation of the fuel gas subsystem. As discussed earlier in this section, only two valves are included in the simulation, instead of the five shown in Figure 2.1.

The worst-case scenario for differential valve pressures was selected for the main trip- and vent-valve set (Valves 1 and 2). The functional specifications for Valves $3,4 a$, and $4 b$ (Figure 2.1) would be the same except for differences in sizes and flow rates.

The procedure and equations used in this simulation are similar, from an analytical standpoint, to those used for the air supply/bypass subsystem. Aside from physical arrangement, pipe lengths, valve sizes, etc., the main difference was that control of the flow through Valve 2 could not be accomplished simply by changing its flow resistance (see Section 4.3). To simulate sufficient shut-off of fuel flow to the combustors, we found that the required flow resistance was high enough to cause the equations associated with the vaive to become "stiff." In other words, the time constant associated with the equations for the valve becomes extremely short compared with those for the other simulated elements. In reality, the flow through a valve would reach its steady-state value extremely quickly because the flow resistance is increased by closing the valve. Therefore, the time step required to simulate such a fast event must typically be made an order of magnitude smaller than the smallest time constant in the system for the results to be accurate or for the solution to be stable. Hence the simulation of the rest of the elements is severely limited by the prohibitively small time steps required to simulate this valve. The remedy, and thus a difference in this simulation, was always to use the steady-state solution for flow through the valve because, in reality, the steady state is reached extremely rapidiy in any case.

Another difference was that "choked" flow was anticipated upon venting the fuel line at 205 psia to atmospheric pressure at the flare stack. Therefore, the flow resistances required that appropriate adjustments be made in the elements of piping and that Valve 1 containing this flow stream be representative of real flows driven by this large pressure differential. It may be desirable to reduce the size of the vent valves and lines from the 28-in. I.D. used in the Phase 1 study. As discussed in the introduction, only full-flow venting is required but, from Table 2.1, choked flow to atmospheric pressure through a 28-in. line produces about three times the fuel gas flow normally passing through the open primary and secondary fuel trip valves. There may also be a need to explore other considerations, such as controlling the upstream pressure of the vent valves, to 7 imit some undesirable transients occurring elsewhere in the plant. Such features were not modeled in this study. 
Ref.: DE-AC21-86MC21023

Date: August 1994

To Flare Stack

Pres. \& Temp. Bndry.

Conds. (Atmosphere)

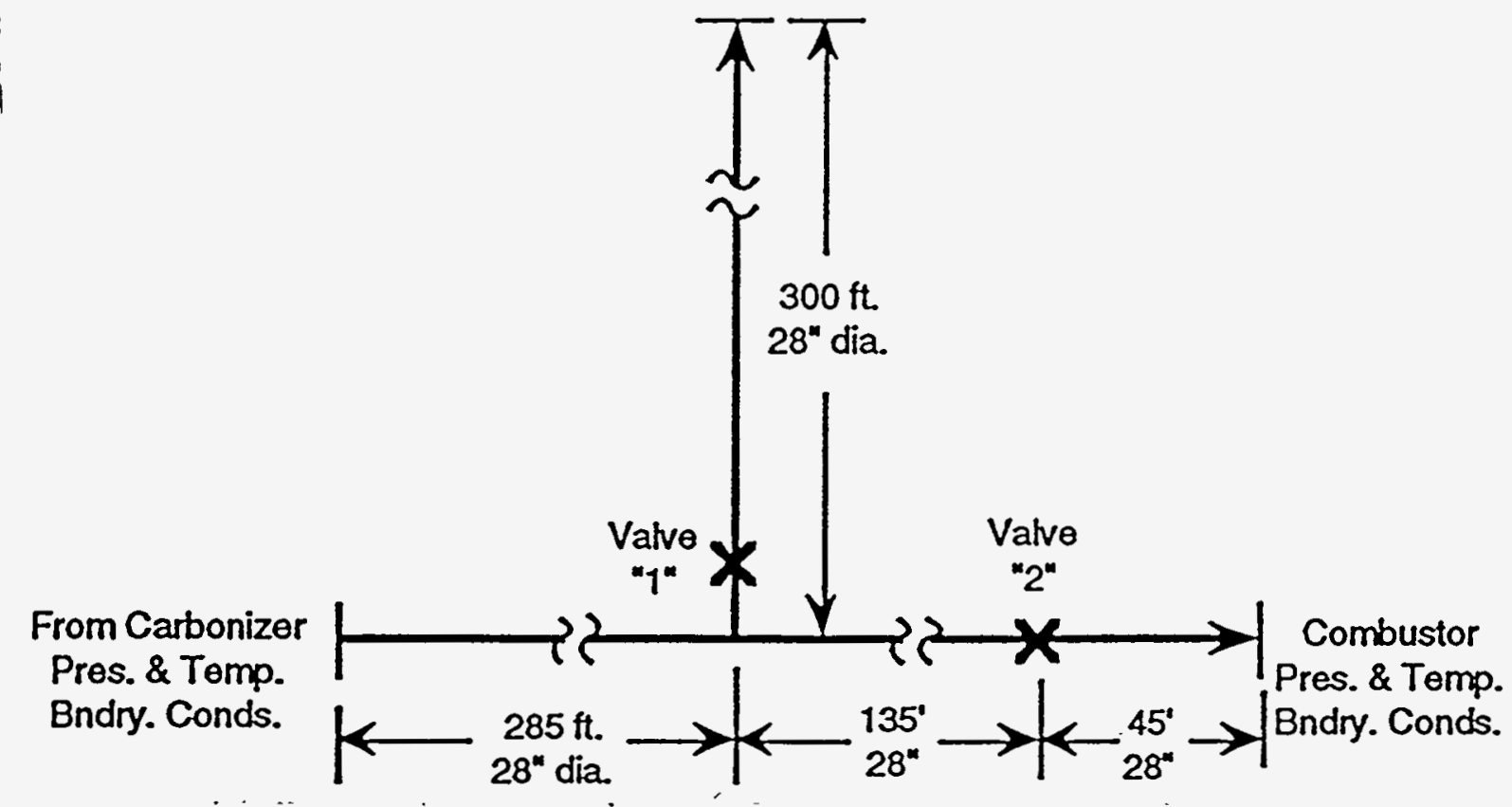

Figure 4.4 Fuel-Gas Subsystem Simulation

The results of the simulation are shown in Figure 4.5 for Valve 1 and in Figure 4.6 for Valve 2, with time zero corresponding to the time just before valve operation. As Figure 4.5 shows for Valve 1 , the differential and working pressures are about equal to the minor differential pressure in the reverse direction and only small pressure "peaks" in the plots. The plots in Figure 4.6 show another difference between this and the bypass subsystem simulation. The actual time-varying pressure at the inlet to the combustor could be predicted during the simulation time period; accordingly, the pressure downstream of Valve 2 was explicitly varied as a function of simulated time, as shown in the plot. The final differential pressure is approximately half the working pressure, and there is a 0.3 -second duration peak in the differential pressure of the same order of magnitude. (The differential pressure during venting of the fuel line is in the direction opposite to that under normal operating conditions.)

From this information and from Table 4.1, the conclusion must be reached that all valves in the fuel gas subsystem will require special design considerations. These conclusions are represented in the functional specifications (Tables 2.1 through 2.7). 
Ref.: DE-AC21-86MC21023

Date: August 1994

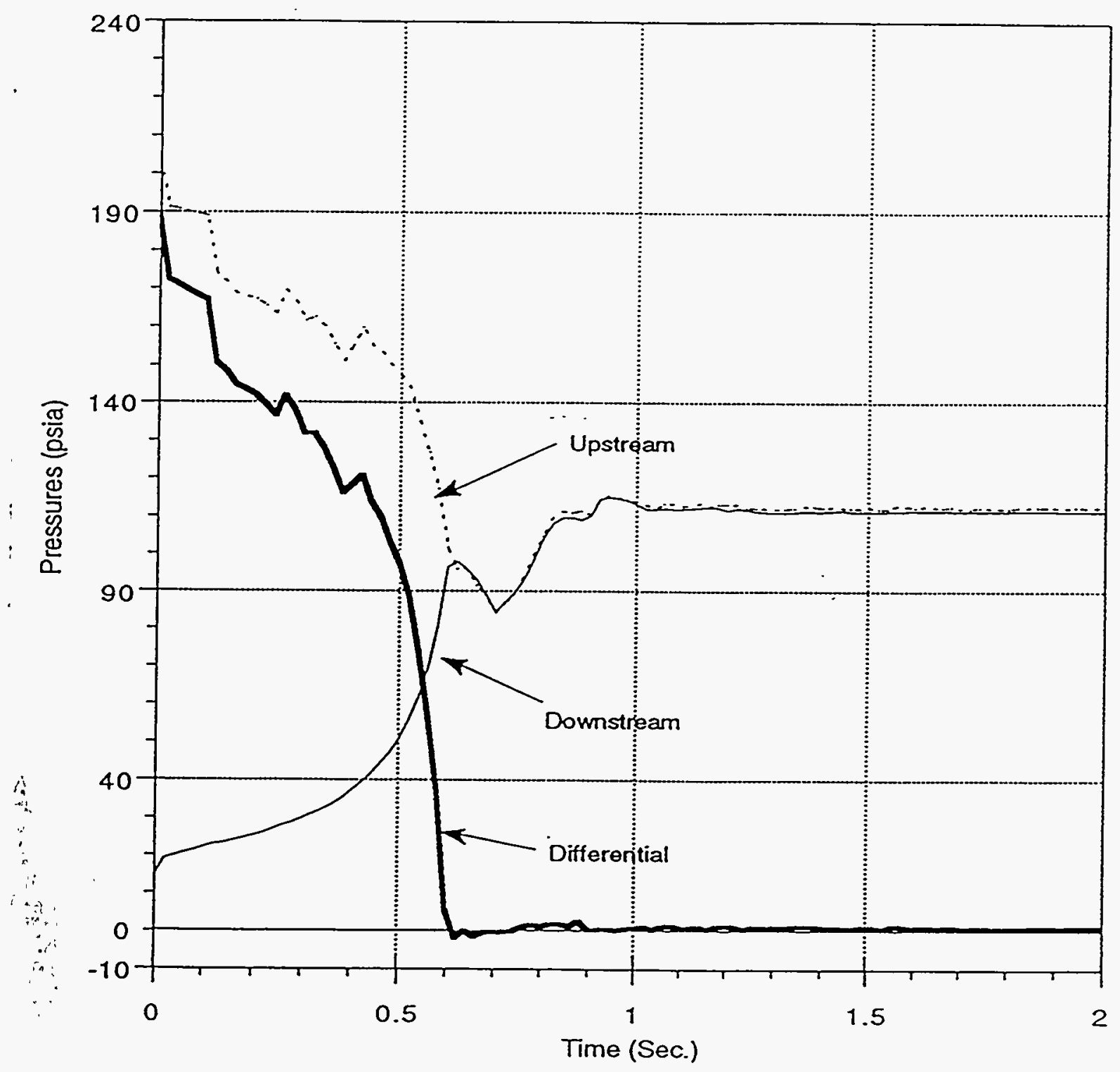

Figure 4.5 Pressures at Valve "1" 
Ref.: DE-AC21-86MC21023

Date: August 1994

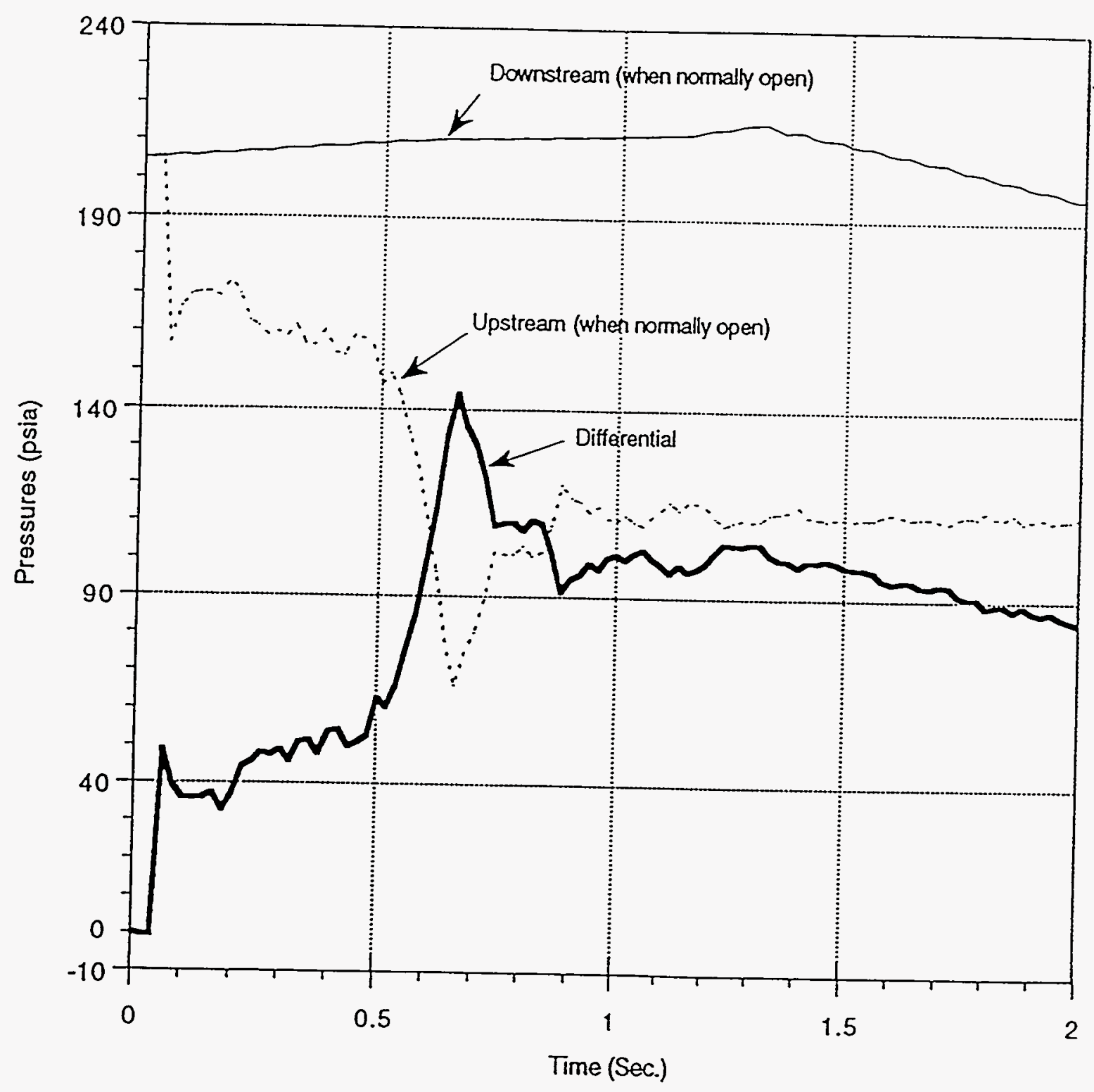

Figure 4.6 Pressures at Valve ${ }^{n}{ }^{n}$ 
Ref.: DE-AC21-86MC21023

Date: August 1994

\subsection{NUMERICAL METHODS OF SIMULATIONS}

The equations implemented in the simulations can be derived from the three basic conservation equations-namely, the mass, energy, and momentum balance equations. These equations are fundamentally partial differential equations. But by spatially quantizing the system representation, in this case, into lumped-parameter pipe sections, as shown schematically in Figure 4.7 , they can be efficiently approximated by ordinary differential equations (ODEs).

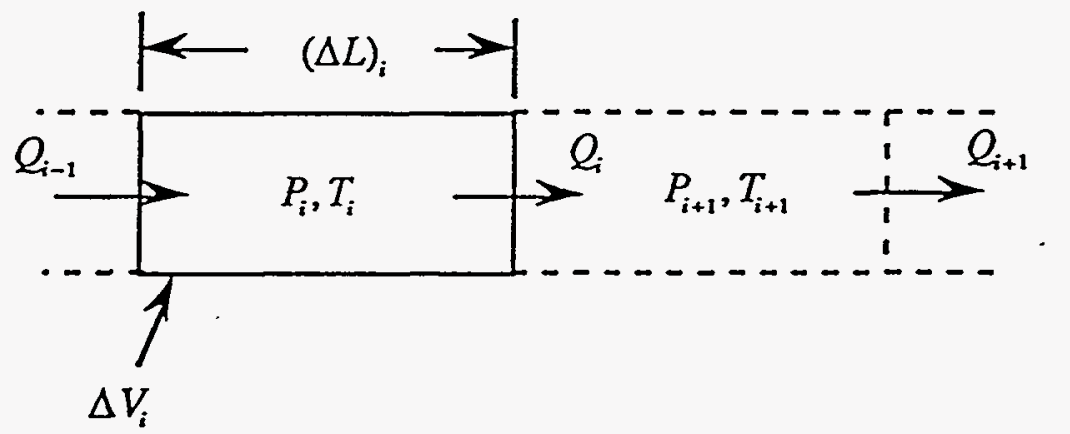

Figure 4.7 Pipe Section Variables

Referring to Figure 4.7 for each pipe section, ODEs of the following basic form were derived and are solved numerically in the simulations. Very similar equations described by Campbell [ㄹ] have been extensively used.

From the momentum balance equation, the following equation describes the volumetric flow rate $\left(Q_{i}\right)$ through the pipe section in response to the pressure difference $\left(P_{i}-P_{i+1}\right)$ applied across the section:

$$
M_{i}\left(\frac{d Q_{i}}{d t}\right)=P_{i}-P_{i+1}-R_{i} Q_{i}
$$

where

$$
\begin{aligned}
& M_{\mathfrak{i}}=\text { "Inertance" of the pipe section } \\
& R_{\mathfrak{i}}=\text { Pipe section flow resistance. }
\end{aligned}
$$

$$
M_{i}=\frac{\rho_{1}(\Delta L)_{i}}{g_{c} A_{i}}
$$

and 
Ref.: DE-AC21-86MC21023

Date: August 1994

$$
R_{i}=\frac{\rho_{i}(\Delta L)_{i} f_{F}}{2 g_{c} r_{h} A_{i}^{2}}\left|Q_{i}\right|
$$

where

$$
\begin{aligned}
& p_{i}=\text { Density of fluid in pipe section } \\
& f_{F}=\text { Pipe wal1 friction factor } \\
& A_{i}=\text { Cross-sectional area of pipe } \\
& r_{h}=\text { Hydrautic radius = area o perimeter } .
\end{aligned}
$$

From the energy and mass balance equations and from the ideal gas relationship $(P=R \rho T)$, the pressure and temperature behavior in the pipe section is described as follows:

$$
\frac{d P_{i}}{d t}=\frac{Q_{i-1}}{C_{i-1}^{*}}-\frac{Q_{i}}{C_{i}^{*}}
$$

and

$$
\frac{D T_{i}}{d t}=\left(\frac{\gamma-1}{\gamma}\right)\left(\frac{T_{i}}{P_{i}}\right)\left(\frac{d p_{i}}{d t}\right)+\left(\frac{Q_{i-1}}{\Delta V_{i}}\right)\left(T_{i-1}-T_{i}\right)
$$

where:

$$
\begin{gathered}
C_{i}^{*}=\frac{\Delta V_{i}}{\gamma P_{i}}=\text { Adiabatic pressure capacity of pipe section } \\
\Delta V_{i}=A_{i}(\Delta L)_{i}=\text { Volume of pipe section } \\
\gamma=\frac{C_{p}}{C_{v}}=\text { Ratio of specific heats }
\end{gathered}
$$


Ref.: DE-AC21-86MC21023

Date: August 1994

Eqs. (1), (4), and (5) are themselves coupled, and each pipe section is coupled to its upstream and downstream neighbor by virtue of physical connections. Valves are usually simulated by adjusting the flow resistances $\left(R_{i}\right)$ of those sections representing the valves. These equations correspond to Figure 4.7, with the fluid flowing unidirectionally as shown. Obvious modifications are required to accommodate two-way flow and are not given for the sake of clarity of presentation. Similarly, the mass, energy, and momentum must be balanced or accounted for in sections representing junctions or tees, thus adding some complexity to the equations for these sections.

Referring to Figure 2.1 (Section 2), the carbonizer, CPFBC, filters, etc., and the combustor/turbine/compressor combination were not dynamically modeled in the sense that the valve/piping models could be simply connected to them, thereby making possible simulation of the entire system. of immediate interest was only the worst-case pressure information needed to functionally specify the valves in the system. Hence, as shown in Figures 4.2 and 4.4, fixed or known time-varying pressure and temperature boundary conditions were used at the interfaces to the unmodeled components in the separate air bypass and fuel gas subsystem simulations.

Nevertheless, there are $3 \mathrm{~N}$ first-order differential equations, in the simulations, for "N" simulated pipe sections. Values for $N$ were 350 and 510 for the air bypass and fuel gas subsystems respectively. They were solved numerically using a fourth-order predictor-corrector technique known generally as the Adams-Bashforth-Moulton method [3]. In the implementation used in the simulations, the algorithm is initialized and subsequently reinitialized whenever the time-step size requires changing with a standard fourth-order Runge-Kutta method. A new value for the time step is automatically determined in the algorithm by its intrinsic controlled-error feature. 


\section{SECTION 5}

\section{DEVELOPMENT OF MODEL TURBINE/COMPRESSOR PERFORMANCE}


Ref.: DE-AC21-86MC21023

Date: August 1994

\section{Section 5}

\section{DEVELOPMENT OF MODEL OF TURBINE/COMPRESSOR PERFORMANCE}

The Westinghouse 501F Performance Code models the turbine, compressor, and generator interaction for a simple cycle 501F combustion turbine power plant. Inputs to the code include a 501F compressor map, turbine blade and stage data, fuel composition and lower heating value (LHV), and turbine inlet temperature and rotational speed.

To model a combined-cycle PFBC system with this Code, specific considerations must be addressed. Since the Code assumes the presence of a "standard" combustor rather than a topping combustor such as for the PFBC system, the combustor inlet fuel composition must be modified to account for the presence of vitiated air. This modification is made by computing a pseudo-fuel composition that, when combined with compressor air, gives the desired topping combustor exit gas composition.

\subsection{PLANT OPERATING CONDITIONS AT LOSS OF LOAD}

For the purposes of this study, pressures, temperatures, and mass flows were taken from Figure 4.1 (Section 4). This schematic shows the Phase 1 predicted heat and material balance for steady-state 100-percent load for a second-generation PFBC $\mathrm{plant}$ with a $1600^{\circ} \mathrm{F}$ carbonizer [1]. The mass flows in the schematic represent the total mass flows for two gas turbines and compressors. Therefore, the actual mass flow per turbine/compressor is half the stated value. Actual pressure drops for individual components may vary as the plant design becomes final and specific valves are incorporated.

At base load, $687.7 \mathrm{lb} / \mathrm{s}$ vitiated air at $1591{ }^{\circ} \mathrm{F}$ and $86.7 \mathrm{lb} / \mathrm{s}$ fuel gas at $1582^{\circ} \mathrm{F}$ flow into the topping combustor assembly. This flow represents an air-to-fuel ratio of $8: 1$. The combustor exit gas flow and temperature are $774.4 \mathrm{~Tb} / \mathrm{s}$ and $2350^{\circ} \mathrm{F}$.

The topping combustor exit gas composition and temperature are obtained from a separate $\mathrm{PC}$-based program which calculates equilibrium composition and temperature of the exit gas based on given inlet fuel gas and vitiated air flows, compositions, and temperatures. Equilibrium is determined for the species $\mathrm{CH}_{4}, \mathrm{CO}, \mathrm{CO}_{2}, \mathrm{H}_{2}, \mathrm{H}_{2} \mathrm{O}, \mathrm{N}_{2}$, and $\mathrm{O}_{2}$ using property data from the JANAF Tables. 
Ref.: DE-AC21-86MC21023

Date: August 1994

\subsection{POWER TRAIN ROTATIONAL INERTIA AND ACCELERATION}

The weight-based rotational inertia $\left(W R^{2}\right)$ of the $501 \mathrm{~F}$ power train was provided by Bertsch [4]]:

\begin{tabular}{|l|c|}
\hline \multicolumn{1}{|c|}{ Component } & Rotational Inertia $\left(\mathbf{l b f} \cdot \mathbf{i n}^{2}\right.$ ) \\
\hline W501F (Turbine/Compressor) & $49,736,527$ \\
\hline $2-97 \times 118$ (Generator/Excitor) & $9,887,807$ \\
\hline Auxi1iary Gear & 7,285 \\
\hline Total $\cdot \%$ & $59,631,619$ \\
\hline
\end{tabular}

The actual rotational inertia (I) is obtained by dividing $W R^{2}$ by the gravitational constant $(\mathrm{g})$ :

$$
I=\frac{W R^{2}}{g}=\frac{59,631,6191 b f \cdot i n^{2}}{32.17 \mathrm{ft} / \mathrm{s}^{2}}=\frac{1,853,6411 \mathrm{bf} \cdot i \mathrm{n}^{2} \cdot \mathrm{s}^{2}}{\mathrm{ft}}=m R^{2}
$$

where

$$
\begin{aligned}
& W=\text { Weight }(1 \mathrm{bf}) \\
& m=\text { Mass (1bm) } \\
& R=\text { Distance from axis of rotation. }
\end{aligned}
$$

The kinetic energy of a rotating system is given by:

$$
\text { Kinetic Energy }=\frac{1}{2} I \omega^{2}
$$

where

$$
\omega=\text { Rotational velocity. }
$$


Ref.: DE-AC21-86MC21023

Date: August 1994

The instantaneous power is the time rate of change of the kinetic energy,

$$
\text { Power }=\frac{d}{d t}(\text { Kinetic Energy })=\frac{d}{d t}\left(\frac{1}{2} I \omega^{2}\right)=\frac{1}{2}\left[I 2 \omega\left(\frac{d \omega}{d t}\right)\right]-I \omega \alpha
$$

where

$$
\alpha=\frac{\mathrm{d} \omega}{\mathrm{dt}} \text { (angular acceleration) }
$$

During norma1 operation of the $501 \mathrm{~F}$ engine in a second-generation PFBC plant, the generator provides about 43 percent of the load on the turbine. Therefore, if the generator becomes decoupled from the external power grid, the load on the turbine instantly drops by 43 percent, resulting in a rapid acceleration of the power train. The rate of increase in rotational speed can be calculated as the power normally consumed by the generator when connected to the external grid, divided by the rotational inertia and rotational velocity. By utilizing the results of the 501F Performance Code, which predicts steady-state generator and compressor power requirements, the instantaneous acceleration can easily be computed as:

$$
\alpha=\frac{\text { Generator Power }}{\mathrm{I} \omega}
$$

\subsection{CASE STUDIES OF FUEL GAS SYSTEM}

\subsubsection{Reference Case}

The reference case is considered the worst case, since it assumes all overspeed protection valves fail to actuate. The acceleration is computed according to the earlier relationship at values of w equal to 3600,3700 , $3800,3900,4000$, and $4100 \mathrm{rpm}$. The total time to reach 112-percent overspeed is assumed to be the sum of the time needed for each incremental increase in w. 
Ref.: DE-AC21-86MC21023

Date: August 1994

Results for these six runs show that the turbine speed increases linearly with time and is predicted by the following equation:

$$
\frac{N}{N_{b}}=0.046711 \times t+1.002121
$$

where

$$
\begin{aligned}
& N=\text { Actual rotational speed }(\mathrm{rpm}) \\
& N_{b}=\text { Base rotational speed }=3600 \mathrm{rpm} \\
& \mathrm{t}=\text { Time (seconds) }
\end{aligned}
$$

Alternatively, solving for time as a function of speed gives

$$
t=\frac{\left(\frac{N}{N_{b}}-1.002121\right)}{0.046711}
$$

The amount of time required for the turbine to reach 112 percent overspeed $\left(N / N_{b}=1.12\right)$ when all overspeed protection valves fail to actuate is 2.5 seconds.

\subsubsection{0-Percent Vitiated Air/0-Percent Fuel}

This case was run to determine whether cutting off the fuel flow to the combustor is sufficient to prevent turbine overspeed during a loss of external load. With an air-to-fuel ratio of $8: 1$, shutting off the fuel flow decreases the combustor exit/turbine inlet mass flow by one-ninth, or 11.1 percent. The turbine inlet temperature becomes that of the vitiated air (1591 $\mathrm{F}$ ) because no combustion occurs. Results for this case show that the turbine will continue to accelerate, but at a much slower rate than with 100 -percent fuel flow. An overspeed of 112 percent will be reached in 29.7 seconds.

\subsubsection{0-Percent Vitiated Air/10-Percent Fuel Leakage}

Because a zero-leakage valve is difficult and costly to implement in practice, we modified the previous case by adding 10-percent fuel leakage past the isolation valve. This value represents a conservative estimate of the valve leakage; the actual valve specification calls for no more than 5 -percent leakage. The modification results in $687.7 \mathrm{lb} / \mathrm{s}$ vitiated air at $1591 \circ \mathrm{F}$ entering the combustor with $8.7 \mathrm{lb} / \mathrm{s}$ fuel at $1582^{\circ} \mathrm{F}$. The subsequent combustor exit/turbine inlet gas temperature is $1680^{\circ} \mathrm{F}$. Results for this case show that the turbine wi11 reach 112 -percent overspeed in 13.7 seconds. 
Ref.: DE-AC21-86MC21023

Date: August 1994

From the results of these three cases, which are summarized in Figure 5.1, it is clear that if an external load loss occurs, actuation of the fuel isolation valve alone cannot adequately protect the turbine from overspeed. The turbine inlet temperature and mass flow do not drop enough to substantially reduce the turbine power output.

\subsection{PFBC SYSTEM VALVE ACTUATION TO DECELERATE TURBINE}

As discussed in Section 1, the PFBC Bypass System includes three valves to protect the turbine from overspeed. These valves are actuated by an overspeed trip signal. Valve A (CPFBC inlet valve, 26-in. I.D., normally open) closes, Valve B (PFBC bypass valve, 26-in. I.D., normally closed) opens, and Valve C (PFBC outlet valve, 40-in. I.D., normally open) closes. In these new valve positions, the compressor air bypasses the carbonizer and CPFBC systems and is routed directly to the topping combustors. However, results of this study indicate that Valve $C$ is not needed for turbine overspeed protection. Valve $C$ is discussed in further detail at the conclusion of this section.

As the $713^{\circ} \mathrm{F}$ bypass air mixes with the $1600^{\circ} \mathrm{F}$ vitiated air and enters the topping combustors, the temperature of the gas leaving the combustors and entering the turbine drops, and the turbine output work diminishes to a point where it just equals the compressor and auxiliary work. For the 501F turbine/ compressor, this turnover point was determined to occur at a reduced turbine inlet temperature of about $1420^{\circ} \mathrm{F}$. The amount of bypass air necessary to cool the turbine inlet gas to this temperature can be determined by a simple energy balance.

In addition to actuating the air bypass valves, the primary fue trip valve will close during the overspeed event. Assuming 10-percent fuel leakage through this trip valve, approximately 30 -percent bypass air $(\approx 2201 \mathrm{bm} / \mathrm{s})$ is required to reduce the turbine inlet temperature to $1421^{\circ} \mathrm{F}$, the temperature at which the turbine output power becomes approximately equal to the compressor input power.

Although all overspeed protection valves will be designed to operate simultaneousiy in the event of a loss of external load, their effect on the turbine and compressor output was analyzed as if they were actuated sequentially. Done as a worst-case analysis, sequential activation gives a clear picture of the effect of each valve. The valve operating sequence is best summarized in Table 5.1 and Figure 5.2 .

Table 5.1 summarizes the mass flow rates through the air bypass and vitiated air 1 ines, as well as the fuel mass flow rate for each of ten cases. Each case represents a one-third portion of the travel time of the different valves, and all valves are assumed to complete their trave 1 in 0.6 seconds. The variation of mass flow rate with percentage of valve closure is assumed to be linear. 
Ref.: DE-AC21-86MC21023

Date: August 1994

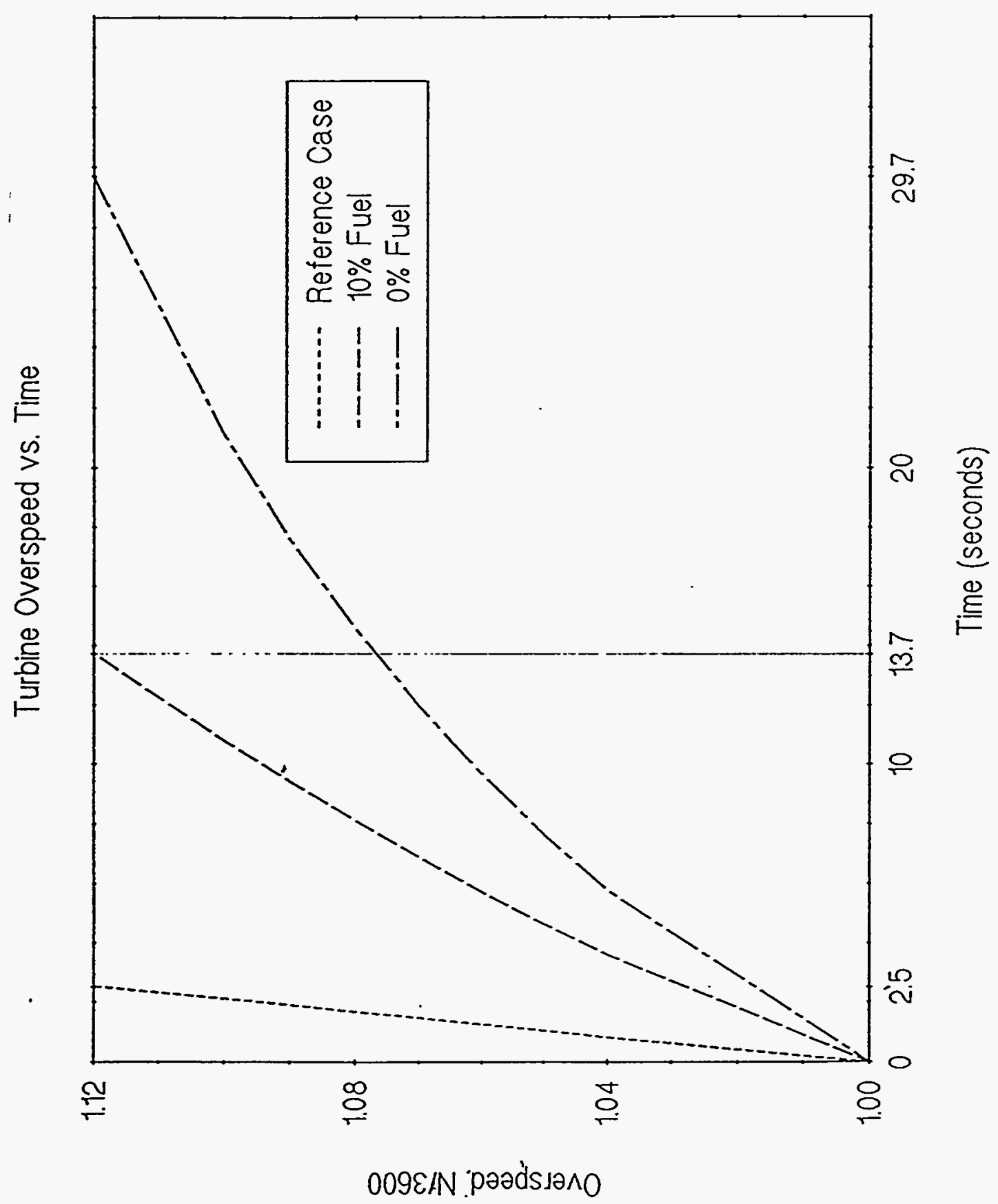

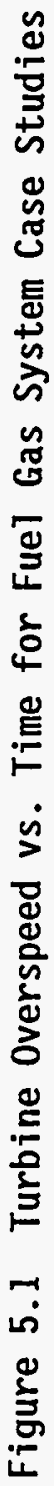


Table 5.1 Summary of Turbine Inlet Mass Flows and Temperatures During Valve Actuation

\begin{tabular}{|c|c|c|c|c|c|c|c|c|c|c|}
\hline \multirow{2}{*}{ Stream } & \multicolumn{10}{|c|}{ Mass Flow $(7 \mathrm{bm} / \mathrm{s})$} \\
\hline & 1 & 2 & 3 & 4 & 5 & 6 & 7 & 8 & 9 & 10 \\
\hline Bypass Air & 0. & 18 & 147. & 220 & 220 & 220 & 220 & 417 & 564 & 663 \\
\hline Fuel & 86.7 & 77.9 & 69.6 & (8). 5 & $(35 \%$ & $187: 6$ & 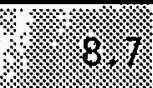 & 8.7 & 8.7 & 8.7 \\
\hline Vitiated Air & 687.7 & 622.8 & 557.0 & 492.1 & 492.1 & 492.1 & 492.19 & 2995 & 4.148 & (49. \\
\hline Total & 774.4 & 773.7 & 773.6 & 773.6 & 747.3 & 729.7 & 720.8 & 720.7 & 720.7 & 720.7 \\
\hline \multicolumn{11}{|c|}{ Temperature $\left({ }^{\circ} \mathrm{F}\right)$} \\
\hline \multirow[t]{2}{*}{ Turbine Inlet Gas } & 2350 & 2209 & 2062 & 1915 & 1684 & 1514 & 1421 & 1188 & 1011 & 888 \\
\hline & \multicolumn{3}{|c|}{$\Delta T=435$} & \multicolumn{3}{|c|}{$\Delta T=494$} & \multicolumn{4}{|c|}{$\Delta T=533$} \\
\hline \multirow{2}{*}{$\begin{array}{l}\text { Valve Operating } \\
\text { Sequence }\end{array}$} & \multirow{2}{*}{$c$} & \multicolumn{2}{|c|}{ Air Bypass } & \multicolumn{3}{|c|}{0 Primary Fuel Trip } & 0 & \multicolumn{2}{|c|}{ Air Inlet } & $c$ \\
\hline & & \multicolumn{2}{|c|}{ Valve $B$} & \multicolumn{3}{|c|}{ Valve 2} & & \multicolumn{2}{|c|}{ Valve $A$} & \\
\hline $\begin{array}{l}\text { Legend: } \\
\begin{aligned} 0 & =\text { Open } \\
C & =\text { Closed }\end{aligned}\end{array}$ & & & & & & & & & & \\
\hline
\end{tabular}


Ref.: DE-AC21-86MC21023

Date: August 1994

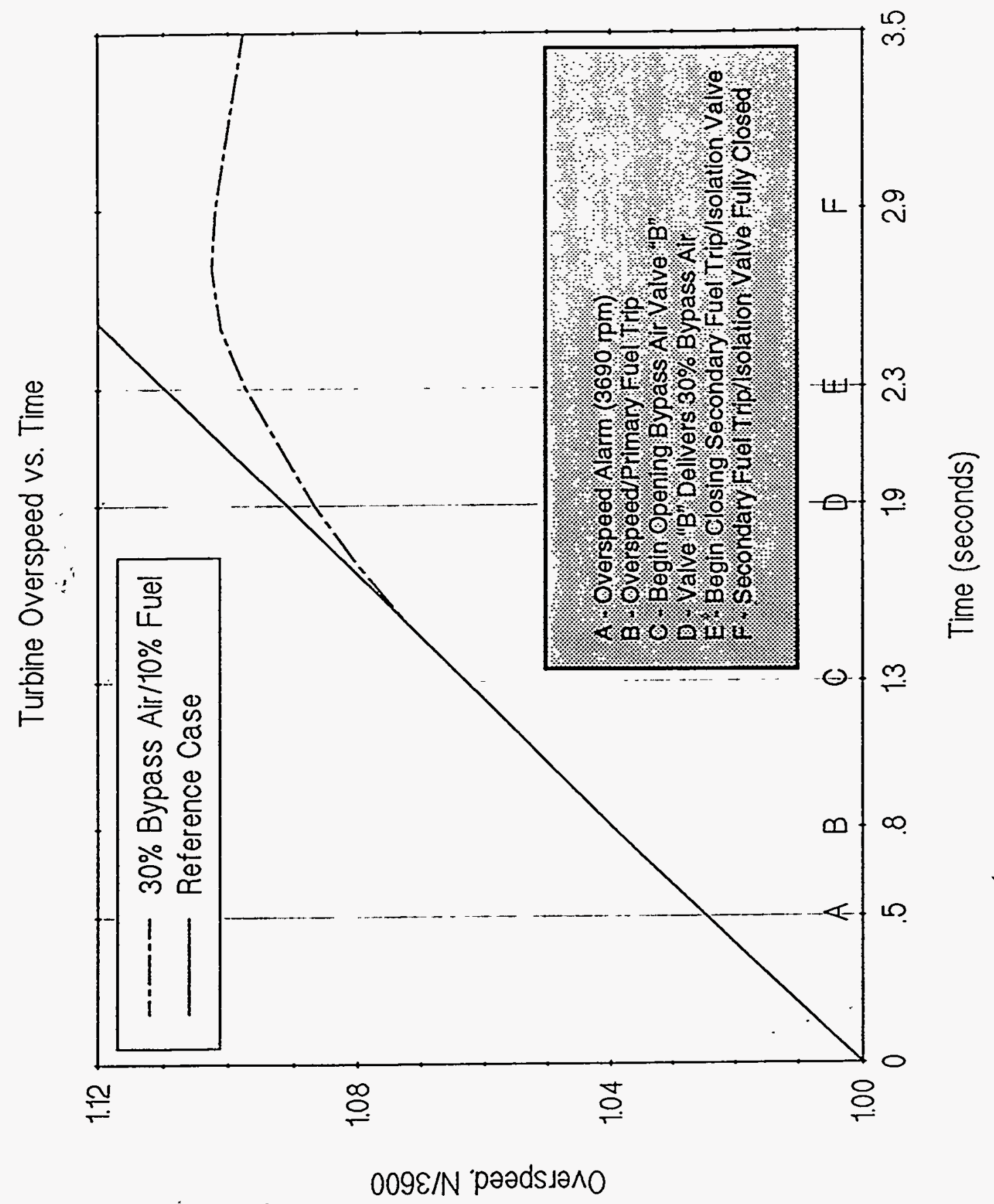

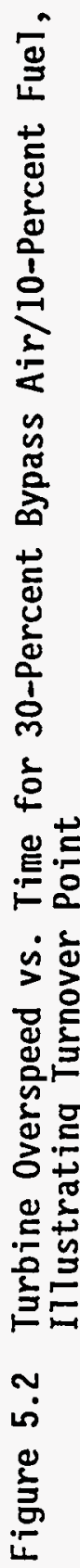


Ref.: DE-AC21-86MC21023

Date: August 1994

As the bypass air is increased up to $2201 \mathrm{bm} / \mathrm{s}$, the corresponding decrease in vitiated air is computed by:

$$
\Delta V=\frac{B}{\left(1+\frac{F}{V}\right)}
$$

where

$$
\begin{aligned}
\Delta V & =\text { Change in vitiated airflow rate }(1 \mathrm{bm} / \mathrm{s}) \\
B & =\text { Bypass airflow rate }(1 \mathrm{bm} / \mathrm{s}) \\
F / V & =\text { Fuel-to-air ratio }
\end{aligned}
$$

Since $F / V=1 / 8$, the change in vitiated airflow rate is simply

$$
\Delta V=\frac{8}{9}(B)
$$

As the vitiated air decreases, the fuel flow rate is assumed to decrease proportionally.

Also shown in Table 5.1 is the turbine inlet temperature for each case. The order of closure of the valves was chosen to correspond to the difference in turbine inlet temperature before and after the valve is opened/closed. The smallest difference in turbine inlet temperature occurs with the opening of the bypass air valve $(B)$, and the largest difference occurs with the closing of the CPFBC inlet valve $(A)$. Thus the valve operation sequence for the purposes of a conservative analysis is assumed to be Valve $B$, followed by the Fuel Isolation Valve, followed by Valve $A$.

Figure 5.2 shows the effects of the valve closures on the speed of the turbine. The overspeed trip occurs 0.8 seconds after loss of load, when the turbine has reached $3744 \mathrm{rpm}$. A delay of 0.5 seconds is allowed for control system response time, and then the actuation of the bypass air valve (B) is assumed to begin at 1.3 seconds. By 1.9 seconds, Valve $B$ is bypassing 30 percent of the compressor air directly to the topping combustors. The turbine continues to accelerate, but at a much slower rate than that of the reference case.

At 2.3 seconds, the secondary fuel trip/isolation valve begins closing and at 2.9 seconds is fully closed. A 1-second delay time was incorporated between opening of the bypass air valve and closing of the primary fuel trip valve to account for the residual volume of fuel left in the combustor inlet manifold and in the combustor itself. The volume of fuel was estimated to be about $185 \mathrm{ft}^{3}$, but has a very short residence time because of the high flow 
Ref.: DE-AC21-86MC21023

Date: August 1994

rate through the combustors. In fact, the residence time of the fuel is probably negligible, but a 1-second delay is included for conservatism.

As seen in Figure 5.2 , by the time the secondary fuel trip/isolation valve is fully closed, the turbine is decelerating. The inflection of the overspeed curve indicates that the compressor and auxiliary power exceed the power output of the turbine. Figure 5.3 shows that the gradual deceleration of the turbine back to $3600 \mathrm{rpm}$ takes approximately 40 seconds.

The results of this analysis show that by cutting off the fuel flow to the topping combustors and bypassing 30 percent of the compressor exit air to the combustors, the turbine will be protected from overspeed caused by a loss of external load and will return to a speed of $3600 \mathrm{rpm}$. However, to bring the turbine into the coast-down mode, the hot vitiated airflow must be cut off entirely, and the remaining compressor exit air must be bypassed to the combustors. These steps can be accomplished by closing Valve $A$ alone, without the use of Valve $C$.

Although Valve A closes in 0.6 seconds, the vitiated airflow decay will take longer because of the large system volume of air, approximately

$71,150 \mathrm{ft}^{3}$. This volume was computed by estimating the largest probable pipe lengths and diameters between Valve $A$ and the topping combustors. It includes the volumes of the CPFBC, FBHE, cyclone, and cross-flow (barrier) filters.

To obtain accurate knowledge of the flow rates and pressures during the decay time, a detailed transient analysis of the entire plant is required but such an analysis is beyond the scope of this study. However, we can estimate the form of the function governing the decrease in mass flow as an exponential decay and thereby estimate an upper bound for the decay time. The mass flow (i) can be approximated by:

$$
\dot{m}=\dot{m}_{\text {init }}\left(e^{-t / \tau}\right)
$$

where

$$
\begin{aligned}
t & =\text { Time } \\
\tan & =\text { Time constant } .
\end{aligned}
$$

This equation is analogous to the flow of current in a resistive/capacitative circuit. The time constant is determined by the system resistance and capacitance, and in a plot of $(\dot{m})$ vs. $t$ can be determined by the initial slope 
Ref.: DE-AC21-86MC21023

Date: August 1994

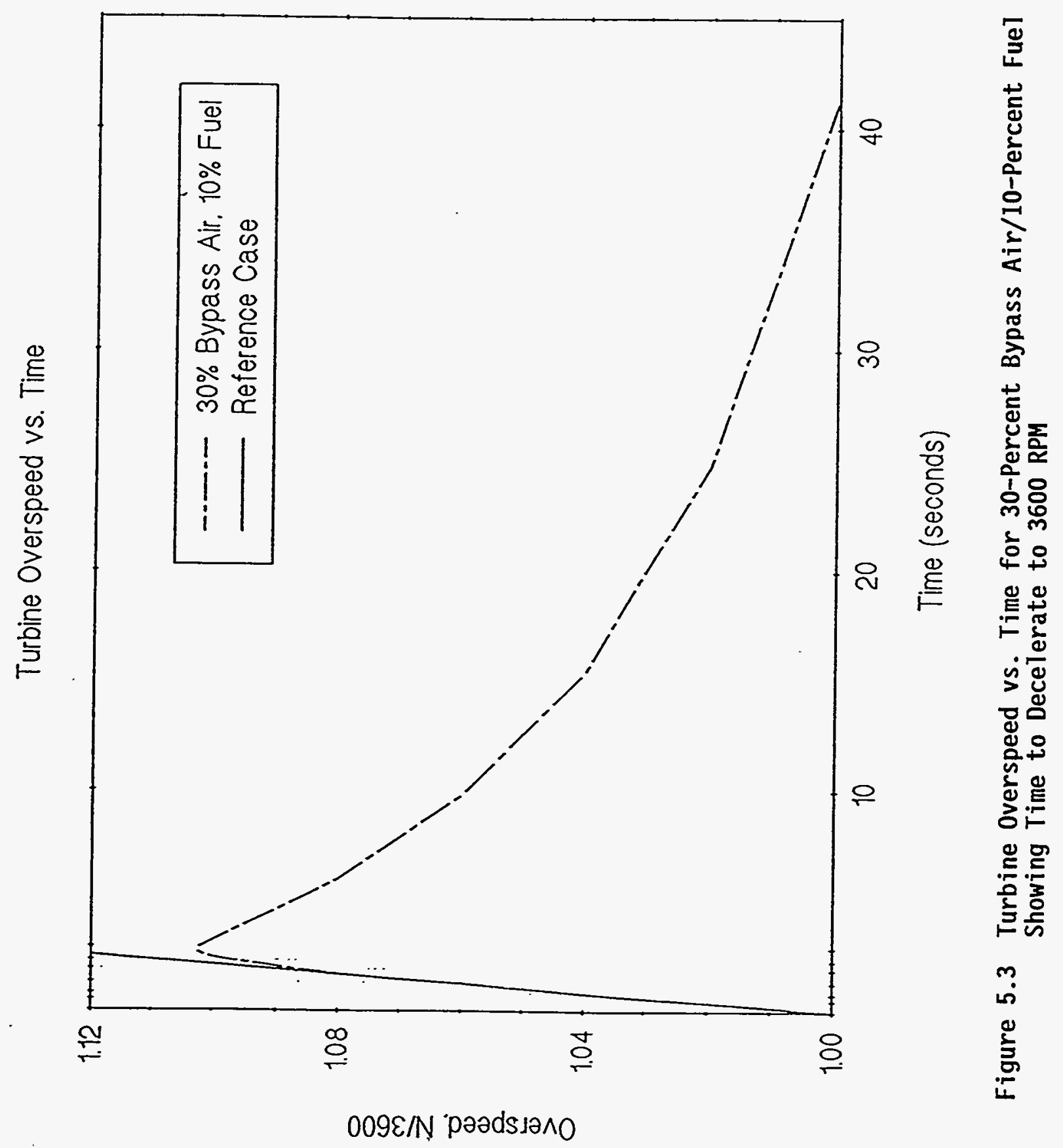


Ref.: DE-AC21-86MC21023

Date: August 1994

of the decay curve. The time constant can be approximated as the vitiated air volume $(V)$, divided by the volumetric flow rate $(Q)$ :

$$
\tau=\frac{V}{Q}
$$

where $Q$ is obtained from the steady-state mass flow rate entering the topping combustor, as shown in Figure 4.1 (Section 4). This flow rate is divided by four because there are four valves.

$$
Q=\dot{\mathrm{m}} / \rho=\frac{\left(4,951,150 \frac{1 \mathrm{bm}}{\mathrm{h}}\right)\left(\frac{\mathrm{h}}{3600 \mathrm{~s}}\right)}{\left(0.2437 \frac{1 \mathrm{bm}}{\mathrm{ft}^{3}}\right)(4)}=1411 \mathrm{ft}^{3} / \mathrm{s}
$$

then

$$
\tau=\frac{71,150 \mathrm{ft}^{3}}{1411 \mathrm{ft}^{3} / \mathrm{s}} \cong 50 \text { seconds }
$$

In a period of time equal to one time constant, the mass flow will decrease by 63 percent. In 3.7 time constants, the mass flow will decrease by 95 percent. Therefore, if the upper bound of the decay time is assumed to be four time constants, we can estimate the decay time as 200 seconds, or approximately 3.5 minutes. Based on this analysis, it appears that valve $C$ is unnecessary, because Valve $A$ can adequately perform the function of cutting off the hot vitiated airflow.

\section{$5.5 \quad$ COAST-DOWN}

For Cases 7 through 10 in Table 5.1 , as the mass flow rate of vitiated air decreases from 492 to $49 \mathrm{lbm} / \mathrm{s}$ (10 percent leakage), the turbine inlet temperature decreases dramatically. Cases 8,9 , and 10 could not be modeled using the 501F Performance Code because the lower turbine inlet temperatures are out of range of Code capabilities. Therefore, we refer to 501F Shop Test Results, shown in Figure 5.4, to predict the full coast-down time. These results were obtained from a simple cycle $501 \mathrm{~F}$ engine, which was first operated at $3600 \mathrm{rpm}$ and then allowed to coast down by cutting off the fue flow. 


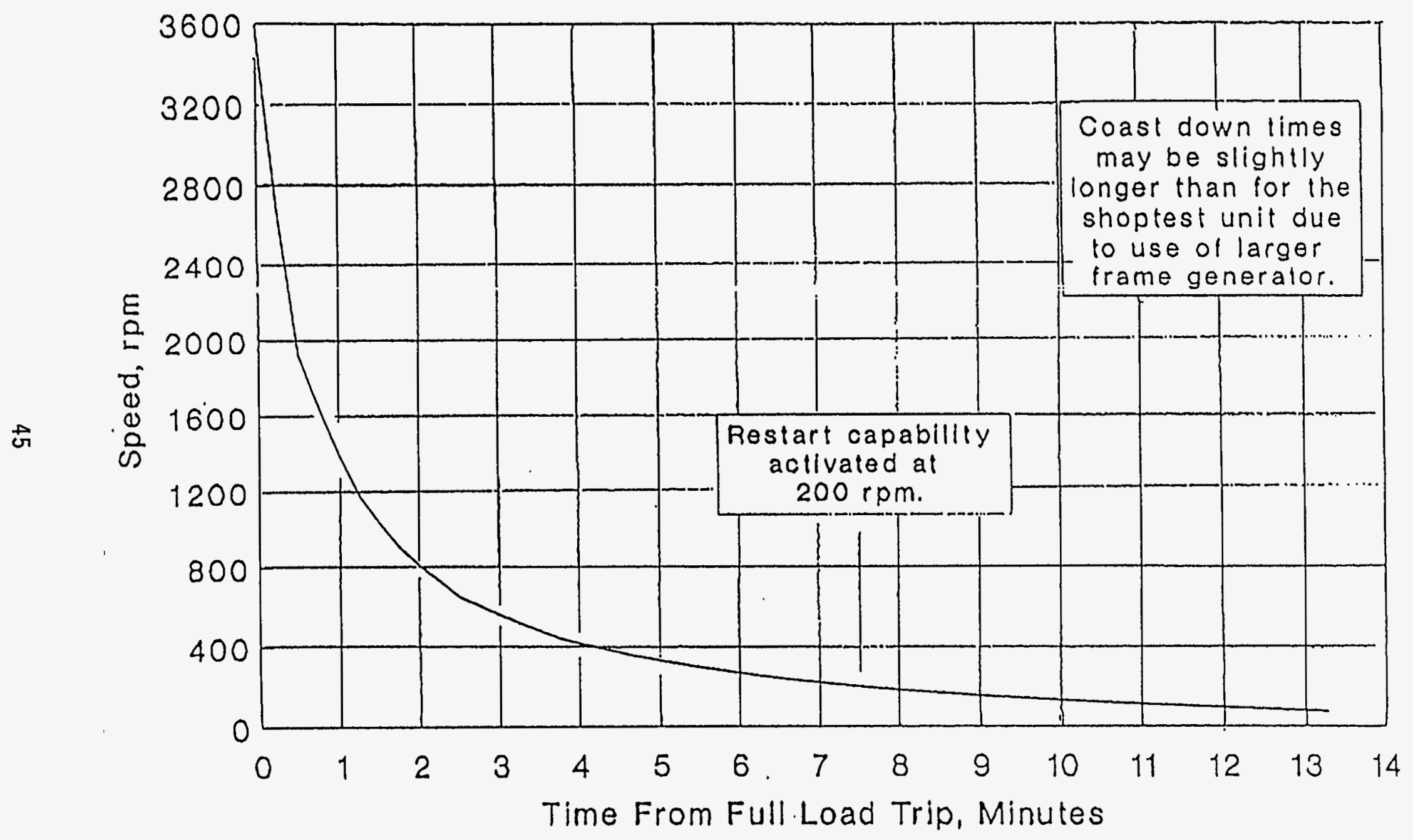

Figure 5.4 Coastdown Time vs. Speed, from 501F Shop Test Results 
Ref.: DE-AC21-86MC21023

Date: August 1994

The most frequent causes for gas turbine trips are:

- Changing load demand or requirements

- Routine maintenance

- Loss of external load (e.g., a generator breaker opens because of some occurrence outside the plant).

In all these trips, the fuel is immediately cut off and the unit coasts down and eventually stops because of the braking action of the air compressor load. This coast-down typically takes about 20 minutes with a 501F machine.

As discussed in the previous section, the CPFBC-to-gas turbine vessels and piping contain high-pressure/high-temperature vitiated air which, if not shut off by Valve $C$, will tend to extend this coast-down period. Assuming 5 minutes to shut off this flow by slowly closing the PFBC system air inlet valve, we anticipate a 25-minute coast-down period for a second-generation PFB 501F gas turbine installation. This coast-down period presently appears acceptable for all of the listed gas turbine trip events. Consequently, from a gas turbine control and protection standpoint, there presently does not appear to be a need for a high-temperature shutoff valve (Valve C) in the vitiated air line leading to the gas turbine. 
SECTION 6

REFERENCES 
Ref.: DE-AC21-86MC21023

Date: August 1994

\section{Section 6}

\section{REFERENCES}

1. A. Robertson, et al., "Second-Generation Pressurized Fluidized Bed Combustion Plant, Conceptual Design and Optimization of a SecondGeneration PFB Combustion Plant, Phase 1, Task 1", DOE Report DOE/MC/ 21023-2825, Vol. 1, September 1989.

2. D. P. Campbe11, Process Dynamics, John Wiley \& Sons, Inc., New York, 1958.

3. 9

W. H. Press, et a1., Numerical Recipes, Cambridge University Press, New York, 1986.

4. 0 . Bertsch, Westinghouse-PGBU, Personal communication to Brigitte Bouvier at Westinghouse-STC. 


\section{APPENDIX A}

\section{DESCRIPTION OF TRANSIENT FLOW CODE}


Ref.: DE-AC21-86MC21023

Date: March 1994

\section{Appendix A}

\section{DESCRIPTION OF TRANSIENT FLOW CODE}

The dynamic simulation implementations are derived from the three basic macroscopic conservation laws-mass, energy, and momentum. They are most generally expressed as first-order partial differential equations, but for reasons beyond the present scope, it is not desirable to apply them directly. By spatially quantizing the representation of the system into discrete control volumes and integrating the partial differential equations over each volume, ordinary differential equations are derived. These can then be solved using well-known techniques such as Runge-Kutta, predictor-corrector, and Bulirsh-Stoer [A1].

\section{A.1 DEFINITION OF CONTROL VOLUMES}

The systems modeled in the simulations are pipelines; therefore, the basic control volumes are those of pipe sections. The other components of the piping system, such as junctions or tees, valves, etc., are modeled by making appropriate modifications to the basic control volume features. The overall model of a pipeline is constructed by dividing it into sections, as shown in Figure A.1. Within each section, the pressure, temperature, enthalpy and density are assumed to be uniformly distributed at each instant of time. Consequently, each section defines a fluid energy storage "node" in the simulations.

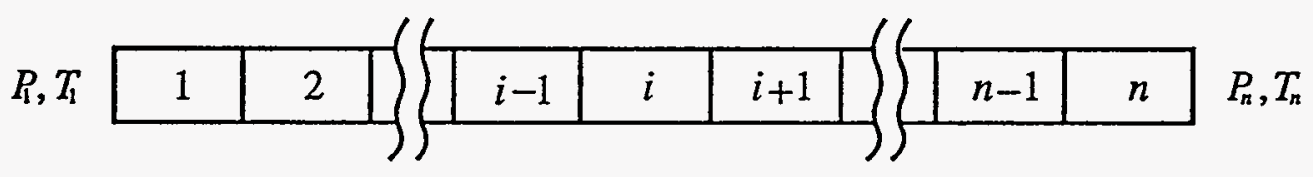

Figure A.1 Pipeline System Quantization

The entering and exiting flows of fluid are associated with each node. To describe these flows, it is convenient to functionally expand the pipe lengths between the nodes of Figure A.1 into flow sections, as shown schematically in Figure A.2. 
Ref.: DE-AC21-86MC21023

Date: March 1994

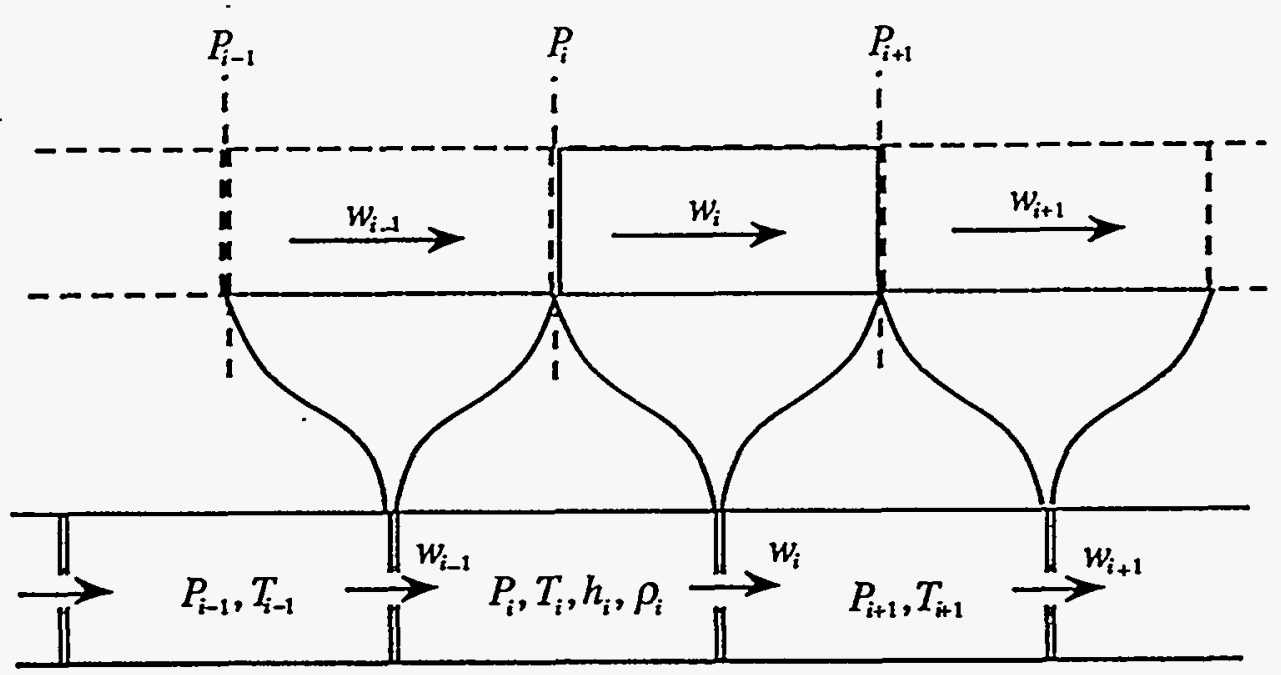

Figure A.2 Energy Nodes and Flow Sections

Alternatively, the flow system can be thought of as having overlapping regions of two types. One type has the properties of energy capacity or storage, as just mentioned and as depicted in Figure A.3. The other type functions primarily as a region where fluid is transported from one node to the next under the influence of the pressure differential, as shown in Figure A.4. Although energy storage is not associated with the flow sections, transient momentum storage is modeled within them exclusively. The describing equations for the energy nodes satisfy the conservation of energy, while the equations for the flow sections express the momentum balance. Conservation of mass or fluid continuity is satisfied in both regions.

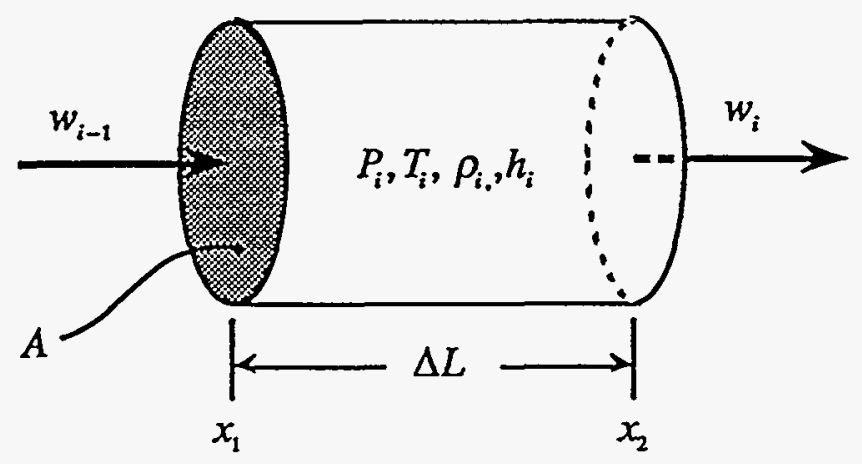

Figure A.3 Energy Node Schematic 
Ref.: DE-AC21-86MC21023

Date: March 1994

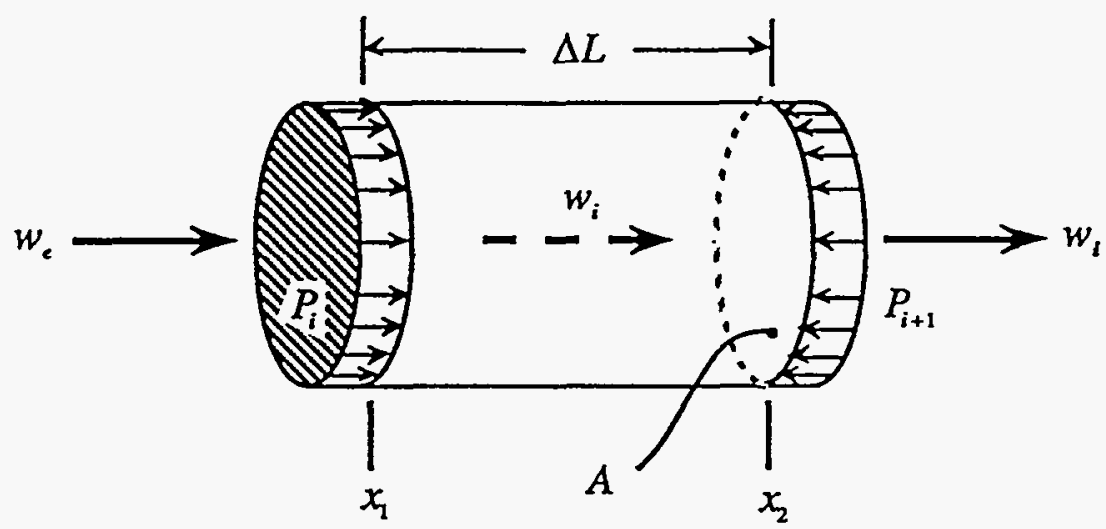

Figure A.4 Flow Section Schematic

\section{A.2 CONSERVATION OF MASS}

Defining positive flow as going from left to right, as shown in Figure A.2, the entering and leaving mass flow rates for the $i$ th node are $w_{i-1}$ and $w_{i}$ respectively, as shown in Figure A.3. Similarly, the entering and leaving mass flow rates for a flow section are respectively designated as $w_{e}$ and $w_{1}$ in Figure A.4. If the mass flow rate $(W)$ is assumed to be uniformly distributed over the cross-sectional area $(A)$ in the figures, then the rate of change of mass within the control volume will be the difference between the entering and leaving mass flow rates. That is,

$$
\frac{d m}{d t}=w_{e}-w_{l}
$$

Assuming that the density within the control volume is uniformly distributed at each instant of time and that the cross-sectional area $(A)$ is constant with respect to $x$ as $x$ varies over the length $(\Delta L)$ Eq. A-1 is equivalently,

$$
(\Delta V) \frac{d \rho}{d t}=w_{e}-w_{l}, \quad(\Delta V)=(\Delta L) A
$$


Ref.: DE-AC21-86MC21023

Date: March 1994

Eq. A-2 is the form of the conservation of mass used in the simulations. Although not explicitly solved, it is implicit in the derivations of the other equations.

The conservation of mass expressed in Eq. A-2 can be reduced to the continuity equation if the following additional assumptions are made:

- The flow is one-dimensional and the velocity $(u)$ is assumed to be uniform over the volume cross-section, i.e.:

$$
\begin{aligned}
\mathbf{a}(x, y, z, t) & =u(x, y, z, t) \mathbf{i}+v(x, y, z, t) \mathbf{j}+w(x, y, z, t) \mathbf{k} \\
& =u(x, t) \mathbf{i}
\end{aligned}
$$

- The density is only a function of $x$ and time, i.e.:

$$
\rho(x, y, z, t)=\rho(x, t),
$$

- The density within the control volume is distinguishable from the entering and leaving densities.

Therefore, with these assumptions, Eq. A-2 becomes:

$$
(\Delta L) A \frac{d \rho}{d t}=A\left(\rho_{e} u_{e}-\rho_{l} u_{l}\right) \text {. }
$$

Dividing by $(\triangle L) A$ yields

$$
\frac{d \rho}{d t}=\frac{\rho_{e} u_{e}-\rho_{l} u_{i}}{\Delta L} \quad,
$$

In the limit as $(\Delta L)$ approaches zero, Eq. A-5 becomes the following:

or

$$
\begin{gathered}
\frac{\partial \rho}{\partial t}=\lim _{\Delta L \rightarrow 0} \frac{\rho_{e} u_{e}-\rho_{l} u_{t}}{\Delta L}=-\frac{\partial}{\partial x}(\rho u), \\
\frac{\partial \rho}{\partial t}+u \frac{\partial \rho}{\partial x}+\rho \frac{\partial u}{\partial x}=0,
\end{gathered},
$$


Ref.: DE-AC21-86MC21023

Date: March 1994

\section{A.3 MOMENTUM BALANCE EQUATIONS}

The momentum balance equations will be derived to further illustrate the use of control volume techniques and to identify the additional assumptions necessary to define the equations used in the simulations.

The linear momentum of a differential element of fluid is given as the product of its density $(\rho)$ and velocity vector $(u)$ so that the momentum of fluid within a control volume can be obtained by integrating this element of momentum over the volume as in Eq. A-7. The total or substantial derivative of

$$
\mathbf{M}=\int_{V_{c}} \rho u d v \text {, }
$$

$M$ with respect to time is equal to the sum of forces acting upon the control volume. This, of course, is the statement of the conservation of linear momentum.

\section{A.3.1 Rate of Change of Linear Momentum}

Taking into account constraints imposed by the conservation of mass [A2], differentiation of Eq. A-7 is given as follows:

$$
\frac{D \mathbf{M}}{D t}=\int_{V_{c}} \rho \frac{D \mathbf{u}}{D t} d v \text {, }
$$

Where, in Cartesian coordinates,

$$
\frac{D}{D t}=\frac{\partial}{\partial t}+u \frac{\partial}{\partial x}+v \frac{\partial}{\partial y}+w \frac{\partial}{\partial z},
$$

and

$$
\mathbf{u}=u \mathbf{i}+v \mathbf{j}+w \mathbf{k}
$$


Ref.: DE-AC21-86MC21023

With the assumptions of one-dimensional flow and those about density variations from Section A.2, Eq. A-8 reduces to the following integral in conformance with the control volume of Figure A.4.

$$
\frac{D M}{D t}=\mathrm{i}\left\{A \int_{x_{1}}^{x_{2}} \rho(x, t)\left[u(x, t) \frac{\partial u(x, t)}{\partial x}+\frac{\partial u(x, t)}{\partial t}\right] d x\right\},
$$

Dropping the notational use of the arguments, unless needed for clarity, and the directional vector notation, Eq. A-11 becomes

$$
\frac{D M}{D t}=A \int_{x_{1}}^{x_{2}}\left[\rho u \frac{\partial u}{\partial x}\right] d x+A \int_{x_{1}}^{x_{2}}\left[\rho \frac{\partial u}{\partial t}\right] d x
$$

The first integral in Eq. A-12 can be integrated by parts to obtain

$$
\begin{aligned}
\frac{D M}{D t}= & A\left(\rho u^{2}\right)_{x_{1}}^{x_{2}}-A \int_{x_{1}}^{x_{2}}\left[u \frac{\partial}{\partial x}(\rho u)\right] d x+A \int_{x_{1}}^{x_{2}}\left[\rho \frac{\partial u}{\partial t}\right] d x \\
= & A\left[\rho\left(x_{2}\right) u^{2}\left(x_{2}\right)-\rho\left(x_{1}\right) u^{2}\left(x_{1}\right)\right] \\
& +A \int_{x_{1}}^{x_{2}}\left[\rho \frac{\partial u}{\partial t}-u \frac{\partial}{\partial x}(\rho u)\right] d x
\end{aligned}
$$

From Eq. A-6, the argument of the integral in Eq. A-13 must be as follows:

$$
\rho \frac{\partial u}{\partial t}-u \frac{\partial}{\partial x}(\rho u)=\rho \frac{\partial u}{\partial t}+u \frac{\partial \rho}{\partial t}=\frac{\partial}{\partial t}(\rho u)
$$

And hence, under the further-assumption that the density and velocity are uniform within the control volume, Eq. A-13 reduces to

$$
\frac{D M}{D t}=A\left(x_{2}-x_{1}\right) \frac{d}{d t}(\rho u)+A\left[\rho\left(x_{2}\right) u^{2}\left(x_{2}\right)-\rho\left(x_{1}\right) u^{2}\left(x_{1}\right)\right]
$$


Ref.: DE-AC21-86MC21023

Date: March 1994

Recognizing that $x_{1}$ and $x_{2}$ correspond to the entrance to and the exit from the control volume respectively, in Figure A.4, the total time derivative of the momentum of the fluid within the control volume is

$$
\frac{D M_{i}}{D t}=(\Delta L) \frac{d w_{i}}{d t}+w_{l} u_{l}-w_{e} u_{e} \quad,
$$

where

$$
w_{i}=A \rho_{i} u_{i}
$$

and

$$
(\Delta L)=\left(x_{2}-x_{1}\right)
$$

\section{A.3.2 Forces Acting on Control Volume}

Two types of forces acting upon the control volume in Figure A.4 are modeled in the simulations. One type is the force $\left(F_{p}\right)$ exerted by the pressure differential, as depicted in the figure.

$$
F_{P}=g_{c} A\left(P_{i}-P_{i+1}\right),
$$

The other is the flow resistance or the frictional force $\left(F_{w}\right)$ exerted at the interface between the fluid and the pipe wall directed opposite to the flow direction

$$
F_{w}=-g_{c}(\Delta L) \mathrm{P}_{w} \tau_{w}
$$

where

$$
\begin{aligned}
& P_{w}=\text { "Wetted" perimeter of the control volume }=\pi \times \text { Diameter } \\
& T_{w}=\text { Wall surface frictional stress }
\end{aligned}
$$


Ref.: DE-AC21-86MC21023

Date: March 1994

The surface stress $\left(T_{w}\right)$ is usually taken to be proportional to the square of the velocity [A3] within the flow section

$$
\left|\tau_{w}\right|_{i}=f_{i} \rho_{i} \frac{\left|u_{i}\right|^{2}}{2 g_{c}}
$$

where

$$
f_{i}=\text { Dimensionless friction factor }
$$

Therefore, the flow resistance force is as follows where the direction of the force is explicitly constructed to be opposite to that of the velocity of the flow:

$$
\begin{aligned}
F_{w} & =-(\Delta L) \mathbf{P}_{w} f_{i} \rho_{i} \frac{u_{i} \mid}{2} u_{i} \\
& =-\frac{(\Delta L) \mathbf{P}_{w} f_{i}}{2 A}\left|w_{i}\right| u_{i} \\
& =-\frac{(\Delta L) f_{i}}{2 r_{h}}\left|w_{i}\right| u_{i}
\end{aligned}
$$

where

$$
\begin{aligned}
w_{i} & =\rho_{i} A u_{i} \\
r_{h} & \equiv \text { Hydraulic radius } \\
& =A / P_{w}=\text { Diameter } / 4
\end{aligned}
$$

\section{A.3.3 Momentum Storage and Bidirectional Flow}

Combining Eq. A-20 with Eqs. A-16 and A-17 provides the momentum balance equation

$$
\frac{D M_{i}}{D t}=F_{p}+F_{w}
$$

or

$$
(\Delta L) \frac{d w_{i}}{d t}+w_{l} u_{l}-w_{e} u_{e}=g_{c} A\left(P_{i}-P_{i+1}\right)-\frac{(\Delta L) f_{i}}{2 r_{h}}\left|w_{i}\right| u_{i},
$$


Ref.: DE-AC21-86MC21023

Date: March 1994

The righthand side of the equation is the sum of forces acting on the control volume. The first term on the left of the equal sign is the rate of change of momentum stored in the control volume, and the next two terms on the left account for the difference between the leaving and entering momentum fluxes.

Referring to Figure A.2, the momentum flux entering the $i^{\text {th }}$ flow section is conceptually that of the upstream flow $\left(w_{i-1}\right)$, while the leaving flux can be identified with the downstream flow $\left(w_{i+1}\right)$. Eq. A-21 can then be interpreted to be

$$
(\Delta L) \frac{d w_{i}}{d t}=w_{i-1} u_{i-1}-w_{i+1} u_{i+1}+F_{p}+F_{w},
$$

However, it is equally plausible to state that the flow within the control volume $\left(w_{i}\right\rangle$ is synonymous with the output flow $\left(w_{1}\right)$ so that Eq. A-21 would then be implemented as follows:

$$
(\Delta L) \frac{d w_{i}}{d t}=w_{e} u_{e}-w_{i} u_{i}+g_{c} A\left(P_{i}-P_{i+1}\right)-\frac{(\Delta L) f_{i}}{2 r_{h}}\left|w_{i}\right| u_{i}
$$

Eq. A-23 represents a "stirred tank" approximation in which momentum storage "at the exit" of the control volume is assumed.

Either approach can be implemented as can other, more complex, higher-order extrapolation schemes. The second approach of the two outlined will lead to a more compact set, since the control volume momentum is influenced by only one neighboring flow stream. The main concern, however, comes with adequately describing situations in which reversed flow occurs so that, in Figure A.2, the flows may be bidirectional instead of all of them being in one direction as shown. With the assumptions leading to Eq. A-22, it is relatively easy to identify the entering and leaving flow streams-regardless of their direction. The signs of the momentum flux terms on the righthand side of Eq. A-22, however, remain as shown because of the vector nature of momentum flux.

In the approach of Eq. A-23, the identification of the entering momentum flux is not so straightforward. Since $w_{i}$ is always an output or leaving stream, the flux associated with $w_{i-1}$ will be the entering flux when $w_{i}$ is positive - that is, to the right 
Ref.: DE-AC21-86MC21023

Date: March 1994

in Figure A.2. When $w_{i}$ is negative, the flux $\left(w_{i+1} u_{i+1}\right)$ will be the entering momentum flux. The algorithm for implementing Eq. A-23 is then as follows:

$$
(\Delta L) \frac{d w_{i}}{d t}=\left\{\begin{array}{rr}
w_{i-1} u_{i-1}, & w_{i} \geq 0 \\
-w_{i+1} u_{i+1}, & w_{i}<0
\end{array}\right\}-\left[1+\frac{(\Delta L) f_{i}}{2 r_{h}}\right]\left|w_{i}\right| u_{i}+g_{c} A\left(P_{i}-P_{i+1}\right)
$$

The signs of the terms in braces are as shown, again because momentum flux is a vector quantity. Even though a flow stream can have two possible directions with the one-dimensional flow assumptions made, consider the flux term $\left(w_{i-1} u_{i-1}\right)$. When $u_{i-1}$ is positive, and hence so is $w_{i-1}$, the flux $\left(w_{i-1} u_{i-1}\right)$ is "into" the control volume and contributes to an increase in the positive momentum (i.e., momentum in the positive direction) stored within the control volume. However, when $u_{i-1}$ is negative, the flow is out of the control volume and hence decreases the momentum stored within the control volume-but now the reduction is in momentum in the negative direction. Therefore, storage of positive momentum in is augmented by the flux of negative momentum out of the control volume. Hence the sign of the flux term must remain positive. A mathematically rigorous description of momentum flux for flow directions in general is presented in Milne-Thomson [A2].

\section{A.3.4 Steady Flow}

Returning to Eq. A-21, it is necessary to outline a means of "calibrating" the flow equations relative to the real flow system being modeled. Since plant data are usually taken from steady-state heat and material balance data, Eq. A-21 must be put into a form to use these data in determining unknown system constants. Generally, however, most of the constants can be determined from the geometry of the system except for the friction factor $\left(f_{i}\right)$ in the case of Eq. A-21.

In the steady state, the time derivative on the left-hand side of A-21 is zero, so that all of the mass flow rates will be equal as follows:

$$
\cdots=w_{i-1}=w_{i}=w_{i+1}=\cdots=w,
$$

Therefore, Eq. A-21 will become:

$$
\frac{w^{2}}{A}\left(\frac{1}{\rho_{l}}-\frac{1}{\rho_{c}}\right)=g_{c} A\left[P_{i}-P_{i+1}-C_{f_{i}} \frac{w^{2}}{\rho_{i}}\right],
$$


Ref.: DE-AC21-86MC21023

Date: March 1994

where

$$
\begin{aligned}
& u=w / \rho A(\text { in Eq. A-21) } \\
& C_{f i}=(\Delta L)_{f i} / 2 g_{c} J_{h} A^{2} \equiv i \text { th flow coefficient }
\end{aligned}
$$

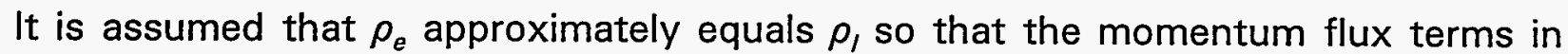
Eqs. A-21 and A-26 become zero, that is,

$$
w_{l} u_{l}-w_{e} u_{e}=\frac{w^{2}}{A}\left(\frac{1}{\rho_{l}}-\frac{1}{\rho_{e}}\right) \cong 0
$$

Then Eq. A-26 can be rewritten as follows:

$$
P_{i}-P_{i+1}=C_{f_{1}} \frac{w^{2}}{\rho_{i}},
$$

Determining $C_{f i}$ is therefore equivalent to determining the friction factor $\left(f_{j}\right)$ in Eq. A-21. Referring to Figure A.2, the density $\left(\rho_{i}\right)$ in a flow section is assumed to be the average of the constant densities in adjacent nodes so that Eq. A-29 can be rewritten as

$$
P_{i}-P_{i+1}=2 C_{f_{t}} \frac{w^{2}}{\rho_{i}+\rho_{i+1}}
$$

or by using the ideal gas relationship, $p=\rho R T$, as

$$
P_{i}-P_{i+1}=2 R C_{f_{i}} \frac{w^{2}}{\frac{P_{i}}{T_{i}}+\frac{P_{i+1}}{T_{i+1}}}
$$

If the flow is assumed to be isothermal so that $T_{i}=T_{i+1}=T$, Eq. A-30b becomes

$$
P_{i}^{2}-P_{i+1}^{2}=2 R T C_{f_{i}} w^{2}
$$


Ref.: DE-AC21-86MC21023

Date: March 1994

Summing the terms on each side of Eq. A-31 yields

$$
\sum_{i=1}^{N-1}\left(P_{i}^{2}-P_{i+1}^{2}\right)=P_{0}^{2}-P_{N}^{2}=2 R T w^{2} \sum_{i=1}^{N-1} C_{f_{i}} \quad,
$$

If, further, the flow coefficients are assumed equal for all flow sections, then $C_{f}$ can be found as follows:

$$
C_{f_{t}}=C_{f}=\frac{P_{0}^{2}-P_{N}^{2}}{2 N R T w^{2}}
$$

Typical steady-state data provide the pressures at each end of the pipe $\left(P_{0}\right.$ and $\left.P_{N}\right)$, the mass flow rate in the pipe plus temperatures at both ends. In general, even with steady flow, adiabatic pipe flow with friction does not have such a simple solution as in Eq. A-32. However, in many cases, if the temperature ( 7 ) in Eq. A-33 is taken to be the average of the temperatures at both ends of the pipe, Eq. A-33 will be accurate enough.

With the ability to calibrate the momentum of Eq. A-21 under the assumption of Eq. A-28, the individual pressures must be adjusted according to Eq. A-34 in the simulations so that, in the steady state, real flow data are matched by satisfying Eq. A-31. This will assure that the time derivative is

$$
\begin{aligned}
P_{i+1} & =\sqrt{P_{i}^{2}-2 R T_{A v g} C_{f} w^{2}} \\
& =\sqrt{P_{i}^{2}-\frac{1}{N}\left(P_{0}^{2}-P_{N}^{2}\right)}, \quad i=1,2, \cdots, N-1, \quad P_{1}=P_{0},
\end{aligned},
$$

zero in the following equation, which is just Eq. A-21 rewritten to include the assumption of Eq. A-28.

$$
\frac{d w_{i}}{d t}=\frac{g_{c} A}{(\Delta L)}\left[P_{i}-P_{i+1}-C_{f} \frac{\left|w_{i}\right|}{\rho_{i_{A r g}}} w_{i}\right],
$$


Ref.: DE-AC21-86MC21023

Date: March 1994

\section{A.3.5 Quasi-Linear Flow Equations}

If the volumetric flow rate $(Q)$ is introduced where $w=\rho Q$, Eq. A-35 becomes

$$
\frac{d}{d t}\left(\rho_{i} Q_{i}\right)=\frac{g_{c} A}{(\Delta L)}\left[P_{i}-P_{i+1}-C_{f} \rho_{i}\left|Q_{i}\right| Q_{i}\right]
$$

If the rate of change of density within a flow section is assumed as approximately zero,

$$
\frac{d Q_{i}}{d t}=\frac{g_{c} A}{(\Delta L) \rho_{i}}\left[P_{i}-P_{i+1}-C_{f} \rho_{i}\left|Q_{i}\right| Q_{i}\right]
$$

This equation can be linearized for $Q_{i}$ in the vicinity of some nominal steady-state volumetric flow rate $\left(Q_{0}\right)$ as

$$
\frac{d Q_{i}}{d t}=\frac{1}{\mathfrak{M}}\left[P_{i}-P_{i+1}-\mathfrak{M} Q_{i}\right]
$$

where

$\mathfrak{M}=(\Delta L) \rho_{o} / g_{c} A \equiv$ Inertance of pipe section

and

$\Re=C_{f} \rho_{o}\left|Q_{o}\right| \equiv$ Flow resistance.

Note that the formulation of Eq. A-38 assumes that $Q$ is a constant in all pipe sections in the steady state or, equivalently, that the fluid is approximately incompressible. This can be a valid assumption for flows with small pressure differences and high flow rates. Eq. A-38 is the equation discussed in Section 4 and is described in Campbell [A4]. It is also the equation for the electrical current between voltage nodes in a lumped-parameter approximation to a transmission line if the pressures in Eq. A-38 are replaced by node voltages, $\Re$ is replaced by the $D-C$ resistance between nodes, and if the line inductance between the voltage nodes is substituted for $\mathrm{Mn}$. 
Ref.: DE-AC21-86MC21023

Date: March 1994

In the simulations, both Eqs. A-37 and A-38 were used. Eq. A-38 was used when approximate incompressibility was a reasonable assumption, as was the case in the simulation described in Section 4.1. Eq. A-37 was used when large pressure differentials were possible, such as in the case described in Section 4.2. In these cases, both equations make solutions possible when flows are bidirectional.

\section{A.4 ENERGY EQUATIONS}

In a manner similar to the development of momentum balance equation (Eq. A-21), the energy balance for an energy storage node can be derived. For the constant control volume of the $i^{\text {th }}$ node, the rate of change of stored energy, neglecting geopotential energy, is described as follows:

$$
(\Delta V) \frac{d}{d t}\left(\rho_{i} e_{i}\right)=w_{e} h_{e}-w_{l} h_{l}+\dot{q}-\dot{W}_{m} \text {, }
$$

where

$$
\begin{array}{ll}
(\Delta h) & \equiv \text { Control volume of the } i^{\text {th }} \text { node } \\
\rho_{i} & =\text { Fluid density within }(\Delta V) \\
e_{i} & =\text { Specific internal energy in }(\Delta V) \\
h_{e^{r}} h_{l} & =\text { Enthalpies entering and leaving }(\Delta V) \\
w_{e^{r}} W_{l} & =\text { Mass flow rates entering and leaving }(\Delta V) \\
\dot{W}_{m} & =\text { Mechanical rate of work done by control volume } \\
\dot{q} & =\text { Rate of heat transferred to }(\Delta V)
\end{array}
$$

The enthalpies in Eq. A-39 are stagnation enthalpies, since the assumption is that either the kinetic energy of the corresponding stream is included in them or the fluid velocity is negligible within an energy storage node-as in a reservoir, for example. Eq. A-39 states that the rate of change of stored energy is equal to the difference between the rates of in-flowing and out-flowing energy resulting from mass transfer, plus the net rate of heat transferred into the control volume, minus the rate of any mechanical work performed by the control volume. In the following derivations, however, the flow system components are assumed to be thermally insulated, so that $\dot{q}$ in Eq. A-39 is zero. Further, there are no means provided for the control volume elements to perform mechanical work; hence, $\dot{W}_{m}$ is zero also. 
Ref.: DE-AC21-86MC21023

By substituting the relationship $e=h-P /(J \rho)$ into the left-hand side of Eq. A-39 and using the approximation $h=c_{p} T$, the time derivative of the stored energy can be expanded as follows:

$$
(\Delta V) \frac{d}{d t}\left(\rho_{i} e_{i}\right)=(\Delta V) \frac{d}{d t}\left(\rho_{i} h_{i}-\frac{P_{i}}{J}\right)=(\Delta V) \frac{d}{d t}\left(c_{p} \rho_{i} T_{i}-\frac{P_{i}}{J}\right),
$$

With $\rho T=P / R$ and then with $R=J\left(c_{\rho}-c_{v}\right)$, the rate of change of energy stored in the node can be reduced to time derivative of pressure only.

$$
(\Delta V) \frac{d}{d t}\left(\rho_{i} e_{i}\right)=(\Delta V)\left[\frac{c_{p}}{R}-\frac{1}{J}\right] \frac{d P_{i}}{d t}=\frac{(\Delta V)}{J(\gamma-1)} \frac{d P_{i}}{d t} \quad,
$$

where

$$
\begin{aligned}
& P_{i}=\text { Fluid pressure in } i^{\text {th }} \text { node } \\
& T_{i}=\text { Temperature of fluid in } i^{\text {th }} \text { node } \\
& c_{p}=\text { Constant pressure specific heat } \\
& c_{v}=\text { Constant volume specific heat } \\
& T \quad=c_{p} / c_{v} \\
& J \quad=\text { Energy conversion factor }=778(\mathrm{ft} \cdot \mathrm{bf} / \mathrm{Btu})
\end{aligned}
$$

After substituting the results of Eq. A-41, Eq. A-39 then reduces to the following under the assumptions that $\dot{q}$ and $\dot{W}_{m}$ are zero:

$$
\frac{(\Delta V)}{J(\gamma-1)} \frac{d P_{i}}{d t}=w_{e} h_{e}-w_{l} h_{l}
$$

Eq. A-42 was derived with no regard for how the fluid density varies within the control volume. For the density to vary in a manner that satisfies the conservation of mass, either Eq. A-2 must be solved explicitly or another is needed which accounts for the rate of change of density accordingly. Since, in addition to the pressure from Eq. A-42, the fluid temperature must usually be known, another energy can be derived from Eq. A-39 which describes the rate of change of temperature and simultaneously correctly accounts for density variations. 
Ref.: DE-AC21-86MC21023

Date: March 1994

Specifically, the differentiation in the last equality of Eq. A-40 can be performed, term by term, so that

$$
\begin{aligned}
(\Delta V) \frac{d}{d t}\left(\rho_{i} e_{i}\right) & =(\Delta V) c_{p} \rho_{i}\left[\frac{d T_{i}}{d t}-\frac{1}{J c_{p} \rho_{i}} \frac{d P_{i}}{d t}\right]+(\Delta V) c_{p} T_{i} \frac{d \rho_{i}}{d t} \\
& =(\Delta V) c_{p} \rho_{i}\left[\frac{d T_{i}}{d t}-\frac{\gamma-1}{\gamma} \frac{T_{i}}{P_{i}} \frac{d P_{i}}{d t}\right]+(\Delta V) c_{p} T_{i} \frac{d \rho_{i}}{d t}
\end{aligned}
$$

Substituting the results in Eq. A-43 into Eq. A-39 with $\dot{q}$ and $\dot{W}_{m}$ equal to zero as before and rearranging terms yields:

$$
\frac{d T_{i}}{d t}-\frac{\gamma-1}{\gamma} \frac{T_{i}}{P_{i}} \frac{d P_{i}}{d t}=\frac{w_{e} h_{e}-w_{t} h_{t}-(\Delta V) c_{p} T_{i} \frac{d \rho_{i}}{d t}}{(\Delta V) c_{p} \rho_{i}}
$$

or

$$
\frac{d T_{i}}{d t}-\frac{\gamma-1}{\gamma} \frac{T_{i}}{P_{i}} \frac{d P_{i}}{d t}=\frac{c_{p}\left(w_{e} T_{e}-w_{l} T_{l}\right)-c_{p} T_{i}\left(w_{e}-w_{l}\right)}{(\Delta V) c_{p} \rho_{i}}
$$

where Eq. A-2 has been used to provide the necessary functional relationship for the rate of change of density.

The term on the right of the equal sign in Eq. A-44 is the contribution made to the rate of change of temperature as a result of mass transfer to and from neighboring nodes. Note that if this term were zero, Eq. A-44 would describe the isentropic expansion or compression of an ideal gas as just:

$$
\frac{d T}{d t}-\frac{\gamma-1}{\gamma} \frac{T}{P} \frac{d P}{d t}=0
$$


Ref.: DE-AC21-86MC21023

Date: March 1994

or

$$
\frac{d}{d t}(\ln T)=\frac{\gamma-1}{\gamma} \frac{d}{d t}(\ln P)
$$

and hence

$$
\left(\frac{T_{2}}{T_{1}}\right)=\left(\frac{P_{2}}{P_{1}}\right)^{\frac{\gamma-1}{\gamma}} \quad \text {, }
$$

Summarizing, and from Section A.3.3, the basic conservation laws will be satisfied if the following three equations or their equivalents are solved simultaneously: the pressure equation (Eq. A-42), the temperature equation (Eq. A-44), and from Section A.3.3, the momentum balance (Eq. A-21).

\section{A.4.1 Bidirectional Flow}

As in Section A.3.3, the issue of bidirectional flow must be addressed to resolve the entering and leaving energy flow rates as a result of mass transfer or convection between nodes. Referring to Figure A.2, one way of interpreting the righthand side of Eq. A-42 is via the following algorithmic logic.

$$
\frac{(\Delta V)}{J(\gamma-1)} \frac{d P_{i}}{d t}=\left\{\begin{array}{ll}
w_{i-1} h_{i-1}, & w_{i-1} \geq 0 \\
w_{i-1} h_{i}, & w_{i-1}<0
\end{array}\right\}-\left\{\begin{array}{ll}
w_{i} h_{i}, & w_{i} \geq 0 \\
w_{i} h_{i+1}, & w_{i}<0
\end{array}\right\},
$$

where the signs of $w_{i}$ and $w_{i-1}$ account for whether each stream is an input or an output stream to the node. Note that there can be two output or two input streams as well as the usual case in which only one stream is an input stream while the other is an output stream. The logic of Eq. A-48 assumes that energy within the control volume is always an output energy carried by whichever stream would carry it out of the node to a neighboring node/nodes.

An alternative view can be based on the idea that the enthalpy associated with a flow stream is the average of the uniform enthalpies of the two nodes between which the stream flows, regardless of its direction. Then Eq. A-42 can be interpreted as the following simpler formulation in which the sign of each flow rate automatically determines whether the particular average enthalpy is an input or an output enthalpy. 
Ref.: DE-AC21-86MC21023

Date: March 1994

$$
\frac{(\Delta V)}{J(\gamma-1)} \frac{d P_{i}}{d t}=w_{i-1} \frac{h_{i-1}+h_{i}}{2}-w_{i} \frac{h_{i}+h_{i+1}}{2}
$$

The situation with Eq. A-44 is more complex than with Eq. A-42, but it can be interpreted by either of these lines of reasoning. The numerator on the righthand side of Eq. A-44 can be rewritten as the convective energy flow rate $\left(\dot{E}_{c}\right)$. Then, for the sake of clarity, with terms of the form of $c_{\rho} T$ being replaced by the corresponding enthalpies, $h=c_{p} T, \dot{E}_{c}$ becomes

$$
\dot{E}_{c}=w_{e} h_{e}-w_{l} h_{l}-h_{i}\left(w_{e}-w_{l}\right)
$$

Following the same approach leading to Eq. A-48 gives, for $\dot{E}_{c}$

$$
\begin{aligned}
\dot{E}_{c} & =\left\{\begin{array}{ll}
w_{i-1} h_{i-1}, & w_{i-1} \geq 0 \\
w_{i-1} h_{i}, & w_{i-1}<0
\end{array}\right\}-\left\{\begin{array}{ll}
w_{i} h_{i}, & w_{i} \geq 0 \\
w_{i} h_{i+1}, & w_{i}<0
\end{array}\right\}-h_{i}\left(w_{i-1}-w_{i}\right) \\
& =\left\{\begin{array}{cc}
\left(h_{i-1}-h_{i}\right) w_{i-1}, & w_{i-1} \geq 0 \\
0, & w_{i-1}<0
\end{array}\right\}-\left\{\begin{array}{cc}
0, & w_{i} \geq 0 \\
\left(h_{i+1}-h_{i}\right) w_{i}, & w_{i}<0
\end{array}\right\},
\end{aligned}
$$

Or, using the alternative enthalpy-averaging approach which led to Eq. A-49 results in $\dot{E}_{c}$ being given as

$$
\begin{aligned}
\dot{E}_{c} & =\frac{h_{i-1}+h_{i}}{2} w_{i-1}-\frac{h_{i}+h_{i+1}}{2} w_{i}-h_{i}\left(w_{i-1}-w_{i}\right) \\
& =\frac{h_{i-1}-h_{i}}{2} w_{i-1}-\frac{h_{i+1}-h_{i}}{2} w_{i}
\end{aligned}
$$

The choice of Eq. A-51 as the interpretation of Eq. A-50 corresponds to the assumption that the node specific energy $\left(h_{i}\right)$ is always the output energy. By way of illustration, the simplest formulation of Eq. A-51 results when both flow rates are positive, in which case Eq. A-44 becomes

$$
\frac{d T_{i}}{d t}=\frac{\gamma-1}{\gamma} \frac{T_{i}}{P_{i}} \frac{d P_{i}}{d t}+\frac{w_{i-1}\left(h_{i-1}-h_{i}\right)}{(\Delta V) c_{p} \rho_{i}}
$$


Ref.: DE-AC21-86MC21023

Date: March 1994

where $d P_{i} / d t$ in Eq. A-54 would be determined, also for the case where $w_{i-1} \geq 0$ and wi $\geq 0$, from Eq. A-48 as

$$
\frac{d P_{i}}{d t}=\frac{J(\gamma-1)}{(\Delta V)}\left(w_{i-1} h_{i-1}-w_{i} h_{i}\right)
$$

As another example of interpreting the convection term in Eq. A-44, consider the case where $w_{i-1}<0$ and $w_{i-1} \geq 0$ in Figure A.2. In this case, there is no input stream to the $i^{\text {th }}$ node and, if the logic of Eq. A-51 is used, $\dot{E}_{c}=0$, so that the righthand side of Eq. A-44 vanishes. With this interpretation, energies in adjacent nodes, do not influence the temperature in the node and the temperature follows the pressure as in adiabatic expansion or compression of an ideal gas given by Eq. A-47.

In contrast to the rationale of Equations $A-48$ and $A-51$, the alternative average-enthalpy approach from Eq. A-49 and Eq. A-52 yields simpler interpretations for which the pressure and temperature equations are given as follows. In both equations

$$
\frac{d P_{i}}{d t}=\frac{J(\gamma-1)}{(\Delta V)}\left[\frac{h_{i-1}+h_{i}}{2} w_{i-1}-\frac{h_{i}+h_{i+1}}{2} w_{i}\right]
$$

and

$$
\frac{d T_{i}}{d t}=\frac{\gamma-1}{\gamma} \frac{T_{i}}{P_{i}} \frac{d P_{i}}{d t}+\frac{h_{i-1}-h_{i}}{2(\Delta V) c_{p} \rho_{i}} w_{i-1}-\frac{h_{i+1}-h_{i}}{2(\Delta V) c_{p} \rho_{i}} w_{i}
$$

the signs of the flow rates specify the input and output flow streams. 
Ref.: DE-AC21-86MC21023

Date: March 1994

\section{A.4.2 Quasi-Linear Pressure Equations}

There are a number of ways to implement quasi-linear approximations to Eq. A-42. One way is the straightforward interpretation given in Eq. A-48, as follows, using the relationships,

$$
h=c_{p} T=\frac{c_{p}}{R} \frac{P}{\rho}=\frac{\gamma}{J(\gamma-1)} \frac{P}{\rho},
$$

so that

$$
\frac{d P_{i}}{d t}=\left\{\begin{array}{cc}
\frac{w_{i-1}}{C_{i-1}^{\dagger}}, & w_{i-1} \geq 0 \\
\frac{w_{i-1}}{C_{i}^{\dagger}}, & \dot{w}_{i-1}<0
\end{array}\right\}-\left\{\begin{array}{ll}
\frac{w_{i}}{C_{i}^{\dagger}}, & w_{i} \geq 0 \\
\frac{w_{i}}{C_{i+1}^{\dagger}}, & w_{i}<0
\end{array}\right\},
$$

where

$$
C_{i}^{\dagger}=\frac{(\Delta V) \rho_{i}}{\gamma P_{i}}
$$

$C_{i}^{\dagger}$ can be defined as the pressure capacity of the control "mass" $\left(\Delta V \rho_{i}\right.$. If it is assumed that $C_{i-1}^{+} \equiv C_{i}^{\dagger} \equiv C_{i+1}^{+}$or, if it is always true that both flows are only in one direction, then the obvious quasi-linear form results from Eq. A-59. Perhaps, the simplest form containing the mass flow rates, $w_{i}$ and $w_{i-1}$, is obtained from Eq. A-49, as follows, with $C_{i}^{\dagger}$ as defined in Eq. A-60:

$$
\frac{d P_{i}}{d t}=\frac{w_{i-1}}{C_{(i-1))_{e r}}^{\dagger}}-\frac{w_{i}}{C_{i_{e z}}^{\dagger}}
$$

where

$$
\frac{1}{C_{i m}^{\dagger}}=\frac{1}{2}\left[\frac{1}{C_{i}^{\dagger}}+\frac{1}{C_{i+1}^{\dagger}}\right] \text {, }
$$


Ref.: DE-AC21-86MC21023

Date: March 1994

It is also desirable to have equations in terms of the volummetric flow rate, $Q$, for which Eq. A-48 can be put in a form similar to that of Eq. A-59, but in terms of $Q$ instead of $w$ as in the following:

$$
\frac{d P_{i}}{d t}=\frac{\gamma}{(\Delta V)}\left\{\begin{array}{cc}
P_{i-1} Q_{i-1}, & Q_{i-1} \geq 0 \\
P_{i} Q_{i-1}, & Q_{i-1}<0
\end{array}\right\}-\frac{\gamma}{(\Delta V)}\left\{\begin{array}{cc}
P_{i} Q_{i}, & Q_{i} \geq 0 \\
P_{i+1} Q_{i}, & Q_{i}<0
\end{array}\right\}
$$

or

$$
\frac{d P_{i}}{d t}=\left\{\begin{array}{ll}
\frac{Q_{i-1}}{C_{i-1}^{*}}, & Q_{i-1} \geq 0 \\
\frac{Q_{i-1}}{C_{i}^{*}}, & Q_{i-1}<0
\end{array}\right\}-\left\{\begin{array}{ll}
\frac{Q_{i}}{C_{i}^{*}}, & Q_{i} \geq 0 \\
\frac{Q_{i}}{C_{i+1}^{*}}, & Q_{i}<0
\end{array}\right\},
$$

The adiabatic pressure capacity $[\mathrm{A} 4],\left(C_{i}^{*}\right)$ of the $i^{\text {th }}$ node control volume $(\Delta V$, is defined as

$$
C_{i}^{*}=\frac{(\Delta V)}{\gamma P_{i}}
$$

Eq. A-49, employing the average-enthalpy approach, when put into the form of Eq. A-61 in terms of $Q$, becomes

$$
\frac{d P_{i}}{d t}=\frac{Q_{i-1}}{C_{(i-1)_{e r}}^{*}}-\frac{Q_{i}}{C_{i_{\text {eq }}}^{*}}
$$

where

$$
\frac{1}{C_{j_{a z}}^{*}}=\frac{1}{2}\left(\frac{1}{C_{j}^{*}}+\frac{1}{C_{j+1}^{*}}\right)=\frac{\gamma\left(P_{j}+P_{j+1}\right)}{2(\Delta V)}
$$


Ref.: DE-AC21-86MC21023

Date: March 1994

A variety of further assumptions is possible, at this point, aimed at making the required logic simpler or to make the implementation easier, etc., while still accommodating bidirectional flow capability in the simulation. The following approach emphasizes the local properties of the node, namely its pressure capacity, instead of involving the properties of other nodes in its pressure as is the case in Eq. A-64. Eq. A-48 can, however, be put in the following form:

$$
\begin{aligned}
& \frac{d P_{i}}{d t}=\frac{Q_{i-1}-Q_{i}}{C_{i}^{*}}
\end{aligned}
$$

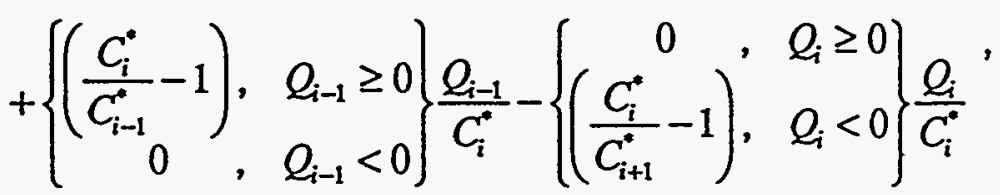

or, from Eq. A-65 and using the ideal gas relationship

$$
\begin{aligned}
& \frac{d P_{i}}{d t}=\frac{Q_{i-1}-Q_{i}}{C_{i}^{*}}
\end{aligned}
$$

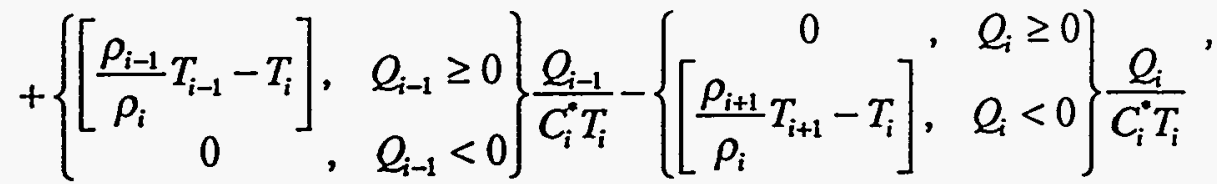

If it is assumed that $\rho_{i-1} \equiv \rho_{i} \equiv \rho_{i+1}$ in the last two terms, Eq. A-69 becomes

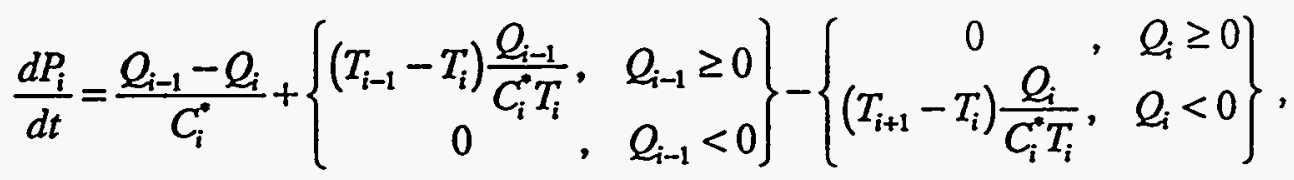

Further, for either direction of flow, assume that $Q_{i}$ and $Q_{i-1}$ are in the same direction at any instant of time. This is equivalent to saying there cannot be two simultaneous inputs with no outputs and vise versa. Finally, with respect to only the last two terms in Eq. A-70, if it is assumed that the magnitudes of $Q_{i}$ and $Q_{i-1}$ are approximately equal, Eq. A-70 reduces to the following:

$$
\frac{d P_{i}}{d t}=\frac{Q_{i-1}-Q_{i}}{C_{i}^{*}}+\frac{\left|Q_{i}\right|}{C_{i}^{*} T_{i}}\left(T_{\text {Input }}-T_{i}\right),
$$


Ref.: DE-AC21-86MC21023

Date: March 1994

where

$$
T_{\text {Input }}=\left\{\begin{array}{ll}
T_{i-1}, & Q_{i} \geq 0 \\
T_{i+1}, & Q_{i}<0
\end{array}\right\},
$$

Both Eqs. A-70 and A-71 were used in the simulations described in Section 4, depending on the validity of the above assumptions under the circumstances in the simulations.

\section{A.4.3 Quasi-Linear Temperature Equations}

The equations for the rate of change of temperature, from Eq. A-44, are of the following form in which the thermal capacity [A4] of the node $\left(C_{T}\right)$ is

$$
\frac{d T_{i}}{d t}=\frac{\gamma-1}{\gamma} \cdot \frac{T_{i}}{P_{i}} \cdot \frac{d P_{i}}{d t}+\frac{\dot{E}_{c}}{C_{T}}
$$

defined as

$$
C_{T}=(\Delta V) c_{p} \rho_{i}
$$

The convective energy flow rate, $\dot{E}_{6}$, in Eq. A-73 is the interpretation of Eq. A-50 given by either Eq. A-51 or by the average-enthalpy interpretation given in Eq. A-52.

Therefore, in terms of mass flow rates, Eq. A-73 becomes as follows upon substituting $\dot{E}_{c}$ from Eq. A-51 with enthalpies replaced by products of temperature and specific heat $\left(c_{p}\right)$.

$$
\frac{d T_{i}}{d t}=\frac{\gamma-1}{\gamma} \cdot \frac{T_{i}}{P_{i}} \cdot \frac{d P_{i}}{d t}+\frac{c_{p} w_{i-1}}{C_{T}}\left\{\begin{array}{cc}
\left(T_{i-1}-T_{i}\right), & w_{i-1} \geq 0 \\
0, & w_{i-1}<0
\end{array}\right\}-\frac{c_{p} w_{i}}{C_{T}}\left\{\begin{array}{cc}
0, & w_{i} \geq 0 \\
\left(T_{i+1}-T_{i}\right), & w_{i}<0
\end{array}\right\},
$$


Ref.: DE-AC21-86MC21023

Date: March 1994

And, for $\dot{E}_{c}$ from Eq. A-52, Eq. A-73 becomes

$$
\frac{d T_{i}}{d t}=\frac{\gamma-1}{\gamma} \cdot \frac{T_{i}}{P_{i}} \cdot \frac{d P_{i}}{d t}+\frac{c_{p} w_{i-1}}{2 C_{T}}\left(T_{i-1}-T_{i}\right)-\frac{c_{p} w_{i}}{2 C_{T}}\left(T_{i+1}-T_{i}\right)
$$

In Eqs. A-75 and A-76, the value of $d P_{i} / d t$ is determined from Eq. A-59 and from Eq. A-61 respectively.

Eqs. A-75 and A-76, in terms of the volumetric flow rate $(Q)$, are derived by making the appropriate substitutions for the mass flow tares of the form $w=\rho Q$. Then, for Eq. A-75, the following equation results.

$\frac{d T_{i}}{d t}=\frac{\gamma-1}{\gamma} \cdot \frac{T_{i}}{P_{i}} \cdot \frac{d P_{i}}{d t}+\frac{c_{p} \rho_{i-1} Q_{i-1}}{C_{T}}\left\{\begin{array}{cc}\left(T_{i-1}-T_{i}\right), & Q_{i-1} \geq 0 \\ 0, & Q_{i-1}<0\end{array}\right\}-\frac{c_{p} \rho_{i} Q_{i}}{C_{T}}\left\{\begin{array}{cc}0, & Q_{i} \geq 0 \\ \left(T_{i+1}-T_{i}\right), & Q_{i}<0\end{array}\right\},(\mathrm{A}-77 \mathrm{a})$

or

$$
\frac{d T_{i}}{d t} \cong \frac{\gamma-1}{\gamma} \cdot \frac{T_{i}}{P_{i}} \cdot \frac{d P_{i}}{d t}+\frac{Q_{i-1}}{(\Delta V)}\left\{\begin{array}{cc}
\left(T_{i-1}-T_{i}\right), & Q_{i-1} \geq 0 \\
0, & Q_{i-1}<0
\end{array}\right\}-\frac{Q_{i}}{(\Delta V)}\left\{\begin{array}{cc}
0, & Q_{i} \geq 0 \\
\left(T_{i+1}-T_{i}\right), & Q_{i}<0
\end{array}\right\}
$$

The assumptions yielding the approximate equality in Eq. A-77b are, in the second term,

$$
\frac{c_{p} \rho_{i-1}}{C_{T}}=\frac{c_{p} \rho_{i-1}}{(\Delta V) c_{p} \rho_{i}} \cong \frac{1}{(\Delta V)}
$$

and, in the third term, where

$$
\frac{c_{p} \rho_{i+1}}{C_{T}}=\frac{c_{p} \rho_{i+1}}{(\Delta V) c_{p} \rho_{i}} \cong \frac{1}{(\Delta V)}
$$


Ref.: DE-AC21-86MC21023

Date: March 1994

However, in Eq. A-76, the substitutions for the mass flow rates are, referring to Figure A.2:

$$
w_{i-1}=\rho_{(i-1)} Q_{i-1}=\frac{\rho_{i-1}+\rho_{i}}{2} Q_{i-1}
$$

and

$$
w_{i}=\rho_{\mathrm{icm}_{\mathrm{cm}}} Q_{i}=\frac{\rho_{i}+\rho_{i+1}}{2} Q_{i}
$$

so that Eq. A-76, in terms of volumetric flow rates, becomes

$$
\frac{d T_{i}}{d t}=\frac{\gamma-1}{\gamma} \cdot \frac{T_{i}}{P_{i}} \cdot \frac{d P_{i}}{d t}+\frac{c_{p}\left(\rho_{i-1}+\rho_{i}\right) Q_{i-1}}{2 C_{T}} \cdot \frac{T_{i-1}-T_{i}}{2}-\frac{c_{p}\left(\rho_{i}+\rho_{i+1}\right) Q_{i}}{2 C_{T}} \cdot \frac{T_{i+1}-T_{i}}{2},
$$

and

$$
\frac{d T_{i}}{d t} \cong \frac{\gamma-1}{\gamma} \cdot \frac{T_{i}}{P_{i}} \cdot \frac{d P_{i}}{d t}+\frac{Q_{i-1}}{2(\Delta V)}\left(T_{i-1}-T_{i}\right)-\frac{Q_{i}}{2(\Delta V)}\left(T_{i+1}-T_{i}\right)
$$

The approximations made to obtain the second form given in Eq. A-82b result from Eq. A-74 and with $\left(\rho_{i-1}+\rho_{i}\right) \equiv 2 \rho_{i} \equiv\left(\rho_{i}+\rho_{i+1}\right)$.

By making the same assumptions which led to Eq. A-71 for the rate of change of pressure, Eq. A-77a can, in the same way, be simplified to the following:

$$
\frac{d T_{i}}{d t}=\frac{\gamma-1}{\gamma} \cdot \frac{T_{i}}{P_{i}} \cdot \frac{d P_{i}}{d t}+\frac{c_{p} \rho_{i} Q_{i}}{C_{T}}\left\{\begin{array}{cc}
\left(T_{i-1}-T_{i}\right), & Q_{i} \geq 0 \\
-\left(T_{i+1}-T_{i}\right), & Q_{i}<0
\end{array}\right\}
$$

Both Eqs. A-77a and A-83 were used in the simulations described in Section 4. The choice between the equations was dependent upon the validity of assumptions as with the use of the pressure equations, Eqs. A-70 and A-71. In addition, note that the result of Eq. A-70 is intended to be substituted for the rate of change of pressure in Eq. A-77a and that the numerical result from Eq. A-71 is to be substituted into Eq. A-83. Similarly, Eq. A-66 is based on the same rationale upon which Eq. A-82a is based, so that $d P_{i} / d t$ from Eq. A-66 is to be substituted into Eq. A-82a. 
Ref.: DE-AC21-86MC21023

Date: March 1994

\section{A.5 FLOW SYSTEM COMPONENTS}

The flow system components are, for the purposes of this study, valves, junctions or tees, bends, and components in which the cross-sectional area changes along the direction of flow. Such components include reducers and expanders in which the area is a continuous function of linear distance as well as components with area discontinuities or abrupt changes in area as the flow travel through the component. As indicated in Section A.1, these components are modeled by making appropriate modifications to the basic features and properties of pipe sections. Since, up to this point, the only equations developed are for control volumes corresponding to finite lengths of pipe, the purpose of this section is to outline these modifications to the extent they are employed in the simulations described in Section 4.

\section{A.5.1 Valves}

A valve is modeled as an ordinary flow section between two energy nodes, as shown schematically in Figures A.2 and A.4. The flow through the section is described by Eq. A-35 or by the quasi-linear simplifications derived from Eq. A-37 in which the flow coefficient $\left(C_{f}\right)$ is purposely changed to vary the resistance to flow through the section. In this way, the opening and closing of the valve can be simulated wherein the flow coefficient is made time varying or a function of some other command signal such as, for example, the output of a simulated controller. Typically, when the simulated valve is "open", its flow resistance is made equal to that of the pipe sections connected to both ends. An increasingly larger value of $C_{f}$ or $\Re$ is used to simulate closing of the valve.

While this is the basic simulation procedure for a valve, it happens that the value of $C_{f}$ and therefore of $\Re$ for some pressure differentials $\left(P_{i}-P_{i+1}\right)$, can be sufficiently large so that the equations associated with this flow section and the adjacent nodes become "stiff". Under these conditions, the speed of the simulation becomes too slow for reasons which become clear after examination of the flow response of the section linearized about the current operating point given in Eq. A-38. From Eq. A-38, the time constant can be shown to be inversely proportional to the flow resistance $(\Re)$. Hence as $\Re$ increases, the time constant becomes extremely small or, in other words, flow rate changes will become extremely fast events. Therefore, for the simulation to accurately model such an event, the time-step size must be greatly reduced, typically, to about one-tenth of the time constant value. Since there is usually only one step size definition, the entire simulation suffers for the sake of accurately modeling this one flow section.

While allowing the time-step size to become extremely small can be a satisfactory procedure and, in some cases, multiple precision arithmetic may be required, another approach is possible. Since the event intended to be modeled is extremely fast, it will reach its steady-state value very quickly. Therefore, in Eq. A-35, for 
Ref.: DE-AC21-86MC21023

Date: March 1994

example, only the steady-state solution can be used, that is, when the time derivative is zero. The result is a variation of the Fanning Equation:

$$
\left|w_{i}\right|=C_{v} \sqrt{\rho_{i}\left|P_{i}-P_{i+1}\right|},
$$

in which the valve coefficient $\left(C_{v}\right)$ in this case is

$$
C_{v}=\frac{1}{\sqrt{C_{f}}}
$$

The same approach can be applied to Eq. A-37 and to the equation derived from it.

However, it may still happen that the valve model is problematic. Another approach could, therefore, be to specify the flow through the valve section as a timevarying boundary condition although some of the fidelity of the simulated dependencies will be lost. All three of the approaches outlined were used in the simulations described in Section 4.

\section{A.5.2 Junctions (or tees)}

Three-way junctions or tees in the simulations are modeled by modifying or extending the descriptions of an energy node as given in Section A.4. It turns out that all of the pressure and temperature equations can be modified by adding just one term necessary to append the vertical a-pipe section shown schematically in Figure A.5 to the basic horizontal pipe for which descriptions have already been given. For example, Eq. A-48 is rewritten below with the third term included to the right of the equal sign for the added flow with flow rate $\left(w_{a}\right)$. 
Ref.: DE-AC21-86MC21023

Date: March 1994

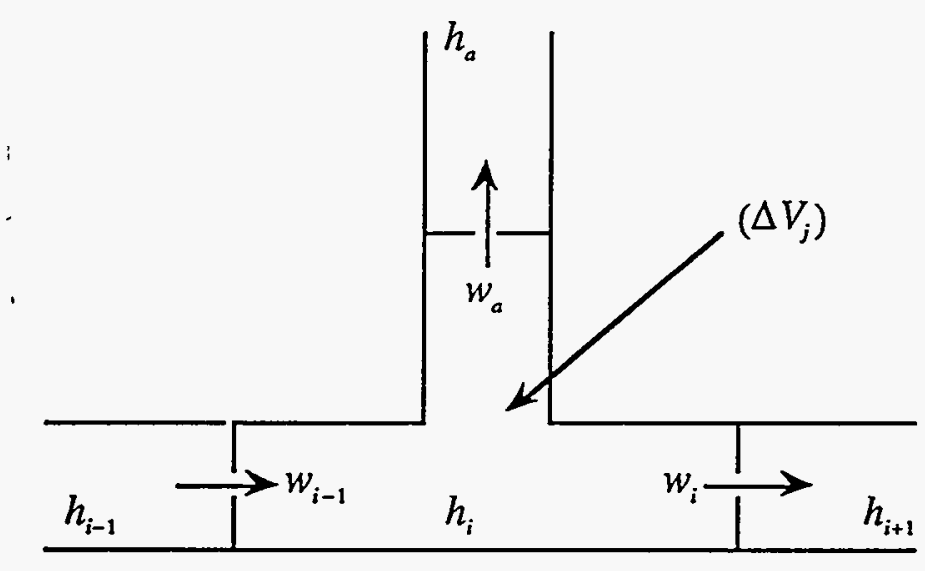

Figure A.5 Junction Schematic

Referring to the nomenclature of Figure A.5,

$$
\frac{\left(\Delta V_{j}\right)}{J(\gamma-1)} \frac{d P_{i}}{d t}=\left\{\begin{array}{ll}
w_{i-1} h_{i-1}, & w_{i-1} \geq 0 \\
w_{i-1} h_{i}, & w_{i-1}<0
\end{array}\right\}-\left\{\begin{array}{ll}
w_{i} h_{i}, & w_{i} \geq 0 \\
w_{i} h_{i+1}, & w_{i}<0
\end{array}\right\}-\left\{\begin{array}{ll}
w_{a} h_{i}, & w_{a} \geq 0 \\
w_{a} h_{a}, & w_{a}<0
\end{array}\right\},
$$

Similarly, Eq. A-44 rewritten with $\dot{E}_{c}$ given in Eq. A-51 becomes as follows with the added Third term:

$$
\begin{aligned}
\left(\Delta V_{j}\right) c_{p} \rho_{i}\left[\frac{d T_{i}}{d t}-\frac{\gamma-1}{\gamma} \frac{T_{i}}{P_{i}}\right]=\left\{\begin{array}{cc}
\left(h_{i-1}-h_{i}\right) w_{i-1}, & w_{i-1} \geq 0 \\
0 \quad, & w_{i-1}<0
\end{array}\right\} \\
-\left\{\begin{array}{cc}
0 \quad, & w_{i} \geq 0 \\
\left(h_{i+1}-h_{i}\right) w_{i}, & w_{i}<0
\end{array}\right\}-\left\{\begin{array}{cc}
0, & w_{a} \geq 0 \\
\left(h_{a}-h_{i}\right) w_{a}, & w_{a}<0
\end{array}\right\}
\end{aligned},
$$


Ref.: DE-AC21-86MC21023

Date: March 1994

Additionally, for the average-enthalpy interpretation of the convective energy flow terms, Eq. A-49 becomes

$$
\frac{\left(\Delta V_{j}\right)}{J(\gamma-1)} \frac{d P_{i}}{d t}=w_{i-1} \frac{h_{j-1}+h_{i}}{2}-w_{i} \frac{h_{i}+h_{i+1}}{2}-w_{a} \frac{h_{i}+h_{a}}{2}
$$

and with the additional term included in $\dot{E}_{c}$ in Eq. A-52, Eq. A-44 becomes, after being rewritten

$$
\left(\Delta V_{j}\right) c_{p} \rho_{i}\left[\frac{d T_{i}}{d t}-\frac{\gamma-1}{\gamma} \frac{T_{i}}{P_{i}}\right]=\frac{h_{i-1}-h_{i}}{2} w_{i-1}-\frac{h_{i+1}-h_{i}}{2} w_{i}-\frac{h_{a}-h_{i}}{2} w_{a}
$$

From this point, the remaining equations in Sections A.4.2 and A.4.3 naturally follow, and only the ones actually used in the simulations described in Section 4 will be enumerated. Eq. A-69 becomes

$$
\begin{aligned}
& \frac{d P_{i}}{d t}=\frac{Q_{i-1}-Q_{i}-Q_{a}}{C_{j}^{*}}+\frac{Q_{i-1}}{C_{j}^{*} T_{i}}\left\{\left(\begin{array}{cc}
\left.\frac{\rho_{i-1}}{\rho_{i}} T_{i-1}-T_{i}\right), & Q_{i-1} \geq 0 \\
0, & Q_{i-1}<0
\end{array}\right\}\right.
\end{aligned}
$$

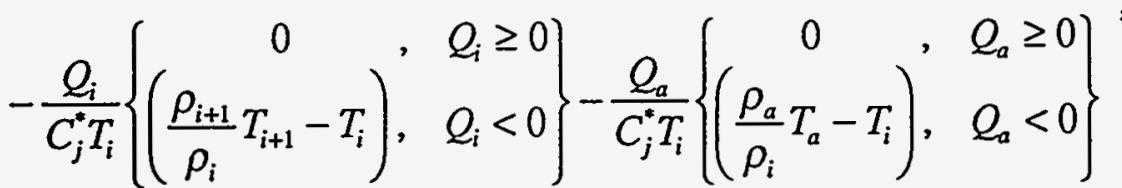

from which, with $\rho_{i-1} \equiv \rho_{i} \equiv \rho_{i+1} \equiv \rho_{a}$ Eq. A-92 replaces Eq. A-70 used in the simulations for a three-way junction with the pressure capacity of the junction given as

$$
C_{j}^{*}=\frac{\left(\Delta V_{j}\right)}{\gamma P_{i}}
$$


Ref.: DE-AC21-86MC21023

Date: March 1994

$$
\begin{aligned}
& \frac{d P_{i}}{d t}=\frac{Q_{i-1}-Q_{i}-Q_{a}}{C_{j}^{*}}+\left\{\begin{array}{cc}
\left(T_{i-1}-T_{i}\right) \frac{Q_{i-1}}{C_{j}^{*} T_{i}}, & Q_{i-1} \geq 0 \\
0, & Q_{i-1}<0
\end{array}\right\} \\
& -\left\{\begin{array}{cc}
0, & Q_{i} \geq 0 \\
\left(T_{i+1}-T_{i}\right) \frac{Q_{i}}{C_{j}^{*} T_{i}}, & Q_{i}<0
\end{array}\right\}-\left\{\begin{array}{cc}
0, & Q_{a} \geq 0 \\
\left(T_{a}-T_{i}\right) \frac{Q_{a}}{C_{j}^{*} T_{i}}, & Q_{a}<0
\end{array}\right\} \text {, }
\end{aligned}
$$

Finally, Eq. A-77a for the rate of change of temperature becomes as follows with the additional term included.

$$
\begin{aligned}
& \frac{d T_{i}}{d t}=\frac{\gamma-1}{\gamma} \cdot \frac{T_{i}}{P_{i}} \cdot \frac{d P_{i}}{d t}+\frac{c_{p} \rho_{i-1} Q_{i-1}}{C_{T_{j}}}\left\{\begin{array}{cc}
\left(T_{i-1}-T_{i}\right), & Q_{i-1} \geq 0 \\
0, & Q_{i-1}<0
\end{array}\right\} \\
& -\frac{c_{p} \rho_{i} Q_{i}}{C_{T_{j}}}\left\{\begin{array}{cc}
0, & Q_{i} \geq 0 \\
\left(T_{i+1}-T_{i}\right), & Q_{i}<0
\end{array}\right\}-\frac{c_{p} \rho_{a} Q_{a}}{C_{T_{j}}}\left\{\begin{array}{cc}
0, & Q_{a} \geq 0 \\
\left(T_{a}-T_{i}\right), & Q_{a}<0
\end{array}\right\},
\end{aligned}
$$

where the thermal capacity of the junction node is,

$$
C_{T_{j}}=\left(\Delta V_{j}\right) c_{p} \rho_{i},
$$

Eqs. A-92 and A-93 are the basic equations implemented in the simulations although minor simplifying variations of them can be satisfactory. For example, in near-isothermal flow, the convective energy flow terms in Eq. A-92 can be omitted as was the case with the bypass subsystem simulation described in Section 4.

\section{A.5.3 Bends (or Elbows)}

As with valves, bends or elbows are modeled as ordinary flow sections between adjacent energy nodes without bends. In other words, the flow resistances are, as always, modeled in flow sections and, additionally in this case, the resistances are by virtue of diverting the flow stream as well as the result of wall friction. The flow in bends is also described by Eq. A-35 or by Eqs. A-37 and A-38 as it was with valves but, unlike valves, the flow coefficient $\left(C_{f i}\right)$ or the flow resistance $(\Re)$ are ideally constants, but also include the additional flow resistance that results from changing the direction of flow. 
Ref.: DE-AC21-86MC21023

Date: March 1994

Flow resistance data for bends and elbows is usually given in terms of the dimensionless coefficient $(K)$, where $H_{1}$, below, is the head loss in feet.

$$
K=\frac{2 g H_{\ell}}{u^{2}}=\frac{2 g_{c} \Delta P}{\rho u^{2}},
$$

From Eq. A-29 with $w$ in terms of $u$ substituted from Eq. A-27a, the flow coefficient $\left(C_{f}\right)$, in Eq. A-96 is then

$$
C_{f}=\frac{K}{2 g_{c} A^{2}},
$$

Therefore, if $K$ is known, the model can be calibrated by obtaining $C_{f}$ from Eq. A-96.

Data for 90-deg bends [A5] show that $K$ is approximately constant with respect to changing Reynolds number and ranges from about 0.06 to 0.30 for "smooth" pipe and from 0.17 to approximately 0.52 for "rough" pipe bends. The coefficient is more nearly a constant for rough pipe than for smooth pipe with the major variation caused by different ratios of bend radius to pipe diameter. The highest values are for small radius bends where the ratio of radius to pipe diameter is unity.

These data are from one source, and it is easy to obtain other data providing disagreements - partly because of the subjectiveness of definitions using terms such as "rough." Nevertheless, the importance of data with which to "calibrate" the model is to be emphasized.

\section{A.5.4 Cross-Sectional Area Changes (Reducers, Expanders, etc.)}

Changes in the geometry of the flow system are mostly accommodated in the basic definitions of the control volumes shown in Figures $A .3$ and A.4. With the definition of $(\Delta V$ in Eqs. A-64 and A-75, for example, pressure and temperature changes respectively are correctly described as a function of the current pressure, temperature and flow. Addition ally, changes in flow are correctly represented in Eq. A-36 with the definitions of $(\Delta L)$ and $A$.

However, flow resistance due to forces other than wall friction need to be accounted for in a way similar to how losses resulting from changing the flow direction in 90-degree bends were described in Section A.5.3. Correct modeling is still accomplished by determining representative values for the flow resistance $(\Re)$ in Eq. A-38 or the flow coefficient $\left(C_{f}\right)$ in Eq. A-96, but now these constants include, in 
Ref.: DE-AC21-86MC21023

Date: March 1994

addition to the loss caused by wall friction, loss which is only the part attributable to an area change. If the cross-sectional area change is considered to be "gradual" as the distance in the direction of flow increases, then no modifications are needed to the effects already modeled by the basic equations. Conversely, if the area change is considered to be more abrupt than this, the additional effects of energy loss resulting from internal friction should be modeled. The actual system geometry should dictate how abrupt or how gradual the area transition function effects should be in the model.

Again, however, there is a wide latitude in choosing the value of $K$ and hence of $C_{f}$ and $\Re$, with the attendant high potential for error. The value of $K$ for a sudden area increase, as shown in Figure A.6, is analytically derivable as follows, giving reasonable accuracy.

$$
K=\left(1-\frac{A_{1}}{A_{2}}\right)^{2}
$$

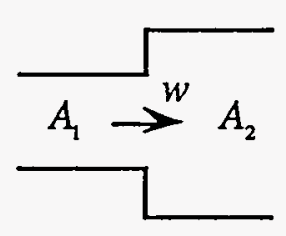

Figure A.6 Sudden Enlargement

On the other hand, for a sudden area decrease, as shown in Figure A.7, the following equation is an analytical result in which assumptions have been made [A5] about the contraction coefficient at the vena contracta which expresses the apparent contraction of the flow stream to an area less than $A_{1}$.

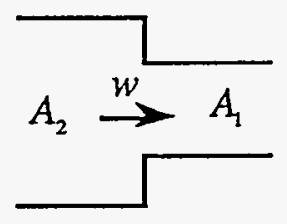

Figure A.7 Sudden Contraction

Figure A. 8 shows values of $K$ for other contraction geometries, with additional subjective definitions such as "slightly rounded." Note that Case (b) corresponds to Figure A.7 and Eq. A-98 with $A_{2}>>A_{1}$. 
Ref.: DE-AC21-86MC21023

Date: March 1994

(a)

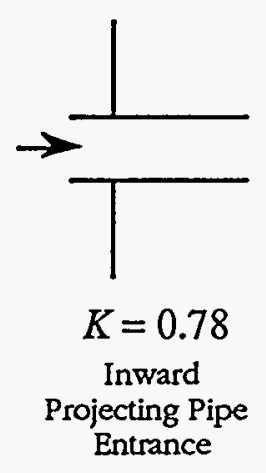

(b)

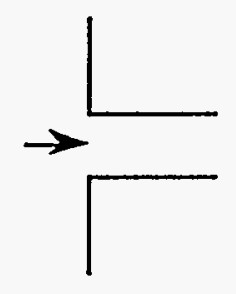

$K=0.50$

Sharp-

Edged

Entrance (c)

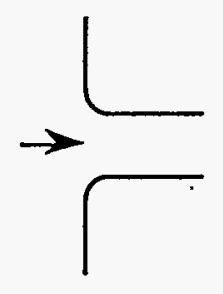

$K=0.23$

Slightly

Rounded

Entrance (d)

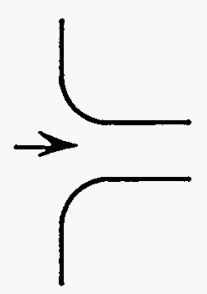

$K=0.04$

Well

Rounded

Entrance

Figure A.8 Resistances of Pipe Entrances

$$
K \cong \frac{1}{2}\left(1-\frac{A_{1}}{A_{2}}\right)^{\frac{3}{2}}
$$

The need for actual data is important to sufficiently calibrate the model. Generally, the more detailed the model, the more extensive the data gathering must be. It is reasonable to expect that for each detail in the model such as a specific $\mathrm{n}$-degree bend or a specific area vs. distance function, there will be a specific test of the actual plant equipment item exhibiting the particular feature. It may also be determined, for example, that flow coefficients are functions of flow rate thus dictating a higher fidelity model than one in which the coefficients are simply made constants.

In many situations, however, it will not be possible to obtain all the desired data. In fact, there may be flow regimes in which the behavior of the certain plant items is unknown. Such is the case when a model is desired for the sole purpose of estimating behavior or currently nonexistent equipment in a new plant design. An alternative to measured data, in these circumstances, is to obtain analytically determined data. Typically, these data might be calculated from a relatively complete steady-state model using, for example, the generalized one-dimensional continuous flow analysis techniques from Shapiro [AG]. Other means of analysis are also possible for flow systems less complex than ones for which the techniques in Shapiro are capable of analyzing. 
Ref.: DE-AC21-86MC21023

Date: March 1994

If detailed examination of a particular component is not required, the calibration procedure outlined in Section A.3.4 can be adequate. In this approach, the total flow resistance is apportioned uniformly among the individual flow sections as the use of Eq. A-33 suggests even though the data could have been derived from an analytical model with much higher fidelity, possibly describing each different flow resistance in the flow system with great detail and accuracy. Needed will be the system flow rate and the pressures an temperatures at the two boundary or end points as required in Eq. A-32. The final calibration is to adjust the node pressures via Eq. A-34 to match the steady-state initial conditions. Higher fidelity calibrations can be accomplished by breaking the system into smaller subsystems and to then apply the same procedure to each subsystem.

\section{A.6 REFERENCES}

A1. W. H. Press, et al., Numerical Recipes, 2nd Ed., Cambridge University Press, New York, 1992.

A2. L. M. Milne-Thomson, Theoretical Hydrodynamics, 5th Ed., The MacMillan Company, New York, 1968.

A3. J. M. Kay and R. M. Nedderman, An Introduction to Fluid Mechanics and Heat Transfer, Cambridge University Press, London, 1974.

A4. D. P. Campbell, Process Dynamics, John Wiley \& Sons, Inc., New York, 1958.

A5. J. C. Hunsaker and B. G. Rightmire, Engineering Applications of Fluid Mechanics, McGraw-Hill Book Company, New York, 1947.

A6. A. H. Shapiro, The Dynamics and Thermodynamics of Compressible Fluid Flow, Vol. I, The Ronald Press Company, New York, 1953. 